University of South Florida

DIGITAL COMMONS

@ UNIVERSITY OF SOUTH FLORIDA
Digital Commons @ University of

South Florida

8-1-2005

\title{
Teenage Attitudes and Perceptions Regarding Transit Use
}

CUTR

Follow this and additional works at: https://digitalcommons.usf.edu/cutr_nctr

\section{Scholar Commons Citation}

CUTR, "Teenage Attitudes and Perceptions Regarding Transit Use" (2005). Research Reports. 238.

https://digitalcommons.usf.edu/cutr_nctr/238

This Technical Report is brought to you for free and open access by the National Center for Transit Research (NCTR) Archive (2000-2020) at Digital Commons @ University of South Florida. It has been accepted for inclusion in Research Reports by an authorized administrator of Digital Commons @ University of South Florida. For more information, please contact digitalcommons@usf.edu. 


\section{TEENAGE ATTITUDES AND PERCEPTIONS REGARDING TRANSIT USE}

\section{National Center} Transit Resear
State of Florida Department of Transportation

605 Suwannee Street Tallahassee, FL 32399 - 0450

Project Manager: Amy Datz
National Center for Transit Research

\section{National Center} for Transit Research

Center for Urban Transportation Research University of South Florida

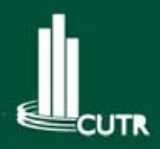

National Center for Transit Research Center for Urban Transportation Research University of South Florida

$$
\begin{aligned}
& 4202 \text { E. Fowler Avenue, CUT100 } \\
& \text { Tampa, FL } 33620-5375 \\
& \text { (813) } 974-3120
\end{aligned}
$$


TECHNICAL REPORT STANDARD TITLE PAGE

\begin{tabular}{|c|c|c|c|}
\hline $\begin{array}{l}\text { 1. Report No. } \\
\text { NCTR Project 576-14; } \\
\text { FDOT Project BD } 549-7\end{array}$ & 2. Government Accession No. & \multicolumn{2}{|c|}{ 3. Recipient's Catalog No. } \\
\hline \multirow{2}{*}{\multicolumn{2}{|c|}{$\begin{array}{l}\text { 4. Title and Subtitle } \\
\text { Teenage Attitudes and Perceptions Regarding Transit Use }\end{array}$}} & \multicolumn{2}{|c|}{$\begin{array}{l}\text { 5. Report Date } \\
\text { August } 2005\end{array}$} \\
\hline & & \multicolumn{2}{|c|}{ 6. Performing Organization Code } \\
\hline \multicolumn{2}{|c|}{$\begin{array}{l}\text { 7. Author(s) } \\
\text { Alasdair Cain, Peter Hamer, Jennifer Sibley-Perone }\end{array}$} & \multicolumn{2}{|c|}{ 8. Performing Organization Report No. } \\
\hline \multirow{2}{*}{\multicolumn{2}{|c|}{$\begin{array}{l}\text { 9. Performing Organization Name and Address } \\
\text { National Center for Transit Research (NCTR) } \\
\text { Center for Urban Transportation Research (CUTR) } \\
\text { University of South Florida, CUT } 100 \\
4202 \text { East Fowler Avenue, Tampa, FL } 33620\end{array}$}} & \multicolumn{2}{|l|}{ 10. Work Unit No. } \\
\hline & & \multicolumn{2}{|c|}{$\begin{array}{l}\text { 11. Contract or Grant No. } \\
\text { DTRS98-G-0032 }\end{array}$} \\
\hline \multicolumn{2}{|c|}{$\begin{array}{l}\text { 12. Sponsoring Agency Name and Address } \\
\text { Office of Research and Special Programs (RSPA) } \\
\text { U.S. Department of Transportation, Washington, D.C. } 20590\end{array}$} & \multicolumn{2}{|c|}{ 13. Type of Report and Period Covered } \\
\hline \multicolumn{2}{|c|}{$\begin{array}{l}\text { Florida Department of Transportation } \\
605 \text { Suwannee St, Tallahassee, FL } 32399 \text { - } 0450\end{array}$} & \multicolumn{2}{|c|}{ 14. Sponsoring Agency Code } \\
\hline \multicolumn{4}{|c|}{ 15. Supplementary Notes } \\
\hline \multirow{2}{*}{\multicolumn{4}{|c|}{ 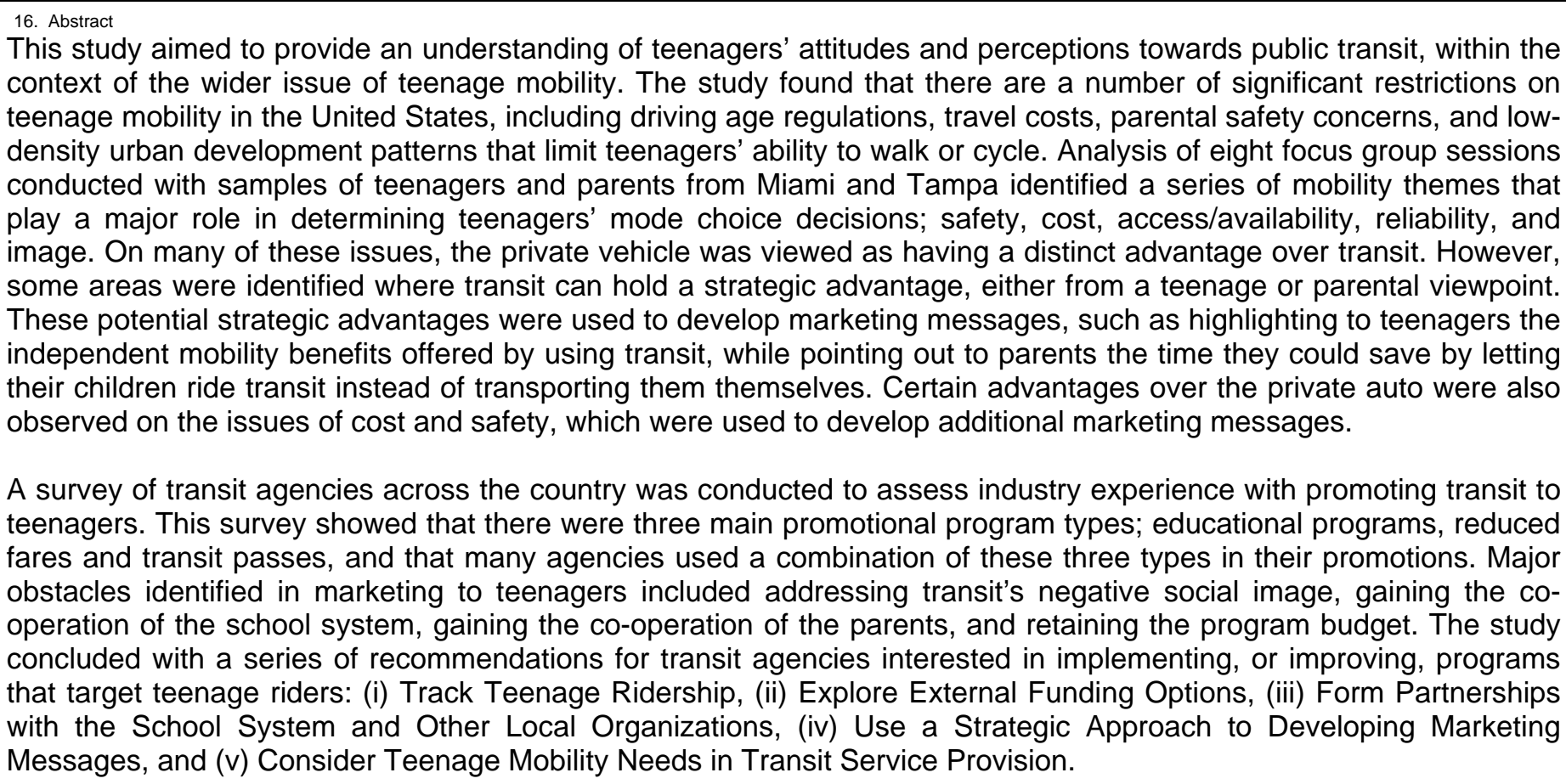 }} \\
\hline & & & \\
\hline $\begin{array}{l}\text { 17. Key words } \\
\text { Teenagers, public transportation, } \\
\text { youth mobility, market research, } \\
\text { market segmentation, } \\
\text { transit marketing }\end{array}$ & \multicolumn{3}{|c|}{$\begin{array}{l}\text { 18. Distribution Statement } \\
\text { Available to the public through the National Technical Information service (NTIS), } \\
5285 \text { Port Royal Road, Springfield, VA 22161, (703) 487-4650, } \\
\text { http://www.ntis.gov/, and through the NCTR website at http://www.nctr.usf.edu }\end{array}$} \\
\hline $\begin{array}{l}\text { 19. Security Classif. (of this report) } \\
\text { Unclassified }\end{array}$ & $\begin{array}{l}\text { 20. Security Classif. (of this page) } \\
\text { Unclassified }\end{array}$ & $\begin{array}{l}\text { 21. No. of pages } \\
74\end{array}$ & 22. Price \\
\hline
\end{tabular}

Form DOT F 1700.7 (8-69) 


\section{Teenage Attitudes and Perceptions Regarding Transit Use - Final Report}

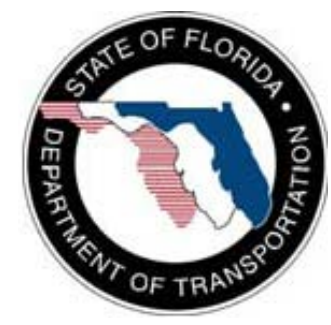

\section{State of Florida Department of Transportation}

Public Transit Office

605 Suwannee Street

Tallahassee, FL 32399-0450

(850) $414-4500$

Project Manager:

Amy Datz
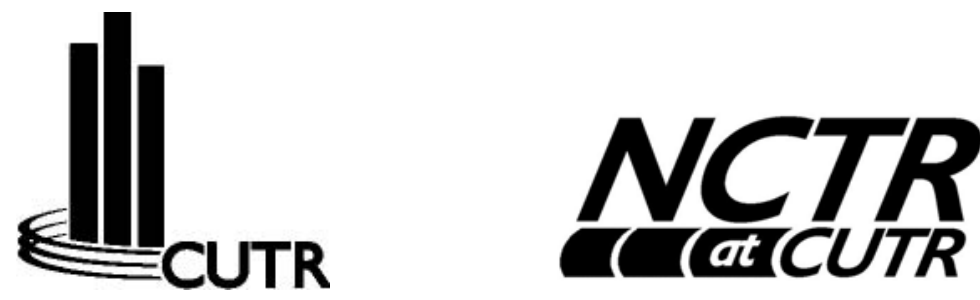

National Center for Transit Research Center for Urban Transportation Research

University of South Florida

4202 E. Fowler Avenue, CUT 100

Tampa, FL 33620-5375

(813) 974-3120

Principal Investigators: $\quad$ Alasdair Cain, Senior Research Associate Jennifer Sibley-Perone, Research Associate

Project Staff: $\quad$ Cheryl Thole, Research Associate

Peter Hamer, Graduate Research Assistant

Lisa Maitland, Program Assistant

Melissa Reed, Graduate Research Assistant

Lisa E. Tucker, Research Associate

The opinions expressed in this publication are those of the authors and not necessarily those of the U.S. Department of Transportation or the State of Florida Department of Transportation. 


\section{EXECUTIVE SUMMARY}

\section{Problem Statement}

Teenagers are an important market segment to the transit industry. They are directly important because, as a mobility impaired group, they are a prime transit user market, which research shows is currently underdeveloped. Indirectly, they are important because today's teenagers are tomorrows adults, and while many young people experience travel by school bus in their daily lives, only a small proportion currently go on to become adult transit users. Only by understanding how teenagers perceive public transit within the wider issue of youth mobility can the transit industry provide for their current transportation needs and increase the likelihood of transit use in later life. A review of research literature found that there was only limited documentation of youth mobility issues in the United States.

\section{Objectives}

This project was designed to obtain an understanding of teenagers' perceptions of public transit within the wider issue of teenage mobility. The initial objective of the project was to gain an understanding of the current level of transit use among teenagers. The next objective was to gain an understanding of the underlying attitudes and perceptions of teenagers towards public transit and transportation in general, and to understand the different ways in which parental views and restrictions affect teenage mobility. The project then aimed to collect information from the transit industry on the experiences and challenges faced in engaging this market segment. The final objective of the project was to synthesize all the acquired information into a best practice summary for transit agencies interested in implementing, or improving, programs that target teenage riders.

\section{Findings and Conclusions}

There are over 28 million teenagers in the United States, of which over 1.4 million reside in Florida. As with other age groups, teenagers rely heavily on the automobile for their travel needs, with transit accounting for only around one to three percent of teenagers' aggregate person trips. Data limitations make it difficult to isolate teenage transit ridership, but it can be observed that passengers aged 18 and under make up 9 to 21 percent of total U.S. transit ridership (depending on urban area size). Considering that people under 18 years old make up over one quarter of the total U.S. population, it was concluded that youth riders are an underrepresented transit user group. On-board survey data suggests that transit ridership in Florida is comparable to the national average, with some locations experiencing higher than average youth ridership due to local circumstances (i.e. college town). A major problem in assessing teenage ridership is the fact that teenagers tend not to be isolated from other age groups in data collection efforts. This makes it difficult to track teenage ridership and obtain a quantitative understanding of teenage mobility needs. 
The study found that there are a number of significant restrictions on teenage mobility in the United States, including driving age regulations, travel costs, parental safety concerns, and lowdensity urban development patterns that limit walking and cycling. A series of mobility themes were identified during a series of eight focus group sessions, held with teenagers and parents in Miami and Tampa, that play a major role in determining teenagers' mode choice decisions safety, cost, access/availability, reliability, and image. On many of these issues, the private vehicle was perceived as holding a distinct advantage over transit. However, some areas were identified where transit could potentially hold a strategic advantage, either from a teenage or parental viewpoint. These issues were used to develop marketing messages, as shown below.

\begin{tabular}{lllll}
\hline $\begin{array}{c}\text { Underlying } \\
\text { Issue }\end{array}$ & \multicolumn{1}{c}{ Teenager } & \multicolumn{1}{c}{ Parent } & Potential Marketing Message \\
\hline $\begin{array}{l}\text { Independent } \\
\text { Mobility }\end{array}$ & $\begin{array}{l}\text { Dependent on } \\
\text { parents for } \\
\text { transportation }\end{array}$ & $\begin{array}{l}\text { Transporting children } \\
\text { is time-consuming }\end{array}$ & $\begin{array}{l}\text { Teenagers: } \\
\text { Parents: }\end{array}$ & $\begin{array}{l}\text { Independence afforded by transit } \\
\text { Don't have to spend time providing } \\
\text { child's transportation }\end{array}$ \\
\hline Safety & $\begin{array}{l}\text { Concerned about } \\
\text { the responsibility } \\
\text { of driving }\end{array}$ & $\begin{array}{l}\text { Concerned about child } \\
\text { driving unsupervised } \\
\text { or traveling with other } \\
\text { teenage drivers }\end{array}$ & $\begin{array}{l}\text { Parent / } \\
\text { Teenager: }\end{array}$ & $\begin{array}{l}\text { Highlight the safety benefits of using } \\
\text { transit }\end{array}$ \\
\hline Cost & $\begin{array}{l}\text { High cost of } \\
\text { car travel }\end{array}$ & $\begin{array}{l}\text { High cost of } \\
\text { car travel }\end{array}$ & Teenagers: & $\begin{array}{l}\text { Highlight how much money could be saved } \\
\text { for other more important things (proms, etc) } \\
\text { Highlight how much money could be saved } \\
\text { by not having to provide a car for their child }\end{array}$ \\
\hline
\end{tabular}

A survey of transit agencies across the country was conducted to assess industry experience with promoting transit to teenagers. This survey showed that there were three main promotional program types; educational programs, reduced fares and transit passes. Major challenges identified in marketing transit to teenagers included addressing transit's negative social image, gaining the co-operation of the school system, gaining the co-operation of parents, and retaining the program budget.

The study concludes with a series of recommendations for transit agencies interested in implementing, or improving, programs that target teenage riders: (i) Track Teenage Ridership, (ii) Explore External Funding Options, (iii) Form Partnerships with the School System and Other Local Organizations, (iv) Use a Strategic Approach to Developing Marketing Messages, and (v) Consider Teenage Mobility Needs in Transit Service Provision.

\section{Benefits}

This report lays out the key issues that a transit agency needs to address to establish a successful youth mobility program, drawing on best practice experience from around the country and abroad. The marketing messages that have been developed relate directly to generic youth mobility problems in the U.S. and may be applied in a variety of different scenarios. 


\section{TABLE OF CONTENTS}

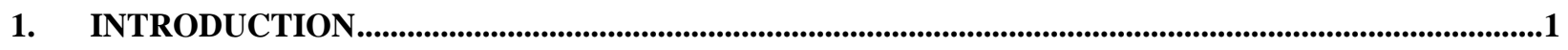

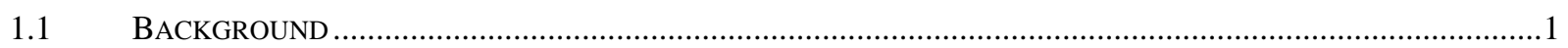

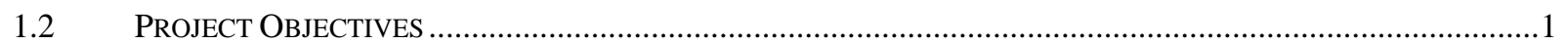

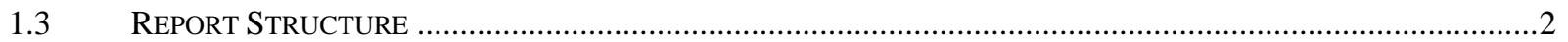

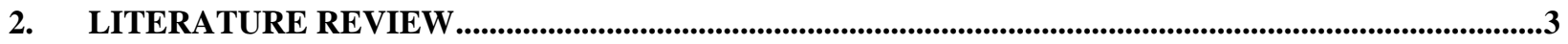

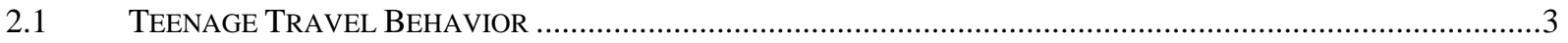

2.1.1 Characteristics of Teenage Public Transit Use in the United Kingdom ................................................

2.1.2 "Kids on the Move" Study in Toronto, Canada...................................................................................

2.1.3 University of Iowa Study on After-School Teenager Travel ...............................................................

$2.2 \quad$ ATtITUdES AND PERCEPTIONS OF TEENAGERS REGARDING TRANSIT .......................................................

2.2.1 Attitudes and Perceptions of Teenagers in the United Kingdom ........................................................

2.2.2 Attitudes and Perceptions of Teenagers in Toronto............................................................................11

2.3 INFLUENCE OF PARENTAL / LEGAL GUARDIAN ON TEENAGE TRAVEL BEHAVIOR......................................11

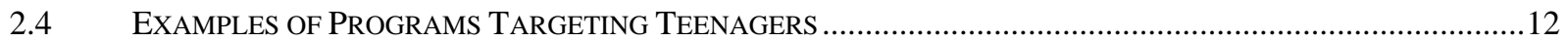

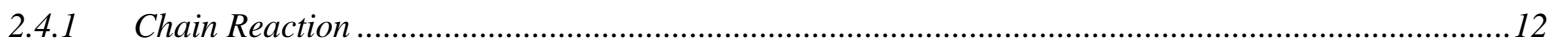

2.4.2 Delaware Transit Corp. Teen Driving Campaign …......................................................................12

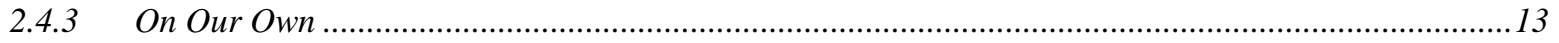

2.4.4 Promoting Public Transit to Teenagers in the United Kingdom .......................................................14

2.4.5 “Transportation Planning by Teenagers" - St Lucie County, Florida ...............................................14

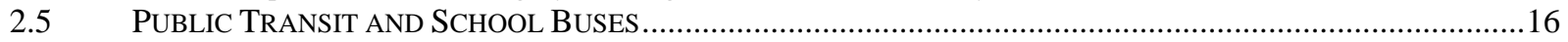

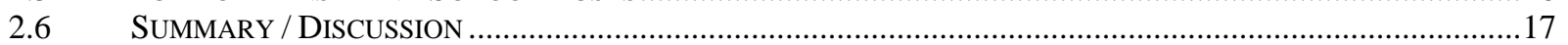

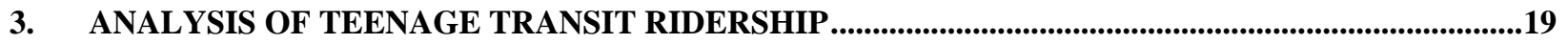

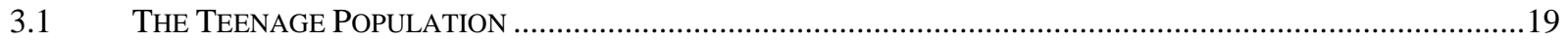

3.2 Aggregate TeEnage Travel BeHAVIOR In the United StATES .....................................................20

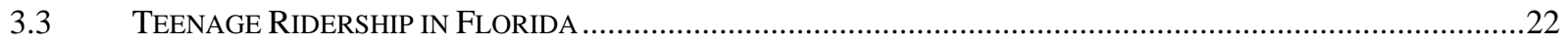

3.4 OTHER ON-BOARD SURVEY INFORMATION ON FLORIDA’S TEENAGE TRANSIT RIDERSHIP.........................23

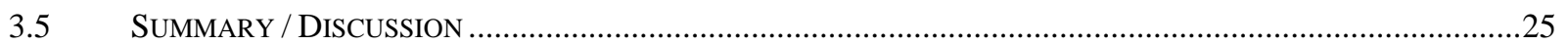

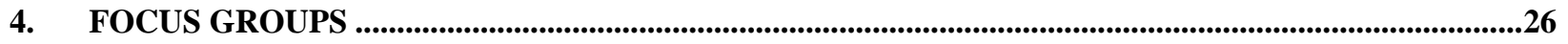

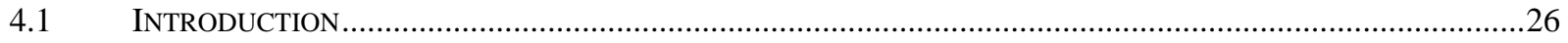

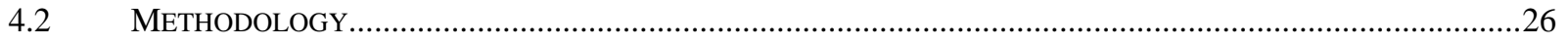

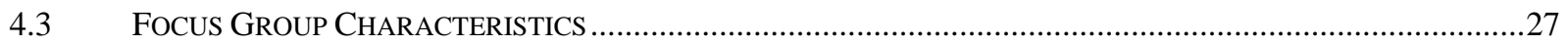

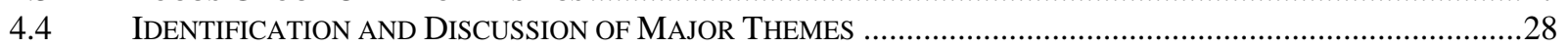

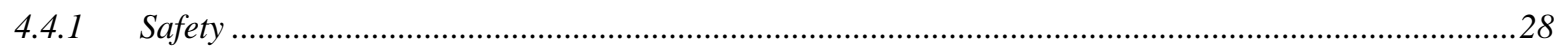

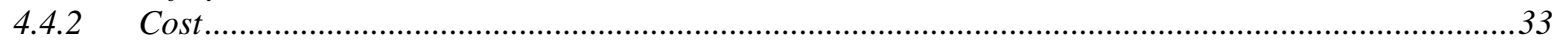

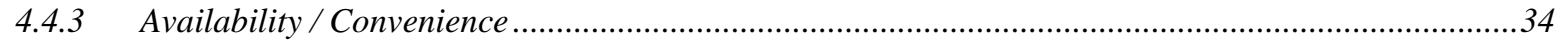

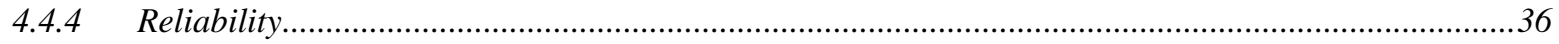

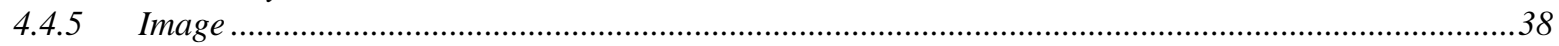

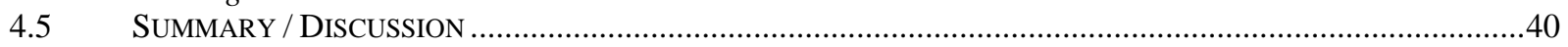

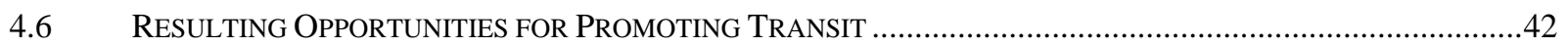

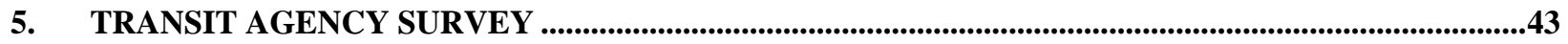

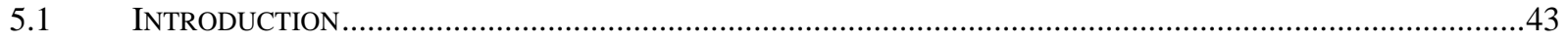

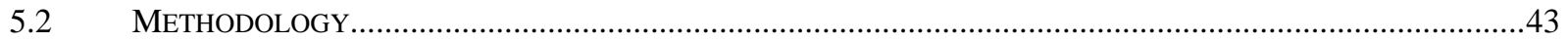

5.3 TRANSIT AgENCIES WITH EXPERIENCE OF PROgRAMs TARgETED AT TEENAGE RidERS ............................43

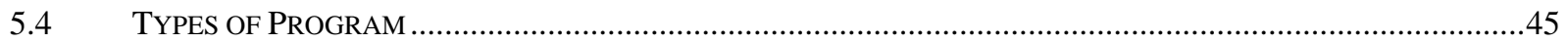

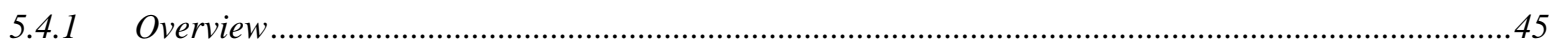

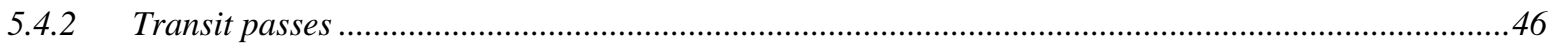




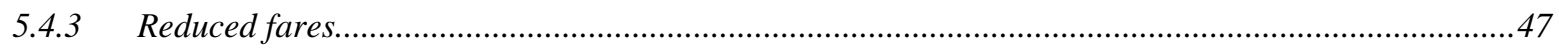

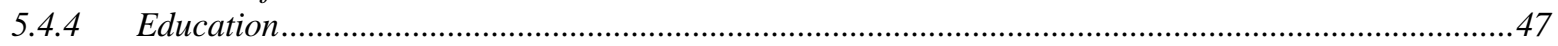

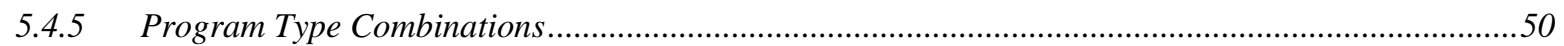

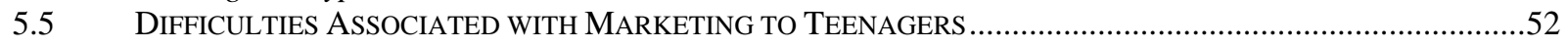

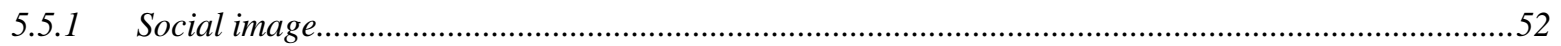

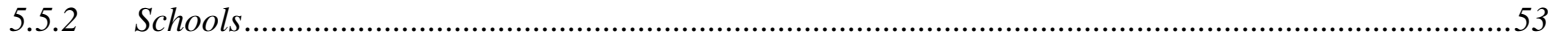

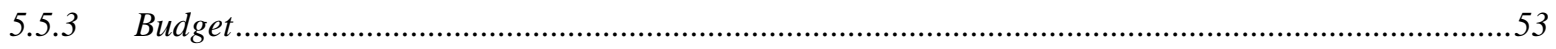

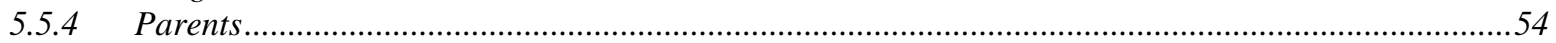

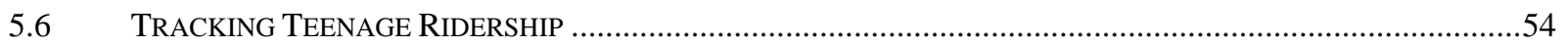

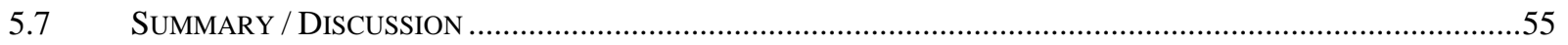

6. CONCLUSIONS / RECOMMENDATIONS.......................................................................................56

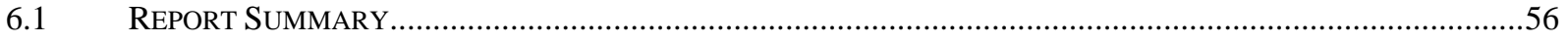

6.2 RECOMMENDATIONS / EXAMPLES OF BEST PRACTICE .....................................................................57

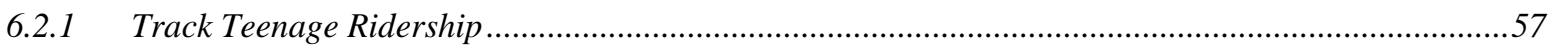

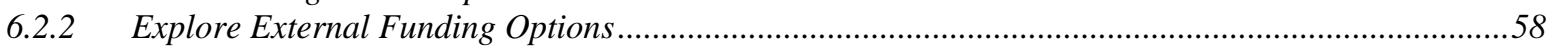

6.2.3 Form Partnerships with the School System and Other Local Organizations ....................................58

6.2.4 Use a Strategic Approach to Developing Marketing Messages.....................................................58

6.2.5 Consider Teenage Mobility Needs in Transit Service Provision ....................................................60

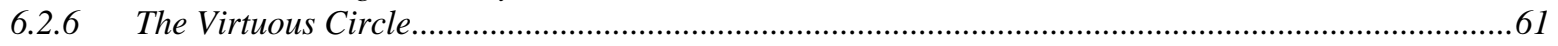

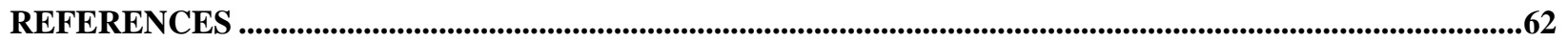

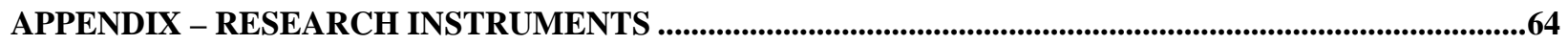




\section{Introduction}

\subsection{Background}

The ages of 13 to 19 are recognized as being a crucial period in a young person's life, when initial steps to independent adulthood are taken. The cultural icon of the "teenager", which emerged initially in the period following World War II, has now matured into an established market segment increasingly targeted by the private sector. In contrast, the public transit industry, like much of the public sector, has been slower in recognizing the importance of this age group and developing the strategies and programs required for effective targeting. While many young people experience travel by school bus in their daily lives, only a small proportion go on to become adult transit users.

In the context of increasing auto dominance in Florida (and across much of the United States), the need to provide transit service that is appealing to teenagers is important for a variety of reasons. First, inherent mobility restrictions make teenagers a prime market segment for transit to target, as a means to boosting current ridership. Secondly, it is recognized that the values and habits formed during teenage years are often retained through to adult life. Exposing teenagers to transit during their teenage years makes it more likely that they will continue using transit as an adult. Thirdly, the teenagers of today are the voters of tomorrow, and transit use as a youth may increase the likelihood of support when asked to vote on a transit related issue, either as member of a constituency or as an elected official. Finally, the success of the transit industry depends on attracting talented young people who understand the importance of transit, and are subsequently willing to commit to a career in this field.

\subsection{Project Objectives}

Although the title of this project suggests a focus on the underlying attitudes and perceptions of teenagers towards public transit, the scope of the project had been designed to address the wider issue of teenage mobility. The initial objective of the project was to gain an understanding of the current level of transit use among teenagers. The next objective was to gain an understanding of the underlying attitudes and perceptions of teenagers towards public transit and transportation in general, and to understand the different ways in which parental views and restrictions affect teenage mobility. The project then aimed to collect information from the transit industry on the experiences and challenges faced in engaging this market segment. The final objective of the project was to synthesize all the acquired information into a best practice summary for transit agencies interested in implementing, or improving, programs that target teenage riders. 


\subsection{Report Structure}

This report has been structured around the different tasks detailed in the updated project scope, and draws heavily from material provided in Technical Memoranda 1 and 2. Chapter 2 provides a summary of existing literature on the subject of teenage mobility, drawing from research conducted in Canada and the United Kingdom as well as the United States. Chapter 3 provides information on teenage transit ridership, using data from the U.S. 2000 Census, the National Household Travel Survey, and on-board surveys conducted for transit agencies around Florida. Chapter 4 presents the focus group methodology and analysis of the eight focus group sessions conducted with teenagers and their parents in Miami and Tampa. Chapter 5 provides the methodology and analysis of a survey of U.S. transit agencies, which was used to gain an understanding of transit industry experience in promoting transit to teenagers. Chapter 6 summarizes the main study conclusions and provides a series of best practice recommendations. 


\section{Literature Review}

\subsection{Teenage Travel Behavior}

\subsubsection{Characteristics of Teenage Public Transit Use in the United Kingdom}

In 1999, a study was conducted in the United Kingdom examining the issue of young people and crime on public transportation (Stafford et al, 1999). A survey of 582 people between the ages of 11 and 19 years old was conducted as part of the study. The questionnaire collected information on existing travel behavior characteristics, as well as attitudes toward public transport and car ownership, and suggestions for encouraging public transport use among young people (discussed later in the review). Table 2.1 below presents the results of a question that asked respondents in different age groups how they traveled to school.

\begin{tabular}{cccc}
\multicolumn{4}{c}{ TABLE 2.1 - Travel Modes Used on the School Trip* } \\
\hline Travel & Age Group \\
Mode & 10 to $12(\%)$ & 13 \& $14(\%)$ & 15 years + (\%) \\
\hline Public Bus & $6 \%$ & $23 \%$ & $17 \%$ \\
School Bus & $22 \%$ & $12 \%$ & $22 \%$ \\
Train & - & $1 \%$ & $1 \%$ \\
Taxi & $1 \%$ & - & $1 \%$ \\
Car & $15 \%$ & $13 \%$ & $14 \%$ \\
Bike & $1 \%$ & $6 \%$ & $1 \%$ \\
Walking & $55 \%$ & $45 \%$ & $44 \%$ \\
\hline
\end{tabular}

* Source: Stafford et al, 1999.

Table 2.1 shows that teens in the United Kingdom utilized a variety of transportation modes for the trip to school. The most common mode across all age groups was walking, at around 50 percent, followed by the school bus, public buses and private car. The reported differences in mode use across the different age groups are large and possibly reflect the relatively small sample sizes used in the study. The study went on to investigate who young people travel with when using public transit. Table 2.2 presents the results of this analysis.

TABLE 2.2 - Transit Traveling Companion Characteristics for Young People in the United Kingdom

\begin{tabular}{|c|c|c|c|c|c|}
\hline \multirow{2}{*}{$\begin{array}{l}\text { Age } \\
\text { Group }\end{array}$} & \multicolumn{5}{|c|}{ Transit Traveling Companion Options } \\
\hline & $\begin{array}{l}\text { Usually on } \\
\text { my own }\end{array}$ & $\begin{array}{c}\text { Usually } \\
\text { with friends }\end{array}$ & $\begin{array}{l}\text { Usually with a brother } \\
\text { or sister but no adult }\end{array}$ & $\begin{array}{c}\text { Usually with a } \\
\text { parent or other adult }\end{array}$ & $\begin{array}{l}\text { Do not use public } \\
\text { transport regularly }\end{array}$ \\
\hline 10 to 12 & $7 \%$ & $33 \%$ & $14 \%$ & $33 \%$ & $13 \%$ \\
\hline $13 \& 14$ & $12 \%$ & $73 \%$ & $13 \%$ & - & $2 \%$ \\
\hline 15 plus & $23 \%$ & $69 \%$ & $7 \%$ & - & $1 \%$ \\
\hline
\end{tabular}

* Source: Stafford et al, 1999. 
Table 2.2 shows that the majority of teens are not using transit alone, and are more likely to ride with friends, siblings, or parents. Among 10 to 12 year olds, the most common riding companions are friends, parents, or other adults. Survey results suggest that riding with parents or other adults is much less common for young people over the age of 12. Over 12s appear more likely to ride with friends, and some also appear to be old enough to ride transit alone. The study commented on this trend, stating that most 10 to 12 year olds were at the start of independent travel, and many of their experiences on transit involved traveling with an adult or family group. People in the 13 to 14 age group tended to have experienced independent travel and often used transit with large groups or friends. Those aged 15 and over increasingly used transit for a variety of trips, including evening services, and had well developed attitudes towards transit and private vehicles.

The study also noted that children and young people living in households without a car were more likely to use public buses for non-school related trips, with about half of those in non-car owning households using the bus at least two or three times per week, compared to only around one third of those in car owning households. Train use, however, was not influenced by car ownership status. It was noted that people living in urban areas were more likely to travel regularly by bus for leisure purposes than those in rural areas.

Overall this study from the United Kingdom suggests some interesting trends in transit use among young people. It appears that, as in the United States, the school bus is a regularly used mode of travel, and perhaps represents the first experience of public transit style travel for many young people. Furthermore, the study suggests that travel characteristics vary considerably across the different teenage age groups, with public transit use probably more likely among older teens. It should be noted, however, that urban form and style of living is different in the United Kingdom where automobile use is generally much less prevalent, and therefore the results of this study should not be assumed to reflect travel characteristics in the United States.

\subsection{2 "Kids on the Move" Study in Toronto, Canada}

In 2003, a reported titled "Kids on the Move in Halton-Peel” was published by the Center for Sustainable Transportation in Ontario, Canada (O’Brien and Gilbert, 2003). The study was inspired by another "Kids on the Move" project conducted by the European Union in 2002, which produced a manual for improving child mobility in Europe. The researchers aimed to determine whether the recommendations of the European "Kids on the Move" project could be adapted for use in North America. The study began by presenting information on travel patterns in the local area across different ages, using data from the 2001 phase of the Transportation Tomorrow Survey (TTS) which covers most of south-central Ontario. This survey collects data on weekday travel behavior of people aged 11 and over. These researchers focused on two local authority areas, Halton and Peel, in the western part of Toronto. Figure 2.1 below shows the proportions of total weekday travel made for different trip purposes by people of different ages. 


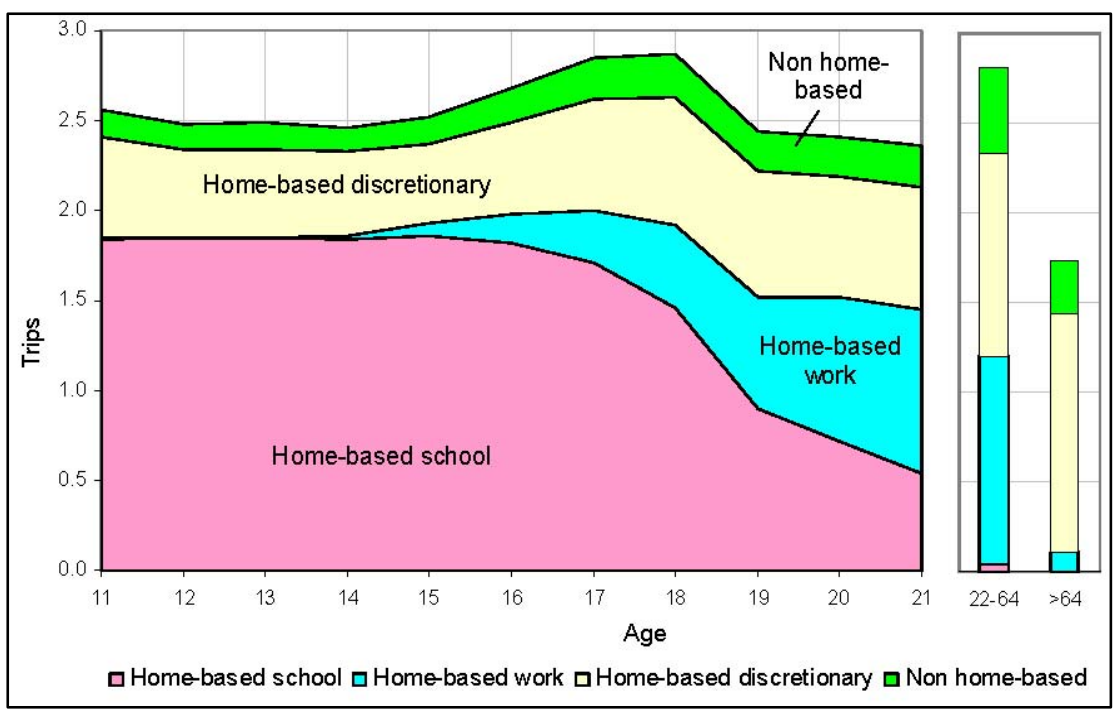

FIGURE 2.1 - Weekday Travel by Purpose and Age in Halton and Peel, 2001

Figure 2.1 shows that children between the ages of 11 and 16 make an average of around 2.5 trips per day, with this rising to around 2.8 trips per day for people aged 17 and 18 . Of these trips, the majority are trips made to and from school, accounting for around 75 percent of all trips. The trip purpose proportions remain relatively static between the ages of 11 and 14, at which point the home-based work trip begins to emerge while the proportion of school trips begins to decline. By the age of 20, weekday trip purposes are divided relatively evenly into school based, work based and home based discretionary. TTS data was then used to assess mode use across the same age range. Figure 2.2 presents the results of this analysis.

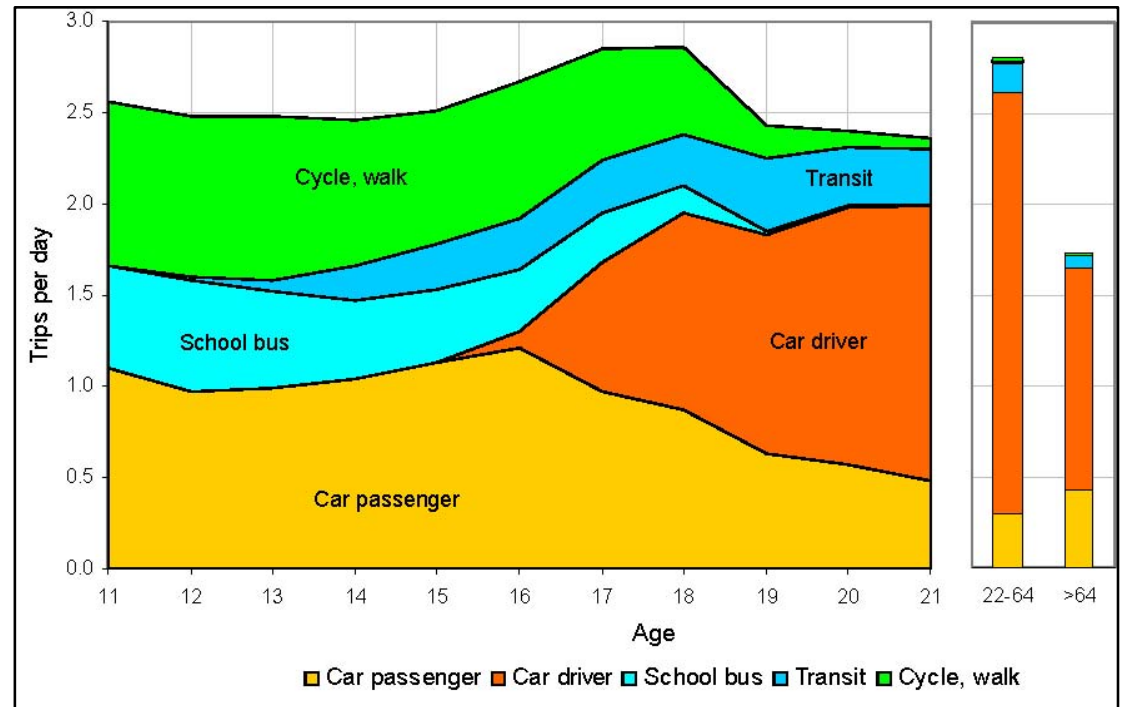

FIGURE 2.2 - Weekday Travel by Mode and Age in Halton and Peel, 2001

Figure 2.2 shows that the main modes of travel used by children under the age of 16 in Ontario are "car passenger", followed by "cycle / walk" and "school bus". Around the age of 16, the "car driver" mode begins to emerge, increasing steadily to become the most popular mode for people 
aged 18 and above. At the same time, travel as a car passenger starts to decline as does travel by school bus. The figure also shows that public transit use is almost zero at the age of 11, but steadily increases up to around 10 percent of total weekday trips at the age of around 16, and then remains relatively constant at this level as people approach their late teenage years and early twenties. The study then went on to compare the travel characteristics in Halton and Peel with those in the inner part of the City of Toronto. Travel characteristics in this location are shown in Figure 2.3 below.

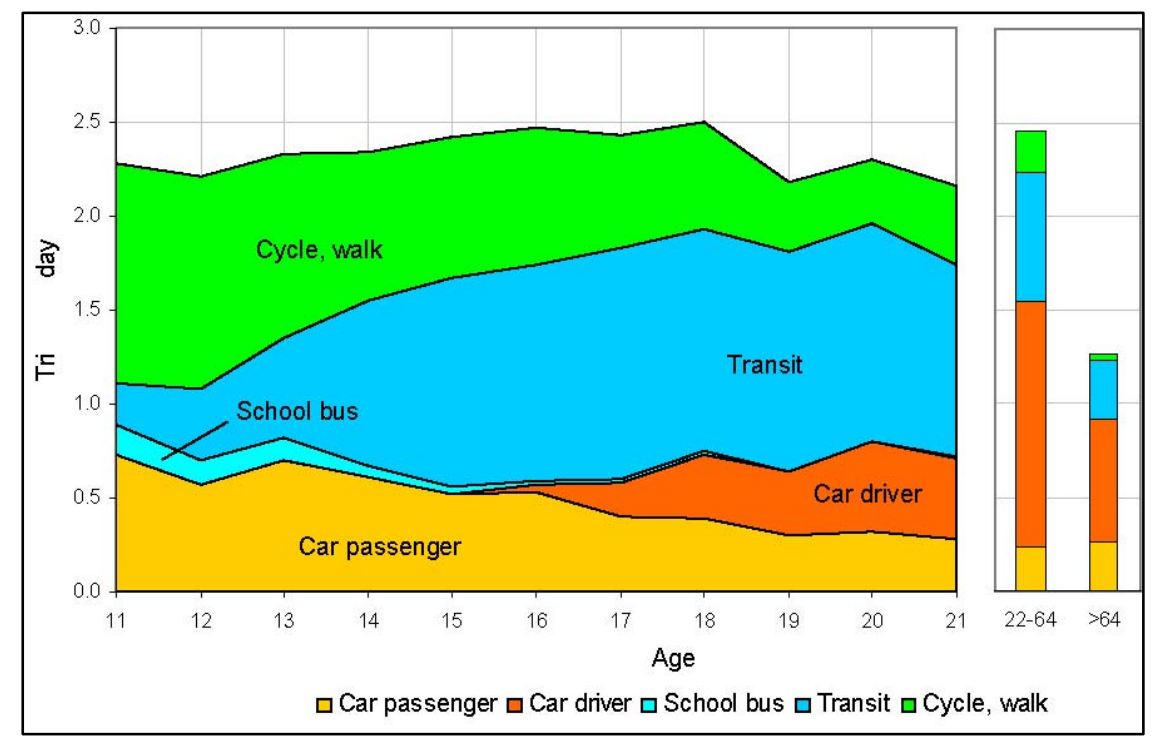

FIGURE 2.3 - Weekday Travel by Mode and Age in Inner Part of the City of Toronto, 2001

Figure 2.3 presents a very different picture, with public transit trips being generally much more common, and increasing significantly with age to become the most prevalent mode by the age of around 16. This occurs to the detriment of car-based travel modes and the school bus. This suggests that children living in this urban environment are more likely to travel to school on public transit services than on a bus provided specifically for school travel. Clearly, inner Toronto is a high density urban environment, where public transit, and non-car based modes in general, are able to be much more competitive against car based travel. Clearly, in this environment young people are much more likely to be regular transit users, although there is still an element of lower usage among younger teens. This again suggests that transit use may only be feasible once a person has reached a particular level of maturity.

Concluding this part of the study, and comparing the findings to the results of an earlier study that used data from the 1986 TTS, the researchers concluded that:

- Until about the age of 18, travel on schooldays is dominated by the journey to and from school. Among 11 to 14 year olds, just over half of these trips are made by school bus (28 percent) or by car (23 percent). The share of journeys by car is larger for older young people, and is also likely to be larger among 6 to 10 year olds.

- The share of journeys by car increased steeply between 1986 and 2001, for all trip purposes 
- The age at which children begin using transit in Halton and Peel increased from around 10 years old in 1986 to around 12 years old in 2001

- Young people in Halton and Peel make more trips overall then their counterparts in inner Toronto. Young people in inner Toronto are much less likely to use the car and school bus, and are much more likely to use transit.

Finally, the researchers noted the lack of available data on the travel characteristics of young people in Canada, and that this needed to be rectified in future survey efforts.

\subsubsection{University of lowa Study on After-School Teenager Travel}

This study focused primarily on how teenagers travel to after-school activities, but also reviewed existing literature on teenage mobility. It noted that independent movement is limited and that many teenagers are heavily reliant on adults for their transportation needs (Clifton, 2003). Walking was a popular teenage mode of transportation, irrespective of household car ownership status, and was in some cases preferred over public transit (Gurin, 1974). Young people's travel patterns were said to differ by income, gender, age and geographic location, with older children tending to have a greater ranger of spatial activities (Van Vliet, 1983). Girls, younger children, and teens from higher income households were more likely to be driven by car. Young people in urban areas were more likely to walk or take transit than those from suburban locations, who tended to travel longer distances to activities and were more likely to use bicycle and car based modes (Van Vliet, 1983). The review also highlighted the fact that the degree of independent mobility among young people was declining, and that there has been a general lack of attention paid to the travel patterns of American teenagers.

The Clifton study itself collected data on after-school teenager travel patterns using travel diary data from the 1995 Nationwide Personal Transportation Survey (NPTS), which used data from 95,360 individuals in 42,033 households across the country. Results on mode use are shown in Table 2.3 below.

TABLE 2.3 - Mode Of Travel For After School Trips By Age Group*

\begin{tabular}{cccccccc}
\hline Mode & \multicolumn{7}{c}{ Age in years (\%) } \\
& 13 & 14 & 15 & 16 & 17 & 18 & All ages \\
\hline Private Vehicle & $33.2 \%$ & $38.9 \%$ & $46.6 \%$ & $62.1 \%$ & $79.8 \%$ & $72.4 \%$ & $54.4 \%$ \\
School Bus & $47.3 \%$ & $41.6 \%$ & $31.7 \%$ & $22.3 \%$ & $7.8 \%$ & $9.5 \%$ & $27.8 \%$ \\
Transit & $4.1 \%$ & $5.0 \%$ & $5.1 \%$ & $4.4 \%$ & $5.0 \%$ & $8.0 \%$ & $5.1 \%$ \\
Walk & $14.2 \%$ & $12.8 \%$ & $14.5 \%$ & $10.5 \%$ & $7.2 \%$ & $9.0 \%$ & $11.5 \%$ \\
Bicycle & $1.3 \%$ & $1.7 \%$ & $1.7 \%$ & $0.2 \%$ & $0.0 \%$ & $0.2 \%$ & $0.9 \%$ \\
\hline
\end{tabular}

* Source: Clifton., K.J. (2003).

Table 2.3 shows that the automobile played a prominent role in after-school travel across all age groups, and that its prominence increased with age, accounting for around one third of after school trips for 13 year olds, rising to around three-quarters of all trips for 18 year olds. Correspondingly, reliance on other modes declined with age. The school bus was the principle mode of after-school travel for 13 and 14 year olds, accounting for around 45 percent of total after-school trips, but this reduced to less than 10 percent among 17 and 18 year olds. Walking 
also decreased with age, and it was suggested that this was in part due to the longer average distances to high schools compared to junior high schools. Transit use remains relatively constant from the ages of 13 to 17, at around 5 percent, rising to 8 percent among 18 year olds.

The study went on to assess the level of lone travel among teenagers, taking this as measure of independence. The study found that the majority of trips made by adolescents were in the company of others, with only around one third of trips made alone. The proportion of unaccompanied trips rose with age, with around two-thirds of trips taken by 18 year olds made alone. Males were more likely to make trips alone.

The study concluded by stating that teenagers gain increasing travel independence with age. However, this comes with an increasing reliance on the automobile. The study hypothesized that teenagers appear to abandon walking and transit use as soon as the automobile becomes an option. Issues identified for further study included examining the extent to which younger teens are constrained from participating in after-school activities by lack of travel options, and the influence of residential environment on travel behavior.

\subsection{Attitudes and Perceptions of Teenagers Regarding Transit}

This review has found little information on teenage attitudes and perceptions of transit use in the United States. Therefore, the review concentrates on findings from studies in the United Kingdom and Canada.

\subsubsection{Attitudes and Perceptions of Teenagers in the United Kingdom}

The study conducted in the United Kingdom by Stafford et at (1999), included a chapter on young people's experiences and perception of public transit, using information obtained from a questionnaire survey and focus group discussions. The subject was introduced with a reference to previous study (Goodwin et al, 1983) which had found that travel habits developed at a young age could influence subsequent behavior, and that those who were not regular transit users as young people were less likely to be transit users in adult life. Furthermore, it was noted that negative experiences with using transit as young people could have a negative impact on travel choices as an adult (Goodwin et al, 1983). The Stafford study found that perceptions of transit were predominantly negative. Teens were critical of (i) cost, (ii) availability and frequency, (iii) cleanliness and comfort, (iv) information and (v) safety. These issues are discussed in more detail below.

(i) Cost

The general cost of using public transit, and the age of qualification for concessionary fares, were both the subject of fierce criticism from young people across the country. Cost of travel, in addition to the issue of poor attitudes among transit staff, were identified as the two main reasons why young people felt unwanted and poorly served by public transport. High fares were seen as a major barrier to transit use, and complaints were made about the fact that the concessions provided to seniors were much better than any provisions made for young people. High fares were also identified as a primary stimulus for fare evasion. When survey respondents were asked 
to describe what improvements would encourage them to use and keep using public transport, cheaper fares was the most popular answer, directly proposed by a third of respondents. Lower fares were more likely to be suggested by older teens compared to younger teens and children.

(ii) Availability and frequency

Stafford et al (1999) reported that teens find the availability and frequency of public transit systems to be a source of great frustration. From a teenage perspective, transit services were not as available as they would like and did not run frequently enough. As one teen reported, "buses are irregular and they don't run on Saturdays and Sundays when we really need them" (Stafford et al, 1999). Lack of late night services were identified as a major problem.

(iii) Comfort

Like adults, teens expect comfortable travel conditions. Teens were critical of the less than comfortable situations that they find themselves in when using public transit (Stafford et al, 1999). Unlike traveling in a personally owned automobile, the state of the public transportation system can vary and at times be uncomfortable. As one teen reported, "Just look at the state of some of the buses...the seats ripped, it smells and we have to pay to travel on them (Stafford et al., 1999)" As another teen reported, "buses can be very cold in winter and there's no air conditioning in summer...” (Stafford et al, 1999).

(iv) Information

In order to effectively use a public transit system, one must first gain access to information like dates and times of departure and destinations. Stafford et al (1999) reported that teens were often frustrated with the lack of information provided about public transit systems. One teen reported "The timetables at the bus stops around here haven't been changed for ten years...the timetables are dirty and no one could rely on them.” (Stafford et al,1999). Real-time information was seen as a requirement that also enhanced travel safety.

(v) Safety

Lack of safety was identified as a major barrier to transit use among young people in the United Kingdom. Safety was an issue both while waiting for the bus or train, and while on the vehicle. Issues raised included antisocial behavior from gangs of youths or drunken adults, graffiti and actual acts of crime perpetrated on transit users. The primary concern seemed to be the act of waiting for the bus or train alone, as shown in Table 2.4 below. 
TABLE 2.4 - How Safe Do Young People Feel Waiting on Their Own - By Age*

\begin{tabular}{lcccc}
\hline & Very Safe/ Safe & Uneasy & Very Unsafe & Never Wait Alone \\
\hline At Bus Stop By Day & & & & \\
10 to 12 years & $62 \%$ & $5 \%$ & $2 \%$ & $31 \%$ \\
13 \& 14 years & $93 \%$ & $4 \%$ & $1 \%$ & $2 \%$ \\
15 years plus & $96 \%$ & $4 \%$ & - & - \\
\hline At Bus Stop After Dark & & & & $59 \%$ \\
10 to 12 years & $20 \%$ & $13 \%$ & $8 \%$ & $4 \%$ \\
13 \& 14 years & $40 \%$ & $38 \%$ & $18 \%$ & - \\
15 years plus & $54 \%$ & $30 \%$ & $16 \%$ & $47 \%$ \\
\hline At Train Station by Day & & & & $4 \%$ \\
10 to 12 years & $38 \%$ & $9 \%$ & $6 \%$ & - \\
13 \& 14 years & $86 \%$ & $9 \%$ & $1 \%$ & \\
15 years plus & $89 \%$ & $9 \%$ & $2 \%$ & $69 \%$ \\
\hline At Train Station After Dark & & & & $5 \%$ \\
10 to 12 years & $8 \%$ & $9 \%$ & $14 \%$ & - \\
13 \& 14 years & $6 \%$ & $30 \%$ & $39 \%$ & \\
15 years plus & $35 \%$ & $29 \%$ & $36 \%$ & \\
\hline
\end{tabular}

* Source: Stafford et al, 1999

Table 2.4 shows that concerns over safety while waiting alone generally decrease with age. Indeed a large proportion of 10 to 12 year olds never waited alone. While the majority of young people felt very safe or safe during the day, young people were much less comfortable after dark, particularly at train stations. Further work showed that women and girls were more likely to feel unsafe waiting for transit than young men or boys. Respondents generally felt much safer once they had boarded the transit vehicle. CCTV cameras at bus and train stations were the most popular measure for improving safety, in addition to better lighting and the provision of security personnel at stations and on transit vehicles (Stafford et al, 1999).

\section{Attitudes to Public Transit Versus the Private Car}

Most teens are greatly concerned with their social appearance, which also has an influence on travel behavior. According to Stafford et al. (1999), many teens find automobile use far more socially desirable than the use of public transit. One teen reported "the car you drive says whether you are posh and how much money you have (Stafford et al., 1999).” Another teen said "people who drive are busy people, they need to get around...they have a good job and money to buy a car (Stafford et al., 1999)." Some alternative views were expressed. The cost of driving and parking were noted as a negative aspect, and some stated that public transit was the cheaper option, particularly in expensive cities like London. 


\subsubsection{Attitudes and Perceptions of Teenagers in Toronto}

The "Kids on the Move" study, conducted by the Center for Sustainable Transportation in Toronto, met with over 100 children in grades 3, 4, 5, and 7 from the Toronto suburbs of Halton and Peel as part of their consultation effort. These meetings found that young people recognized the problems associated with living in auto-dependent communities and felt that there were few transportation choices for them (O’Brien and Gilbert, 2003). Those willing to deal with several transfers to reach their desired destinations felt that the cost of transit was too high. Higher service frequency and longer service span were also desired, but the study noted that this was not financially feasible.

Overall, there appears to be a paucity of information on the subject of teenage attitudes and perceptions of transit, particularly in the United States.

\subsection{Influence of Parental / Legal Guardian on Teenage Travel Behavior}

Research in the United Kingdom used indicators of independent mobility such as the "license" to cross roads, go to places other than school on their own, come home from school alone, go out after dark, use buses, and cycle on main roads (Hillman et al, 1990). The study found that British children in the 1990s were granted fewer licenses and received independence privileges at a much older age than children in the 1970s. Another British study (Tranter and Pawson, 2001) found that permission to travel alone varied by age, sex, and local traffic conditions, with independent mobility generally increasing with age, boys generally given more independence than girls, and independent mobility tending to decrease in highly trafficked areas.

The study conducted by Clifton on after-school travel found that teenagers living in single-parent households were more likely to make the trip home after school alone than children from households with two adults (Clifton, 2003). The study hypothesized that this was due to the greater time constraints placed upon single parents.

Much of the research into young people and travel behavior has been conducted in response to the problem of high travel related accident rates among this group. Research has shown that many auto accidents involving teen drivers occur within the first year of driving (Cvijanovich, Cook, Mann, \& Dean, 2001). Research has also shown that teens with parents who are highly involved in making decisions about their children's driving get into fewer accidents when compared to teens with less involved parents (Hartos, Eitel, Haynie, \& Simons-Morton, 2000). One 1985 study found that young men are often granted permission to drive automobiles before young women (Preusser, Williams, \& Lund, 1985). In some regions of the US, parents wish to extend the amount of time that their children practice driving with a supervisor before they can earn their license (Waller, Olk, \& Shope 2000). This extension of time increases the age and experience of first time drivers.

Overall, these studies suggest that parents have a strong influence on teen travel behavior, including both private automobile and public transit usage. The research suggests that the degree 
of influence may also vary depending on the age and gender of the teenager, as well as a variety of environmental characteristics.

\subsection{Examples of Programs Targeting Teenagers}

This section looks at a selection of programs that have been targeted specifically towards young people's travel behavior, focusing on a variety of different transportation modalities. These modalities have included the promotion of bike, bus, train and subway system use. In what follows, we review the challenges and successes faced by these programs.

\subsubsection{Chain Reaction}

Chain Reaction targeted youths aged 11 to 19 to participate in a bicycling program in Washington, D.C. (Chain Reaction, 2004). This program was promoted strictly by word of mouth. Teens who participated in Chain Reaction were encouraged to take classes featuring topics like bicycle safety and mechanics. Participation in such classes allowed teens to earn points toward earning a free bike through the program.

Chain Reaction increased teen interest in bicycling as a form of transportation. The gift of a bike was a strong incentive used to encourage participation. However, one problem that Chain Reaction faced was participant attrition. The sponsors of Chain Reaction found that participation in classes to earn points toward a new bike often took too long to retain teen interest, as they often lost interest and dropped out before they had earned the new bike. To address this issue, Chain Reaction is currently modifying their program to make classes shorter and to award the free bike in a shorter period of time. Using this strategy, it is hoped that participants will be more likely to complete the program.

There were two important lessons to learn from this program. The first lesson was that in order to make the program effective, the sponsors must provide a significant incentive to encourage participation. Furthermore, it appears that teens have a limited attention span and may not have the patience to participate in a lengthy program before receiving the incentive. This suggests that programs targeted at teens may need to focus on incorporating rewards for participation in a relatively short time frame.

\subsubsection{Delaware Transit Corp. Teen Driving Campaign}

A Teen Driving Campaign was developed in Delaware to promote public transit use (Davis, Carter, Hong \& Kimber, 2002). While one of the goals of this program was to teach teens about driver safety, another goal was to help teens realize that there are alternative transportation modalities available to them, particularly public transit. To promote their program, the Teen Driving Campaign advertised on the radio, TV, internet and billboards (McCaskey, 2002). In these multiple advertisements, the sponsors of this program tried to help teenagers understand that they have choices when it comes to transportation. Sponsors argued that while driving was one choice for transportation, other choices like public transit were available as well. 
Advertisements were geared toward helping teens realize that if their parents would not give them the car when they wanted to get out of the house, that the car was not the only alternative. Advertisements were also designed to convince teens that using public transit would be more affordable and would be much safer than travel using automobiles (McCaskey, 2002).

One factor contributing to the success of the program was the advertising strategy that the Teen Driving Campaign implemented. This program chose to advertise with media that teens frequently accessed. For example, advertisements on local TV and radio stations were selected because these media were the most likely to be viewed by teens. A second factor that may have lead to the success that the program experienced was the choice of message that was advertised. Sponsors of the Teen Driving Campaign created advertisements that appealed to teen concerns about money and safety. Teens were encouraged to use public transit by sponsors who argued that it was more cost effective and safe. Sponsors could have chosen any number of ways to promote the program. These could have included appearance and self worth issues. Instead, sponsors chose to appeal to cost and safety issues. This study suggests that teen marketing efforts should consider the types of issues teens will best respond to when developing their advertisements. This suggests that a social marketing approach may prove to be effective.

\subsubsection{On Our Own}

“On Our Own” was a program developed in New York to influence teens' use of public transit (Project Action of Easter, 1997). Populations of particular focus included teens and young adults that experienced physical disabilities. The goal of the program was to increase use of subways and bus systems in the New York area by reducing parental and teen anxieties about using these travel modes. Sponsors of this program believed that if parents and teens felt less fearful about using these subways and bus systems, then teens would be more likely to use them. This would allow teens and handicapped young adults to increase their independent mobility.

The advertising campaign focused on familiarizing teens with proper use of public transit systems in the New York area, including the use of buses and subway systems. The results of the program were mixed and found to be largely dependent on the region of New York in which the participants lived. Those participants who lived in the most urban areas, Manhattan, for example, were more independent than those who lived in more suburban areas such as Queens. This independence resulted in increased public transit use in urban areas.

The On Our Own program was analyzed in terms of effectiveness, revealing that parents were one of the greatest influences affecting whether participants utilized public transit. The more likely a parent was to be supportive, the more likely the teen would participate. These results suggest that when developing a public transit program for teens, sponsors must not only target teens but their parents as well. Teens may be able to travel alone using public transit, but it is important to acknowledge that they do not make their decisions independently. To an extent, most teens are still children under the influence of their family members. 


\subsubsection{Promoting Public Transit to Teenagers in the United Kingdom}

The study led by Stafford for the United Kingdom's government included a section on previous public transit promotion activities targeted at young people (Stafford et al, 1999). The study conducted a survey of British transit agencies and found that over 40 percent had run campaigns to promote young people's use of public transport. South Tyneside Council conducted a campaign titled "The Real Costs of Travel”, which was promoted through the distribution of a report, leaflets, and the Council's website. It was designed to encourage more sustainable modes of travel by highlighting the real cost of automobile travel is relation to other modes, including unseen costs. In Scotland, the Scotrail train company established a "Kids Loyalty Club" to promote young peoples' continued use of rail services. London Transport introduced a scheme to give discounted fares to students through the implementation of a student photocard, hoping to encourage current students to become life-long users of public transit. On the photocard issue, in South Yorkshire the local transit provider identified reluctance among young people to carry and show the "proof of age" cards that had been issued. To address this, the agency rebranded the card as the "MegaTravel" card with a modern format and image. As an added incentive, the "MegaTravel" card also provided discounts at shops and venues throughout the local area, and produced a quarterly magazine designed to appeal to young people. The local radio station also became involved, funding a special "MegaFile" show as well as an open air music event.

An article published in Global Transport (Yearsley, 1997) noted the need for a national campaign to educate young people "not only to see public transport as a viable alternative to the car, but to have the skills and confidence to use it". The article went on to emphasize that "...if it is worthwhile giving senior scholars pre-driving school training, then it is doubly worthwhile teaching them to navigate their way through a fare structure...they need criteria to enable them to plan a journey, filling gaps with taxis where appropriate, but using buses as well as trains and planes”. A national campaign for providing training in public transport skills was recommended. In summary, the Stafford report identified three key lessons from previous successful promotional campaigns that had targeted young people (Stafford et al, 1999):

- Campaigns need to use images and the media which "speak" to young people and attract and maintain their interest. The use of appropriate celebrities could be particularly effective in promoting public transport amongst young people

- The use of imaginative proof of age cards not only encourages their use by young people but will also reduce the friction between transport staff and young people

- Campaigns or events need to integrate messages about safety and security in a way which young people recognize and understand, but does not lecture them or make assumptions that all young people "are the same"

\subsection{5 "Transportation Planning by Teenagers" - St Lucie County, Florida}

In March 2000, St Lucie Metropolitan Planning Organization (MPO) received a \$117,000 grant from the Federal Highway Administration's (FHWA) Transportation and Community System Preservation program (TCSP). The grant was provided to allow the St Lucie MPO to explore youth involvement in the transportation planning process. The aim of the project, titled 
“Transportation Planning by Teenagers”, was to educate the county's youth on local transportation issues, to allow them to develop a long-range transportation plan for the St Lucie area (St Lucie County MPO and St Lucie County School District, 2002).

The project was lead by the St Lucie MPO, in collaboration with the St Lucie County Board of County Commissioners and the School Board of St Lucie County. The partnership was formalized through a contractual agreement between the St Lucie MPO and the School Board. The project focused on students at Fort Pierce Central High School, mainly 16 and 17 year olds, with some 14 and 15 year olds also involved. Entire classes were identified to work on the project, with grades being allocated to each student in relation to their performance on the project. Overall, around 400 students were involved over the two years of the project (Bonet, 2005).

The project began with students being educated through self study, a series of in class lectures by guest speakers, and interviews with transportation experts outside the classroom. The students then conducted a survey to gain an understanding of the transport improvement priorities of the local population. Using the above information sources, students then worked in groups to produce their long-range transportation plan. Other outputs from the project were a series of eight videos highlighting different local transportation issues, three booklets that were designed to help future classes undertaking similar projects (see Figure 3.4 below), and a project website.

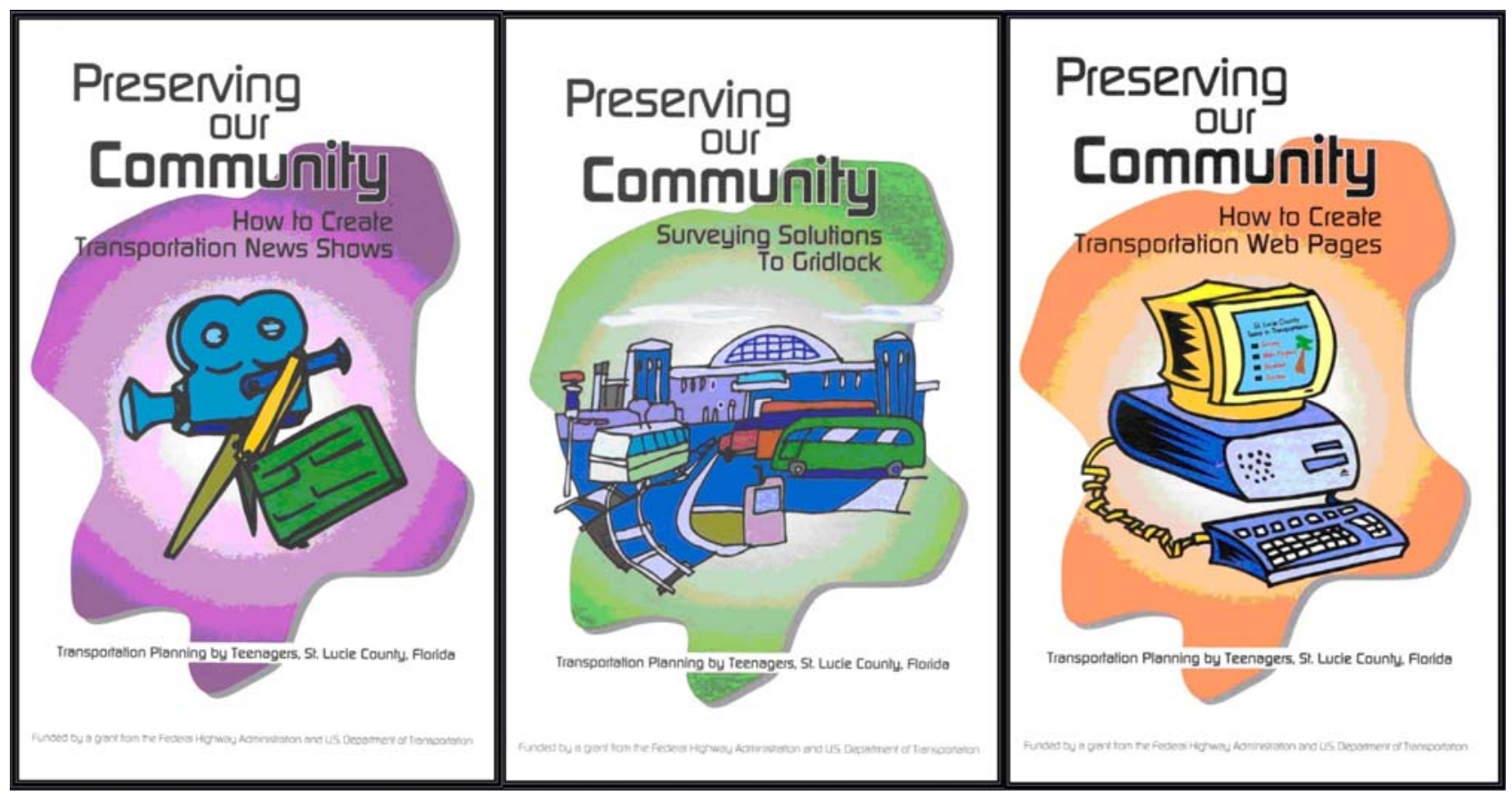

FIGURE 3.4 - Booklets Produced by Students in St Lucie County

In addition to raising youth awareness of local transportation issues, and showing teenagers how to get involved in local government, a major output of the study was the final project presentation to the St Lucie MPO in June 2002. The meeting was very important because the funding for the county's demand response service had just been cut, and another source needed 
to be found. The suggestion put forward was for the establishment of a Municipal Service Taxing Unit (MSTU), creating an additional tax that would fund the transit service. However, there was considerable opposition from local officials to additional taxation. At the meeting, the students presented their long-range transportation plan, highlighting the benefits of the demand response service, and transit in general. Their presentation was crucial in helping convince elected officials that the transit service was worth retaining. The MSTU was subsequently established, collecting $\$ 900,000$ in its first year. In addition to the demand response service, the county now provides three fixed route services (Bonet, 2005).

Discussing the lessons learned from the project, the St Lucie MPO representative stated that the project could not have been a success without the Federal grant. This money was used to pay for computer and video camera equipment, field trip transportation, substitute teachers, a scriptwriter/project coordinator to assist in video production, and the hiring of student interns to develop the website and type the final reports. The St Lucie MPO representative stated that the main challenge was getting the "buy in" from teachers at the school. This was difficult because of other major commitments on teachers' time, such as Florida Comprehensive Assessment Test (FCAT) preparation. The funding allowed the various activities to be conducted and the equipment purchases also acted as an incentive for the school and its teachers to participate. The high level support from the School Board and formal contractual agreement also made it clear that the project was important (Bonet, 2005).

The representative stated that the best way to conduct such an exercise was to incorporate the project in the school syllabus, perhaps as part of a Geography or Civics class. With this approach, the project would not be seen as additional study competing with core syllabus requirements. The three booklets produced by the project were designed to be used by future classes in this type of setting (Bonet, 2005).

\subsection{Public Transit and School Buses}

The United States is the only country in the world to provide a separate network of 435,000 dedicated school buses to take children to and from school every day. This service is regarded as one of the key elements in ensuring the safety of children while traveling, but is also criticized for being expensive and inefficient. Federal transit laws and regulations prohibit transit agencies from providing dedicated services for school students. However, students are permitted to use public transit services to get to and from school, as long as the service is also open to the public. Some transit services take advantage of this by providing "tripper" services that are routed and scheduled to provide for school trips, but are also open to the public (Zeilinger, 2004).

In 1994, efficiency concerns led Florida's Department of Education (DOE) to commission the Center for Urban Transportation Research (CUTR) to investigate different options for funding student transportation in Florida. The report found that inefficiencies did exist, and recommended that a formula based on Average Bus Occupancy (ABO) be used to determine the level of funding granted to individual School Boards. The recommendation was subsequently adopted by the DOE. Although efficiency gains have been made as a result of this policy amendment, it has also resulted in a sense of competition between school bus service providers 
and local transit agencies - if some school students decide to take transit, this could relate to a lower ABO and subsequently less school travel funding for the school board in future years (Baltes, 1994). One transit agency surveyed for this project made reference to this issue, stating that the "aggressive" school bus system in their area made it difficult for the local transit service to promote transit use through the school system, due to school bus operator concerns that "business" (i.e. children riding to and from school) may be reduced (see Section 5.5). In the current context of rising gasoline prices, the issue of rising fixed costs makes it even more important for school bus operators to retain ridership under the ABO funding system.

On the other hand, some examples were also found of transit agencies and school boards working together. In Illinois, the closing of a school in the Waukegan School District meant that the school district was faced with paying significantly higher transportation costs to bus students to the remaining school. Pace, the suburban bus division of Chicago's Regional Transportation Authority, entered into an agreement with the school district to allow students to ride for free from 6:00 a.m. and 8:00 p.m. for a fee of $\$ 186.50$ per student. This resulted in a ridership increase of over 50 percent. However, it was noted that this arrangement had not been repeated in other parts of the service area due to active resistance from private operators of school transportation services (Volinski, 2003).

\subsection{Summary / Discussion}

This review was designed to collate and synthesize existing research knowledge on the subject of teenage mobility. Looking at the general characteristics of young people's travel behavior in the United States, it was observed that the private automobile is the dominant mode of travel, followed by walking. It was apparent that for many American young people, the school bus was likely to be their first experience of public transit style travel. It was also observed that travel characteristics vary by age, with people under the age of 12 unlikely to use transit unaccompanied, while people aged between 12 and 16 were found to be more likely to use transit than those over 16, who are increasingly likely to travel by car. Several studies suggested that youth mobility has been decreasing over time. Florida level statistics suggest that teenagers are even more heavily auto dependent than the national average, particularly those above the legal driving age. It appears that most Florida teenagers have no experience of using public transit in Florida, though some may experience mass transit through riding the school bus.

A study from Toronto, Canada, suggested that teen travel patterns were also influenced by type of environment, with young people in urban areas more likely to be transit users than those living in the suburbs. The review also suggests that parental views are a major influence on teen transit use, particularly for younger teens. Studies in both Canada and the United Kingdom also suggested that teenagers independent mobility was decreasing over time. A paucity of existing research on the attitudes and perceptions of American teenagers towards transit was identified. However, a study conducted in the United Kingdom suggests that teenagers have a predominantly negative view of public transit, with cost, negative transit employee attitudes, availability and frequency, comfort, information and safety all cited as problem issues. It appears that most teenagers aspire to be car users as adults and cease using transit once they are able to drive their own vehicle. 
The review did find evidence of promotional campaigns targeted at young people, in both the United States and elsewhere. It was found that offering incentives, such as a free bus pass or fare discount, was the most effective way to encourage transit use. Overall, a good understanding of problems issues and motivational factors are required in order to plan an effective campaign, which suggests that a social marketing approach may be useful. It may be necessary to design the campaign to also address parental concerns, due to their significant influence on teenage travel behavior. Overall, this review suggests that making transit more attractive to teenagers in Florida, and across the United States, will be a significant challenge. The lack of existing research in this country highlights a critical research need. 


\section{Analysis of Teenage Transit Ridership}

This section provides a variety of different descriptive analyses of teenage travel behavior in the United States. The first section looks at the number of teenagers in the country. Subsequent sections describe different aspects of transit ridership among teenagers, focusing on teenage ridership in Florida.

\subsection{The Teenage Population}

Table 3.1 below made use of Census 2000 data to determine the number of teenagers of different genders in the United States.

TABLE 3.1 - Youth Population in the United States*

\begin{tabular}{|c|c|c|c|c|c|c|}
\hline \multirow{2}{*}{ Age } & \multicolumn{3}{|c|}{ Number } & \multicolumn{3}{|c|}{$\begin{array}{c}\text { Percent } \\
\text { (of Population) }\end{array}$} \\
\hline & $\begin{array}{l}\text { Both } \\
\text { sexes }\end{array}$ & Male & Female & $\begin{array}{l}\text { Both } \\
\text { sexes }\end{array}$ & $\begin{array}{l}\text { Male } \\
\text { Pop. }\end{array}$ & $\begin{array}{l}\text { Female } \\
\text { Pop. }\end{array}$ \\
\hline Under 1 year & $3,805,648$ & $1,949,017$ & $1,856,631$ & 1.4 & 1.4 & 1.3 \\
\hline 1 year & 3,820,582 & $1,953,105$ & $1,867,477$ & 1.4 & 1.4 & 1.3 \\
\hline 2 years & $3,790,446$ & 1,938,990 & $1,851,456$ & 1.3 & 1.4 & 1.3 \\
\hline 3 years & 3,832,799 & $1,958,963$ & $1,873,836$ & 1.4 & 1.4 & 1.3 \\
\hline 4 years & 3,926,323 & $2,010,658$ & $1,915,665$ & 1.4 & 1.5 & 1.3 \\
\hline 5 years & $3,965,103$ & $2,031,072$ & $1,934,031$ & 1.4 & 1.5 & 1.3 \\
\hline 6 years & $4,019,705$ & $2,058,217$ & $1,961,488$ & 1.4 & 1.5 & 1.4 \\
\hline 7 years & $4,118,147$ & $2,109,868$ & 2,008,279 & 1.5 & 1.5 & 1.4 \\
\hline 8 years & $4,179,230$ & $2,137,829$ & $2,041,401$ & 1.5 & 1.5 & 1.4 \\
\hline 9 years & $4,267,320$ & 2,186,291 & $2,081,029$ & 1.5 & 1.6 & 1.5 \\
\hline 10 years & $4,274,056$ & $2,191,244$ & $2,082,812$ & 1.5 & 1.6 & 1.5 \\
\hline 11 years & $4,115,093$ & $2,108,157$ & $2,006,936$ & 1.5 & 1.5 & 1.4 \\
\hline 12 years & $4,075,842$ & $2,087,228$ & $1,988,614$ & 1.4 & 1.5 & 1.4 \\
\hline 13 years & $4,010,850$ & $2,054,008$ & $1,956,842$ & 1.4 & 1.5 & 1.4 \\
\hline 14 years & $4,052,231$ & $2,079,560$ & $1,972,671$ & 1.4 & 1.5 & 1.4 \\
\hline 15 years & $4,019,404$ & $2,065,127$ & $1,954,277$ & 1.4 & 1.5 & 1.4 \\
\hline 16 years & $3,975,021$ & $2,048,582$ & $1,926,439$ & 1.4 & 1.5 & 1.3 \\
\hline 17 years & $4,046,012$ & $2,091,280$ & $1,954,732$ & 1.4 & 1.5 & 1.4 \\
\hline 18 years & $4,051,598$ & $2,078,853$ & $1,972,745$ & 1.4 & 1.5 & 1.4 \\
\hline 19 years & $4,127,855$ & $2,107,162$ & $2,020,693$ & 1.5 & 1.5 & 1.4 \\
\hline 19 and under & $80,473,265$ & $41,245,211$ & $39,228,054$ & 28.6 & 29.8 & 27.4 \\
\hline 13 to 19 & $28,282,971$ & $14,524,572$ & $13,758,399$ & 10.0 & 10.5 & 9.6 \\
\hline Total Population & $281,421,906$ & $138,053,563$ & $143,368,343$ & 100.0 & 100.0 & 100.0 \\
\hline
\end{tabular}

The table shows that from a total population of over 280 million, over 80 million (28.6 percent) are 19 years old or younger. Of these, over 28 million are aged between 13 and 19, equating to 10.0 percent of the total population. The table also shows that the proportion of the population at each age level is very consistent, with around 4 million people of each age (each accounting for 
between 1.4 and 1.5 percent of the total population). It can also be observed that there are slightly more males than females overall, and at each individual age level.

Conducting the same analysis on Florida's population, it was found that out of a state population of almost 16 million, just over 4 million (25.3 percent) were 19 years old or younger, and 1,428,000 (8.9 percent) were between the ages of 13 and 19. This means that Florida has a slightly lower proportion of teenagers than the national average.

\subsection{Aggregate Teenage Travel Behavior in the United States}

The 2001 National Household Travel Survey (NHTS) was used to assess the overall proportion of trips made by different modes in the United States. Table 3.2 below presents the overall person trip mode split for different age groups. The way the data has been segmented means that the teenage age bracket cannot be directly isolated. However, the table does allow overall trends to be considered.

TABLE 3.2 - Mode Split By Age Group for the United States Population

\begin{tabular}{ccccccccc}
\hline $\begin{array}{c}\text { Age } \\
\text { Group }\end{array}$ & $\begin{array}{c}\text { private } \\
\text { vehicle }\end{array}$ & $\begin{array}{c}\text { school } \\
\text { bus }\end{array}$ & $\begin{array}{c}\text { public } \\
\text { bus }\end{array}$ & $\begin{array}{c}\text { transit } \\
\text { other }\end{array}$ & Bicycle & walk & $\begin{array}{c}\text { other } \\
\text { mode }\end{array}$ & TOTAL \\
\hline $0-5$ & $86.3 \%$ & $1.5 \%$ & $1.0 \%$ & $0.2 \%$ & $0.7 \%$ & $9.8 \%$ & $0.5 \%$ & $100.0 \%$ \\
$\mathbf{6 - 1 5}$ & $\mathbf{7 0 . 2 \%}$ & $\mathbf{1 0 . 7 \%}$ & $\mathbf{0 . 8 \%}$ & $\mathbf{0 . 3 \%}$ & $\mathbf{3 . 1 \%}$ & $\mathbf{1 3 . 9 \%}$ & $\mathbf{1 . 1 \%}$ & $\mathbf{1 0 0 . 0 \%}$ \\
$\mathbf{1 6 - 2 0}$ & $\mathbf{8 4 . 7 \%}$ & $\mathbf{2 . 4 \%}$ & $\mathbf{1 . 6 \%}$ & $\mathbf{1 . 1 \%}$ & $\mathbf{0 . 7 \%}$ & $\mathbf{8 . 4 \%}$ & $\mathbf{1 . 1 \%}$ & $\mathbf{1 0 0 . 0 \%}$ \\
$21-25$ & $86.6 \%$ & $0.1 \%$ & $1.9 \%$ & $1.3 \%$ & $0.5 \%$ & $8.9 \%$ & $0.7 \%$ & $100.0 \%$ \\
$26-30$ & $87.2 \%$ & $0.0 \%$ & $1.4 \%$ & $1.2 \%$ & $0.6 \%$ & $8.7 \%$ & $0.9 \%$ & $100.0 \%$ \\
$31-35$ & $88.9 \%$ & $0.0 \%$ & $1.0 \%$ & $0.9 \%$ & $0.4 \%$ & $7.9 \%$ & $0.8 \%$ & $100.0 \%$ \\
$36-40$ & $89.7 \%$ & $0.1 \%$ & $1.0 \%$ & $0.9 \%$ & $0.5 \%$ & $6.9 \%$ & $1.0 \%$ & $100.0 \%$ \\
$41-45$ & $90.7 \%$ & $0.1 \%$ & $0.8 \%$ & $0.6 \%$ & $0.4 \%$ & $6.6 \%$ & $0.9 \%$ & $100.0 \%$ \\
$46-50$ & $90.1 \%$ & $0.1 \%$ & $0.7 \%$ & $0.7 \%$ & $0.5 \%$ & $7.0 \%$ & $1.0 \%$ & $100.0 \%$ \\
$51-55$ & $90.4 \%$ & $0.1 \%$ & $0.9 \%$ & $0.6 \%$ & $0.4 \%$ & $7.0 \%$ & $0.7 \%$ & $100.0 \%$ \\
$56-60$ & $89.6 \%$ & $0.0 \%$ & $0.9 \%$ & $0.6 \%$ & $0.3 \%$ & $7.8 \%$ & $0.8 \%$ & $100.0 \%$ \\
$61-65$ & $89.6 \%$ & $0.0 \%$ & $0.9 \%$ & $0.4 \%$ & $0.4 \%$ & $7.9 \%$ & $0.8 \%$ & $100.0 \%$ \\
$66-70$ & $89.3 \%$ & $0.2 \%$ & $0.9 \%$ & $0.5 \%$ & $0.4 \%$ & $8.1 \%$ & $0.7 \%$ & $100.0 \%$ \\
$71-75$ & $89.8 \%$ & $0.0 \%$ & $0.9 \%$ & $0.2 \%$ & $0.5 \%$ & $8.2 \%$ & $0.4 \%$ & $100.0 \%$ \\
$76-79$ & $88.2 \%$ & $0.0 \%$ & $1.3 \%$ & $0.5 \%$ & $0.3 \%$ & $9.2 \%$ & $0.4 \%$ & $100.0 \%$ \\
$80-84$ & $88.7 \%$ & $0.0 \%$ & $1.1 \%$ & $0.7 \%$ & $0.1 \%$ & $8.9 \%$ & $0.5 \%$ & $100.0 \%$ \\
$85+$ & $87.0 \%$ & $0.0 \%$ & $1.7 \%$ & $1.3 \%$ & $0.2 \%$ & $9.4 \%$ & $0.5 \%$ & $100.0 \%$ \\
\hline Average & $\mathbf{8 6 . 2 \%}$ & $\mathbf{1 . 7 \%}$ & $\mathbf{1 . 1 \%}$ & $\mathbf{0 . 7 \%}$ & $\mathbf{0 . 8 \%}$ & $\mathbf{8 . 7 \%}$ & $\mathbf{0 . 8 \%}$ & $\mathbf{1 0 0 . 0 \%}$ \\
\hline * Source: 2001 National Household Travel $\%$ Survey & & & & & \\
& & & & & & & &
\end{tabular}

Table 3.2 shows that, across all age groups, the vast majority of trips are made by private vehicle, an average of 86.2 percent of total trips. Following the private vehicle, walking is the 
next most common mode for each age group, accounting for 8.7 percent of total trips. This means that all other modes, including transit, account for only around five percent of total trips.

Focusing on the 6-15 age group, it can be seen that this category shows the lowest overall proportion of private vehicle trips, at only 70.2 percent of total trips. This lower than average proportion of private vehicle trips is accounted for by a much higher than average proportion of trips made by school bus (10.7 percent compared to an average of 1.7 percent), in addition to higher than average proportions of both walking (13.9 percent) and cycling (3.1 percent) trips. The proportion of trips made on public transit modes is actually lower than the average for all age groups, with only 0.8 percent of trips made by public bus and 0.3 percent made by other transit modes.

Looking at the 16 to 20 age group, a slightly different pattern is evident. At 84.7 percent, the proportion of private vehicle trips is only slightly below the average of 86.2 percent, while the proportion of trips made by walking and cycling is also close to the overall average values. The proportion of trips made by school bus is higher than for older age groups, but still much lower than for the 6 to 15 age category. The proportion of trips made on transit modes are actually higher than the average, with 1.6 percent made on the public bus and 1.1 percent made on other transit modes. Interestingly, transit mode split actually peaks in the 21 to 25 age group.

Overall, this analysis suggests that the private vehicle is by far the most dominant mode of transportation for young people. Given that this is true for people under the legal driving age of 16 , it must be assumed that many of these trips are made as a passenger. The lower than average transit use figures for those aged 15 and under suggest that transit use is only possible once an individual reaches a certain age. Limitations in the dataset meant that a similar analysis could not be conducted for person trips in Florida. One option for further research would be to investigate the age at which independent transit use becomes feasible.

While the previous analysis considered transit trips as a proportion of total trips, the following analysis (Table 3.3) considers, for areas of different population size, the proportion of transit riders aged 18 and under in relation to the proportion of population in this age group.

TABLE 3.3 - Transit Ridership Versus

Population in Areas of Different Population Size

\begin{tabular}{lcc}
\hline \multicolumn{1}{c}{$\begin{array}{c}\text { Area } \\
\text { (By Population) }\end{array}$} & $\begin{array}{c}\text { \% of U.S. Passengers } \\
18 \text { and Under* }\end{array}$ & $\begin{array}{c}\text { \% of U.S Population } \\
\text { Under 18 Years** }\end{array}$ \\
\hline 50,000 and under (rural) & 21 & No data \\
$50,000-200,000$ & 19 & 25.2 \\
$200,000-500,000$ & 15 & 26.1 \\
$500,000-1,000,000$ & 9 & 25.9 \\
$1,000,000$ and over & 10 & \\
*Source: & Public Transportation Fact Book, $55^{\text {th }}$ Edition, March 2004, APTA \\
** Source: & US Census 2000
\end{tabular}

Although the two sets of figures refer to slightly different age groups - one includes 18 year olds and one does not - the table is useful for considering youth ridership proportions in relation to population. Looking first at the transit ridership column, it can be seen that ridership proportions vary in relation to area size, with under 18s making up over one fifth of ridership in areas of 
50,000 people or less, only around one tenth of ridership in areas with over populations over 500,000 . Looking at the population statistics for this age group, it can be seen that the proportion of under 18s in the total population is relatively consistent, at around 25-26 percent, for areas of different area size. Comparing the two columns, one can conclude that youth in the United States is under-represented in terms of the proportion using transit, and that this under-representation is more pronounced as area size (in terms of population) increases.

\subsection{Teenage Ridership in Florida}

As the focus of this study is teenage mobility in Florida, it was considered important to gain an understanding of teenage ridership in this state. To address this, a collection of 23 onboard survey reports were obtained from different transit agencies around the state (there are a total of 28 transit systems in the state). Table 3.4 provides the youth ridership proportions for each agency, as extracted from each on-board survey report.

TABLE 3.4 - Youth Ridership Proportions on Florida's Transit Systems

\begin{tabular}{|c|c|c|}
\hline Transit Agency & $\begin{array}{l}\text { Year of } \\
\text { Survey }\end{array}$ & $\begin{array}{l}\text { Summarized Youth } \\
\text { Ridership Proportions }\end{array}$ \\
\hline BTC - Broward Transit Commission & 2004 & under $18=10 \% ; 18-24=26.8 \%$ \\
\hline BTT - Bay Town Trolley & 2002 & under $15=0 \% ; 15-18=3 \% ; 19-24=2.5 \%$ \\
\hline CAT - Collier Area Transit & 2005 & 18 or under $=7.4 \% ; 19-24=59.8 \%$ \\
\hline ECAT - Escambia County Area Transit & 2002 & 17 or under $=6.2 \% ; 18-24=18.8 \%$ \\
\hline HART - Hillsborough Area Regional Transit Authority & 2001 & $0-15=4 \% ; 16-21=16 \%$ \\
\hline HCMPO - Hernando County MPO & 2003 & under $15=4.9 \% ; 15-18=23.8 \% ; 19-24=4.9 \%$ \\
\hline IRT - Indian River Transit & 2005 & 17 or under $=10 \% ; 18-24=15 \%$ \\
\hline JTA - Jacksonville Transit Authority & 2004 & 17 or under $=7.5 \% ; 18-24=18.5 \%$ \\
\hline KWT - Key West Transit & 2000 & under 18 = 17.9\%; 18-24 = 13.1\% \\
\hline LAMTD - Lakeland Area Mass Transit Division & 1998 & $10-17=16 \% ; 18-24=19 \%$ \\
\hline LEETRAN - Lee County Transit & 2003 & 17 or under $=8.3 \% ; 18-24=21.5 \%$ \\
\hline LYNX-CFRTA - Central Fl. Regional Transportation Authority & 2001 & under $15=4 \% ; 15-24=24 \%$ \\
\hline MCAT - Manatee County Area Transit & 2004 & 17 or under $=19 \% ; 18-24=15 \%$ \\
\hline MCT - Martin County Transit & 2004 & under $24=42 \%$ (Route 1), 20\% (Route 2) \\
\hline MDT - Miami-Dade Transit & 2005 & 15 or under $=5 \% ; 16-19=14 \%$ \\
\hline PCPT - Pasco County Public Transportation & 2002 & 17 or under $=5.1 \% ; 18-24=8.67 \%$ \\
\hline RTS - Regional Transit System & 2002 & under $18=5 \% ; 18-24=65 \%$ \\
\hline SCAT - Space Coast Area Transit (Brevard) & 2004 & 18 or under $=9 \% ; 19-24=12.4 \%$ \\
\hline SCAT - Sarasota County Area Transit & 2002 & $15-17=15.7 \% ; 18-24=10.3 \%$ \\
\hline TALTRAN - Tallahassee Transit & 2004 & 17 or under $=7.44 \% ; 18-24=59.82 \%$ \\
\hline TRIRAIL - South Florida Regional Transportation Authority & 2004 & 17 or under $=4.15 \% ; 18-24=10.69 \%$ \\
\hline VOTRAN - Volusia County Transportation Authority & 2002 & 18 or under $=15.7 \% ; 19-24=15.6 \%$ \\
\hline OCT - Okaloosa County Transit & 2002 & Age figure missing from report \\
\hline PALMTRAN - Palm Beach County Transportation Department & 2003 & $\begin{array}{l}\text { Youth ridership discussed, but no youth age } \\
\text { category included in survey instrument }\end{array}$ \\
\hline
\end{tabular}

The table shows that almost all the surveys included an age category for youth riders. However, in most cases, this category was defined as "under 18" or "under 17" with no further separation of youth age groups. It was also common to include older teenagers in an "18-24" or "19-24" age group. Some agencies did include additional youth age categories, such as "15 to 18" or " 16 to 19”, but still none of these allowed teenage ridership to be isolated. The closest approximation to 
the teenage age group was LAMTD (Lakeland), who provided a 10 to 17 age group. This means that the exact proportion of teenage riders on Florida's transit systems cannot be determined.

However, the table does provide evidence that each agency has at least some youth riders. The proportions of youth ridership vary considerably across the different agencies, with the majority of the agencies reporting "under 18" or "under 17" ridership in the 4 to 10 percent range. The 18 to 24 or 19 to 24 categories generally showed higher proportions, typically ranging from 10 to 20 percent, but this clearly also includes non-teenage riders. For some agencies it was apparent that youth ridership appeared to make up a significant proportion of total ridership. For example, in Hernando County, the survey found that almost one quarter (23.8 percent) of total ridership was aged 15-18 years old, with a further 4.9 percent under 15 years old and 4.9 percent aged 19 to 24 . The two college towns of Gainesville and Tallahassee also predictably fell into this category, with around 60 percent of its ridership in the 18 to 24 age group. Collier County's CAT system also had a 60 percent ridership in its 19 to 24 age group, and this was attributed to a large, lowincome Hispanic population in this age group.

\subsection{Other On-Board Survey Information on Florida's Teenage Transit Ridership}

Although the main objective of using the on-board survey resource was to assess teenage transit ridership in Florida, the on-board surveys did report other useful information in relation to youth ridership. Seven information type categories were identified:

\section{(i) Age Category}

This related to whether a youth option (i.e. under 18 or under 17) was included in the section asking respondents to provide their age. This was essential to being able to assess youth ridership. An additional subcategory was added to show which agencies included a further subdivision of the youth age range (i.e 15-18 or 16-19).

(ii) Population Comparison

This related to whether the observed youth ridership proportion had been compared to population statistics (i.e. US Census) for the area.

(iii) Temporal Comparison

Whether youth ridership data from the "current survey" is compared to data from previous surveys.

(iv) Crosstabs By Age

Refers to whether the youth age variable is cross tabulated against other survey variables. For example, cross tabulating age by trip purpose allows youth trip purposes to be isolated.

(v) Farebox Data

Refers to whether information on youth ridership is collected through processing of farebox data (i.e. youth passes, school passes or other discounted fares that can be directly attributed to youth ridership). 
(vi) Origin-Destination / Purpose Data

Refers to whether information on youth trip origins / destinations are considered (i.e. school / college / etc.)

(vii) Interpretation

Refers to whether youth ridership has been discussed in more detail than simply quoting the figures already provided in the data tables.

Table 3.5 below provides a categorization of the different information types, and shows which agencies provided which types of information.

TABLE 3.5 - Other Information on Youth Ridership Provided in On-Board Surveys

\begin{tabular}{|c|c|c|c|c|c|c|c|c|}
\hline \multirow{2}{*}{ Agency / County } & \multicolumn{2}{|c|}{ Age Category } & \multirow{2}{*}{$\begin{array}{l}\text { Population } \\
\text { Comparison }\end{array}$} & \multirow{2}{*}{$\begin{array}{l}\text { Temporal } \\
\text { Comparison }\end{array}$} & \multirow{2}{*}{$\begin{array}{c}\text { Crosstabs } \\
\text { By Age }\end{array}$} & \multirow{2}{*}{$\begin{array}{l}\text { Farebox } \\
\text { Data }\end{array}$} & \multirow{2}{*}{$\begin{array}{c}\text { O-D / Purpose } \\
\text { Data }\end{array}$} & \multirow{2}{*}{$\begin{array}{l}\text { Inter- } \\
\text { pretation }\end{array}$} \\
\hline & $>18 / 17$ & Other & & & & & & \\
\hline BTC (Broward) & $\mathrm{X}$ & & & & & & $\mathrm{X}$ & \\
\hline BTT (Bay) & $\mathrm{X}$ & $\mathrm{X}$ & & & $\mathrm{X}$ & $\mathrm{X}$ & $\mathrm{X}$ & $\mathrm{X}$ \\
\hline CAT (Collier) & $\mathrm{X}$ & & & & & & $\mathrm{X}$ & \\
\hline ECAT (Escambia) & $\mathrm{X}$ & & $\mathrm{X}$ & $\mathrm{X}$ & & & $\mathrm{X}$ & \\
\hline HART (Hillsborough) & $\mathrm{X}$ & & $\mathrm{X}$ & & $\mathrm{X}$ & & $\mathrm{X}$ & $\mathrm{X}$ \\
\hline HCMPO (Hernanado) & $\mathrm{X}$ & $\mathrm{X}$ & & & & & $\mathrm{X}$ & \\
\hline IRT (Indian River) & $\mathrm{X}$ & & & $\mathrm{X}$ & & & & \\
\hline JTA (Jax) & $\mathrm{X}$ & & & $\mathrm{X}$ & & & & \\
\hline KWDOT (Key West) & $\mathrm{X}$ & & & & & $\mathrm{X}$ & $\mathrm{X}$ & \\
\hline LAMTD (Lakeland) & $\mathrm{X}$ & $\mathrm{X}$ & & & & & $\mathrm{X}$ & \\
\hline LEETRAN (Lee) & $\mathrm{X}$ & & & & $\mathrm{X}$ & & $\mathrm{X}$ & \\
\hline LYNX (Orlando) & $\mathrm{X}$ & $\mathrm{X}$ & & & & & $\mathrm{X}$ & \\
\hline MCAT (Manatee) & $\mathrm{X}$ & & & $\mathrm{X}$ & & & $\mathrm{X}$ & \\
\hline MCT (Martin) & & & & & & & $\mathrm{X}$ & \\
\hline MDT (Miami) & $\mathrm{X}$ & $\mathrm{X}$ & & & & & $\mathrm{X}$ & \\
\hline PALMTRAN (Palm Beach) & & & & & $\mathrm{X}$ & $\mathrm{X}$ & $\mathrm{X}$ & \\
\hline PCPT (Pasco) & $\mathrm{X}$ & & & & & & $\mathrm{X}$ & \\
\hline RTS (Gainesville) & $\mathrm{X}$ & & & & & $\mathrm{X}$ & & \\
\hline SCAT (Brevard) & $\mathrm{X}$ & & $\mathrm{X}$ & & $\mathrm{X}$ & & $\mathrm{X}$ & $\mathrm{X}$ \\
\hline SCAT (Sarasota) & $\mathrm{X}$ & $\mathrm{X}$ & & $\mathrm{X}$ & & & $\mathrm{X}$ & \\
\hline TALTRAN (Tallahassee) & $\mathrm{X}$ & & & & & $\mathrm{X}$ & $\mathrm{X}$ & \\
\hline TRIRAIL (Tri County Rail) & $\mathrm{X}$ & & & $\mathrm{X}$ & & & & \\
\hline VOTRAN (Volusia) & $\mathrm{X}$ & & & $\mathrm{X}$ & & & $\mathrm{X}$ & \\
\hline
\end{tabular}

The table shows that two information types were included by almost every agency - the youth age category and the origin/destination /purpose data. The remaining categories were included on a much less frequent basis, and no agency included all seven categories. Some of these categories provided very useful additional information on youth ridership. A reconstruction of a "population comparison" chart provided in the Space Coast Area Transit survey is shown in Figure 3.1 below. 


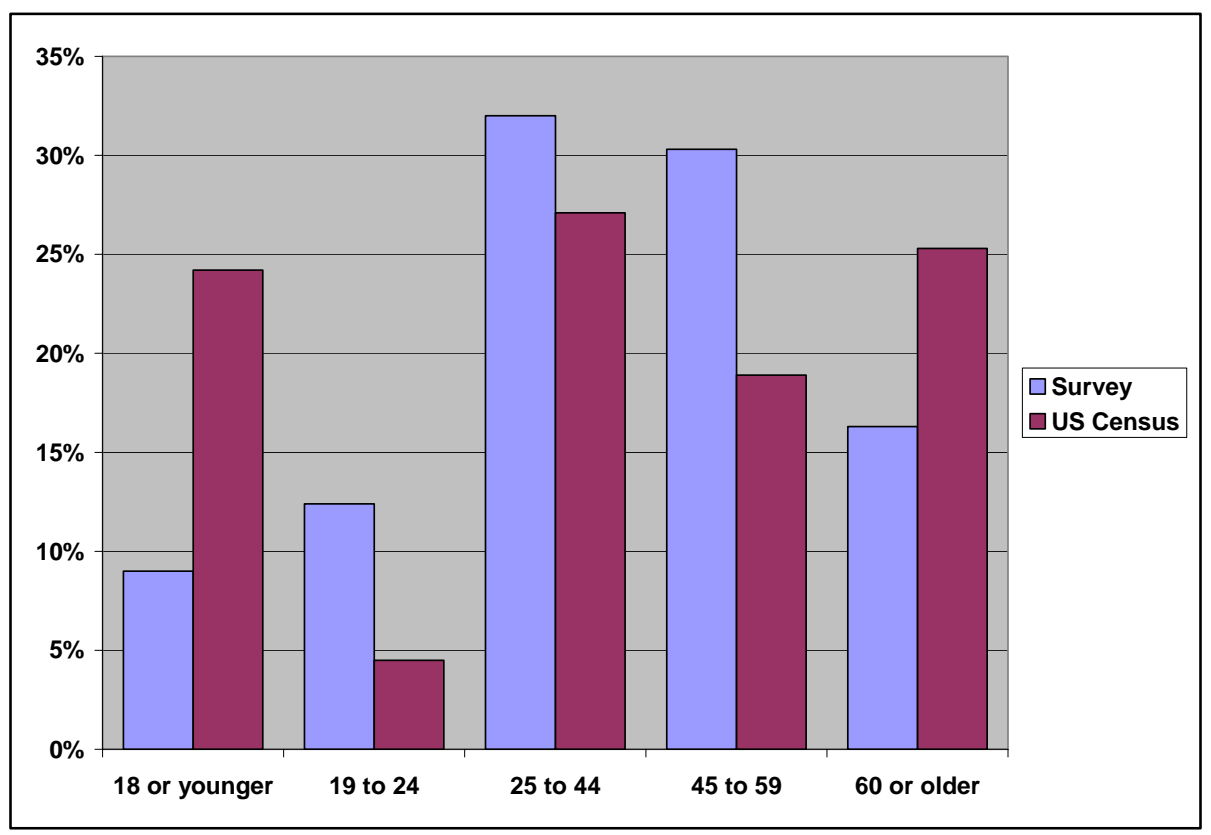

FIGURE 3.1 - Transit Ridership on Space Coast Area Transit

The chart shows that youth ridership is underrepresented on this system when compared to the local population. The report commented on this chart by stating that SCAT riders were disproportionately represented in the 19 to 59 age ranges, and this was attributed to the fact that this age group was likely to have greater travel needs than those in older or younger age categories. It was also noted that less than one in ten riders are 18 or younger, compared to almost one in four for the county as a whole. This survey analysis also included several other tables allowed the characteristics of youth ridership to be understood in significant detail.

\subsection{Summary I Discussion}

There are over 28 million teenagers in the United States, of which over 1.4 million reside in Florida. In terms of aggregate person trips, this age group relies heavily on the automobile, with transit accounting for only around 1 to 3 percent of total trips. Data limitations make it difficult to isolate teenage transit ridership, but it can be observed that passengers aged 18 and under make up 9 to 21 percent of total U.S. transit ridership (depending on urban area size), and it is hypothesized that a large proportion of these are teenage riders. Considering that people under 18 years old make up over one quarter of the total U.S. population, it can be concluded that youth riders are an underrepresented transit user group. On-board survey data suggests that transit ridership in Florida is comparable to the national average, with some locations experiencing higher than average youth ridership due to local circumstances (i.e. college town). A major problem in assessing teenage ridership is the fact that the teenage age group tends not to be isolated from other age groups in data collection efforts. This makes it difficult to track teenage ridership and obtain a quantitative understanding of teenage mobility issues. 


\section{Focus Groups}

\subsection{Introduction}

Task 3 of the project scope involved conducting a series of focus groups in different locations around Florida in order to obtain an in-depth qualitative understanding of the views of Florida teenagers towards public transportation. It was recognized that parental influence may be a significant factor on teen perceptions and travel behavior, and the study methodology therefore required that parent - teen pairs be recruited to participate in the study, allowing parallel focus groups to be conducted with the teenagers and their parents.

\subsection{Methodology}

In each city, a total of four focus groups were conducted:

- One group with teenagers aged 13-15 (pre solo-driving age)

- One group with the parents/guardians of these 13-15 year old teenagers

- One group of teenagers aged 16-19 (driving age)

- One group with the parents/guardians of these teenagers

In each teenager group, additional quotas were defined:

- Approximately equal numbers of regular teen transit users and teens that rarely use transit

- Approximately equal numbers of males and females

- There are no specific criteria for the parent/guardian groups, although an equal balance of males and females was encouraged

Miami was identified at the outset of the project as one of the study locations, due to the fact that this city has the most extensive public transportation network in the state. Focus groups at this location were therefore conducted first. In organizing the Miami focus groups, several problems were encountered:

- In order to be allowed to conduct research in Miami-Dade County schools, one must first obtain authorization from the Miami Dade County Public Schools Research Review Committee. This involved submitting a research prospectus on the research study for review, and obtaining Security Clearance from the District Office. This process was found to be labor intensive and time consuming.

- Having obtained authorization, identifying a school with an appropriate range of children of different ages, socio-economic backgrounds, and from different geographic locations, that was also willing to participate on a volunteer basis, was challenging. However, after considerable searching, a suitable and willing school was identified.

- The final challenge was in recruiting parent-student pairs to participate in the study. The main difficulty here arose from the fact that providing financial incentives to encourage 
participation was not possible, despite the fact that this is standard procedure in the market research industry. The only incentives that could be offered were a free meal, and the opportunity for the students to count their participation towards their school Community Service requirements.

The original project scope intended to assess teenage attitudes and perceptions across the nation, by conducting a series of focus groups in different locations around the country. However, having completed the Miami focus groups, it became clear that there was neither the time nor the financial resources to adequately complete a nationwide qualitative study. It was therefore decided to limit the focus group section the study to locations in Florida only. One further series of focus groups were therefore conducted in Tampa, where local contacts could be used to directly recruit focus group participants. Although this section of the study focused on Florida only, it was still possible to access nationwide perspectives from information collected through other project tasks.

\subsection{Focus Group Characteristics}

A total of 32 people participated in the focus groups, 15 parents and 17 children. The reason for the difference in parent and child numbers is that in three cases, the parent brought more than one child to the session, while in one case both the parents of one child came to the session. The age range of participating youths is shown in Table 4.1 below.

TABLE 4.1 - Age Distribution of Teen Focus Group Participants

\begin{tabular}{cc}
\hline Age & Number \\
\hline 10 & $(1)^{*}$ \\
11 & - \\
12 & 2 \\
13 & 1 \\
14 & 6 \\
15 & 3 \\
16 & 2 \\
17 & 2 \\
18 & 1 \\
19 & - \\
\hline TOTAL & 17 \\
\hline
\end{tabular}

Table 4.1 shows that three children under the age of 13 were brought to the sessions by parents who also brought older siblings. A judgment call had to be made on whether they should be allowed to participate. It was decided to allow the two twelve year olds to be full participants as they were less than twelve months away from being a teenager. It was decided to also let the ten year old participate, but her comments were removed from the data set prior to the analysis stage. Overall, the table shows that a reasonable distribution of ages was obtained, with at least one representative of each age level from 13 up to 18. 
Although only two locations were considered in the study, these did result in a total of 8 focus group sessions, yielding a large amount of qualitative data. This, added to the fact that the two locations were considerably different in terms of transit service availability, provided a good opportunity to consider the range of mobility issues facing teenagers living in Florida's urban areas. However, it should be noted that the decision to focus on teenagers residing in urban areas means that rural teenage mobility issues are not within the scope of this study.

The composition of the groups in Tampa and Miami was different. Although the sampling process aimed to obtain a roughly even mix of transit users and non-users, in Miami most of the teen participants used public transport, mainly for their trips to and from school but also for nonschool-related travel. In Tampa, the majority of participants did not use public transport, although some did use the school bus. Thus, a relatively even distribution of transit users and non-users was achieved at the aggregate sample level, but was not achieved at each individual location. These differences were reflected in the contrasting views obtained from the two locations, which are discussed further below.

\subsection{Identification and Discussion of Major Themes}

The focus groups sessions were recorded on audio digital recording equipment and subsequently transcribed into a textual record. This textual data were then used to conduct descriptive and explanatory analysis. Preliminary thematic analysis identified several issues influencing teenagers' perceptions of different modes of transportation. These core themes were (i) safety, (ii) cost, (iii) access / availability, (iv) reliability and (v) image. Each of these five major themes is discussed in the following sections.

\subsubsection{Safety}

Safety while traveling was a major issue for both parents and teenagers, and had a major impact on teenage travel behavior. In broad terms, it seems that the urban environment is not regarded as very safe, particularly after dark. This lack of perceived safety in public space seemed to make many teenage participants unwilling to use transit, and many parents unwilling to let them. In some cases transit use was permitted by parents under certain caveats, such as only to and from certain areas or only up until a certain time. There seemed to be a consensus, both among parents and teenagers, that using transit after dark was too dangerous, and not permitted under any circumstances. The main source of concern was being kidnapped and / or raped while walking to and from the bus stop, or while waiting at a bus stop, and there was a perception among focus group participants that such crimes were common in Miami. Another source of concern was being hit by a car while walking beside the road, or waiting at the bus stop. Although seen as being less risky, the part of the trip spent in a transit vehicle was also a safety concern, due to the potential for crime and / or intimidation from other passengers.

"The only thing [is that] on public transport there are a lot of people you have to meet, street people, crazy people, dirty. They ride the public transportation, they allow them on the bus. You don't know what they will do. They had people kidnapping kids. Both types of transportation you 
worry sometimes-they hold the school buses sometimes for ransom. It happens in Miami. The other day they took the driver off the school bus, only the driver.” - Female (1), Parent, Miami

"But there is more supervision on the school buses than on the public transportation. I am more relaxed when my son is on the school bus than on public transportation"

- Female (2), Parent, Miami

"My parents are okay with it [transit]. It is a lot easier for me and them, they let me take it, they are busy [and] neither of us are going to have to stop our plans. It depends..... live in Aventura and if I am at South Beach.....it depends on what time and where I am. They are not okay with me taking the bus after 7pm"

- Male, 14, Miami

"Most of the places buses go are bad areas."

- Male, 16, Tampa

“Areas where people can't afford their own cars, areas they go through aren't nice areas.”

- Female, 17, Tampa

"My mom agrees with public transportation for me to get from point A to B but she's afraid because of so many things that have happened. Last month two people got snatched from a bus stop and raped and dropped back at the bus stop. Crazy things are going on. Cars run off the road hit people standing at the bus stop. Drunk drivers are not paying attention to the road. I don't think they do it on purpose, but a lot of bus stops are on the corner, close to traffic. Anything can happen, night or day. People snatching people's kids as far as walking to the bus stop, you can get kidnapped, raped. She is very paranoid and I am sure other parents are too."

- Female (1), 15, Miami

"My mother gets worried but not as much as my father, he will drive me from my house to the bus stop and wait until the bus comes. He trusts me but not anybody else. You can't depend on anybody - that person will only tell you what they want to you to know. They do whatever they want to. There are a lot of risks you are taking by using public transportation."

- Female (2), 15, Miami

Several different participants, both teenagers and parents, mentioned the fact that riding transit in other places (like New York) was much safer because they had a dedicated transit police force. They thought that providing a greater transit security or transit police presence in Florida would address this problem. The current level of security provision was considered to be inadequate:

"They should provide a security force, they have been saying people are getting kidnapped then they should have a security guard at the station to keep people safe while they travel."

- Male, 16, Miami

"They have transit police in New York. That always makes me feel safe. They need transit police there [Miami MetroRail] all the time."

- Male, Parent, Miami 
"Since 9/11 they have police that patrol the train. But on weekdays only, on weekends I don't see them. It's for the kids protection. I asked the police about weekends and they said 'no', they don't cover weekends. They should have transit police there all the time - if I miss my train then I am there alone, standing at the train station for 15 minutes, and I'm like 'oh my God'."

- Female (1), Parent, Miami

"They do have security guards but they don't do anything. A couple months ago there was a fight by the train station and there were two security guards and they watched it and didn't do anything about it, but they were aware of it because they planned another fight and next time they had more security guards for better protection but when it actually happened the security guards did nothing.”

- Female (2), 15, Miami

"I think they [security guards] are scared of certain type of people, as they look intimidating. When that incident happened there were other people doing the same thing and they came over to the innocent looking kids and left the thugs alone. Maybe the security guards need better training."

- Female (1), 15, Miami

"With Security - adding more would get rid of a situation that my parents are fearing: kidnap, rape, and so on. That would be taken care of."

- Male 16, Miami

Safety was also a major issue in relation to car use. Both teenagers and parents were aware of the risks associated with teenage drivers, particularly those that had only just passed their test. Several participants stated that they knew of teenagers who had died in car accidents, and this had made a significant impression on them. For this reason, some teenagers had made the choice not to drive, although they were old enough to do so. The following two quotes illustrate this, and are of interest also because they were provided by the father and daughter of a parent-child pair, thus providing insight into how parental views may have been adopted by the child.

"Miami has selfish, rude, reckless drivers - you may have noticed? It is not the best place for young drivers, not like a small town or city, people aren't very polite on the road here. My daughters haven't developed their survival instincts yet for the road.” - Male, Parent, Miami

"I'm scared to drive...because the drivers are crazy..."

- Female, 18, Miami

The teenagers that did drive were aware that they, and their peers, were inexperienced and at more risk of having an accident. They were aware that their parents worried about them when they were driving, but stated that this concern tended to diminish as their experience increased. Some parents made the decision that this risk was too great, and would not permit their children to drive or ride with other teenage drivers. Other parents allowed this along with certain caveats, such as (i) only to certain areas, (ii) only if a curfew is maintained, (iii) only if other teenage drivers are known to the parents, or (iv) only if the teenage driver is over a certain age.

"My Mom is concerned about how good a driver I am, since I'm not as experienced as older drivers, so that is always a concern. But I haven't had an accident, and I feel comfortable 
driving. I guess parents are always nervous about their kids driving. When I first got my license, I had to call my Mom when I got to my destination. She would even call while I was driving....she was very protective. But now that I am more experienced she isn't as nervous, she feels more comfortable with me driving myself"

- Female, 17, Tampa

"My parents feel the exact same way. The more experience I get, the more time I spend on the road, you gain awareness, you know what to look for, the less they check up on me and the less they are worried."

- Male, 16, Miami

"Particularly it is my father who has a problem with it, he has to know that person, and he has to know they have their driver's license for at least 2 years because he doesn't want his little daughter going with someone he doesn't know or trust. I don't have my license but I drive sometimes and he doesn't have a problem with that as he is always in the car with me, him or my mother, it is fine. He is trying to give me practice, he knows when I go by myself he won't freak out."

- Female, 18, Miami

"I have other friends who take me places, I won't get in a car with someone who just got their license yesterday or two weeks ago. I am particular about who I drive with and if I don't know someone I won't get in a car. My parents are particular about who I get in the car with if they are not over 18. If they don't know them it isn't going to happen."

- Female, 15, Miami

"I wouldn't go with my friends if they just started driving, sometimes they do stupid things so I don't really trust them. About me driving? I don't know. I haven't talked to my parents about it."

- Male, 14, Tampa

"My father is extremely against me getting in a car with a teenager who just got their license, and so is my mother. He will find another alternative to not get me into the car with them. My father especially because there are a lot of aggressive drivers on the road, that is what he is most concerned with not about me following the rules but other people crashing into me, if I need to make an evasive move he wants me to know how to do it."

- Male, 16, Miami

Unsurprisingly, safety had a significant influence on mode choice decisions. The parents not permitting their children to drive themselves, or travel with other teenage drivers, were faced with either allowing their children to use transit, or having to transport them themselves. Conversely, parents who would not let their children use transit were forced to either provide them with their own car, allow them to ride with their peers, or, again, transport them themselves. Both groups of parents were thus faced with either allowing their children to travel on a mode that they were not entirely comfortable with, or having to take on this responsibility themselves. The outcome of this decision depended, at least partly, on how willing and/or able parents were to take responsibility for their child's transportation. Some parents seemed reconciled to this role and did not seem to think there was any alternative. Similarly, on the teenage side, there were differences in awareness of this parental conundrum. While some teenagers were perfectly willing to "freeload off their parents", other teenagers were aware that they were hindering their parents and wanted to find their own forms of transportation. Interestingly, the teenagers most likely to "freeload" were the offspring of the parents reconciled to the role of transportation service. An example of these contrasting views is shown below. 
"My parents usually insist on taking me. That's their main mode of transporting me to any place. I would like to take transit in my sophomore or senior year, save money too, but for now I just choose to freeload off my parents”

- Male, 16, Miami

"I am [a] captive [transit rider]. I have to when my Mom is at work. I don't want to bother anyone so I walk the five blocks to the bus stop in the morning"

- Female, 15, Miami

The following dialogue from the group of 13-15 year old teenagers from Miami touches on the interaction of safety and parental transportation reliance, as well as the wider issue of teenage independence.

"Your friends want you to hang out. Your not going to bother your parents...'oh, take me here' because, first of all, and a lot of parents do this.....they say 'oh, I'm tired, why don't you just read a book?' It's like you're bothering them. Instead, just get up take the bus, get there, just make sure you get out before night just to be on the safe side and you can take the bus back home. I feel that bothering your parents is annoying to both us and them."

"Parents are scared sometimes, they don't want to let you go 'coz they think once you walk out that door that your not coming back."

"I think they need to realize that we are growing up and we do need to experience some type of independence. Since they don't want to take us there, they might us well let us go by public transportation. They should just let us go, it would be a lot easier."

"Sometimes my parents are too lazy to pick me up but they won't let me ride the bus after 9 or 10 as they are afraid something is going to happen to me."

Parents were also aware of the need to accept that their children had to be exposed to some risk as they got older.

"We have a daughter. She is 19, studying in Paris and uses the subway everyday. We feel she is safer there than here. Is it safe? She takes a car, with other teenagers, is that safe? You have to, kind of, let go. Your perception is that it is safer. We feel more comfortable knowing she is there."

- Female, Parent, Miami

The issue of safety also appeared to have an influence on observed differences in treatment of teenagers of different gender. It appeared that some parents were more likely to allow male offspring to use transit, stay out longer, and travel alone (this theme was also noted in the review of existing research literature, see Section 2.3). The following dialogue illustrates such perceptions of gender differences in parental treatment. 
Dialogue on Perceived Gender Differences (Miami, Teens aged 13-15):

"I don't think it matters, they snatch boys/girls, they don't care what you are. If they want something they are going to go after it."

- Female (1), 15, Miami

"I think the parents think that it matters. All the girls, their father will wait for them till the school bus comes. My parents stay sleeping and I go." - Male, 14, Miami

"I think it really does matter between a boy and a girl. If I ask my parents to go to the Falls by the metro bus, they say 'no'. But my brother is 13, I'm 15, and he doesn't even like taking the Metrorail 'coz he's kinda scared. But they would rather him go on rather than me and I really think it is because I am a girl. I asked my mother once and she said 'yes [its true]'”.

- Female (2), 15, Miami

One closing point to note on the issue of safety is the positive impact of affordable cellular telephones. Many teenagers have their own "cell-phone”, allowing them not only to keep in touch with their peers, but also providing their parents with the ability to check on their whereabouts. It was clear from these focus group sessions that parents felt more comfortable knowing that they could call their children at any time, and knowing that their children could call for help if in a dangerous situation. However, some parents warned against the false sense of security that cell-phones provided, stating that many teenagers are adept at lying about where they are. These parents were not aware that some cellular telephone companies offer a locator service that could be used to track untrustworthy offspring.

\subsubsection{Cost}

Car travel was recognized by both teenagers and their parents as being expensive, with the cost of insurance and gas frequently mentioned. All the teenage drivers in Tampa had to pay for their own gas, while one also had to pay for his own insurance.

"I feel like I am throwing away my money when I get my tank filled up. It is too expensive, but there's not much I can do about it"

- Female, 17, Tampa

The cost of parking was also a significant issue on car trips to certain locations, such as downtown Miami and South Beach.

"Parking meters especially. If they have parent meetings you are going to have to pay a lot, the parking lot only fits 15 cars for a school of 400. You have to park on the street and come out and fill the meter every couple of hours. Costs you a lot of money, plus gas.” - Female, 15, Miami

Parents comments related mainly to the cost of insurance and some were not prepared to grant their children the use of the family car for this reason.

"She doesn't mind, she likes it [using transit]. I am happy with it for economic reasons - it would cost me a fortune to insure her."

- Male, Parent, Miami 
Views on the cost of transit were much more favorable. In Miami, the students received a free transit pass, due to their attending a Magnet school with a much larger catchment area than regular schools. This provided a significant incentive to use transit for both school trips and other trips. The following comment also notes that without the pass, transit would be a lot more expensive.

"It is easy, cheap, we get the metro passes each month unless you lose your pass then you are stuck. There used to be student discounts this year they are enforcing that everyone has to pay $\$ 1.25$ to get in. If you buy the pass it is $\$ 30$ it is a lot cheaper. If you have to pay your way its expensive, but we have that privilege, so it's a lot cheaper."

- Female(1), 15, Miami

In some cases, this contrast between the cost of car and transit travel had an impact on mode choice decisions that favored transit.

"Sometimes I have to [take transit], but sometimes I choose to, because it saves gas. Therefore you have more money."

- Female(2), 15, Miami

"My parents drive everywhere, but if there is a carnival and you have to pay a lot for parking then we will take the bus, otherwise they will drive. Downtown they charge $\$ 20$ or $\$ 40$ per day, if you work downtown and are a lawyer then that is what you have to pay."- Female(2), 15, Miami

"We have other things to worry about, as far as expense; prom, graduation, etc.... why waste money on a car when you have public transportation or your parents to drive you around?"

- Female(1), 15, Miami

\subsubsection{Availability / Convenience}

Mode availability is quite a complex issue for teenagers. Initial consideration of which mode to use for a particular trip is determined by whether that mode is available for use, and whether or not its use is prohibited. Age determines whether a teenager can legally drive. On one end of the scale are teenagers over the legal driving age that have access to their own car. These individuals subsequently have a high level of mobility, and may only be constrained by certain time or location restrictions imposed by parents or state law. Low-density development patterns are common in Florida's large urban areas, making walking or cycling to activities very difficult. Thus, if teenagers are too young to drive, or do not have their own car, their options are to depend on others - getting a ride either from their parents, other adults, or their peers - or to consider using public transit. As previously mentioned, safety concerns mean that many parents do not allow their children to travel in cars with other young drivers, while different safety concerns mean that other parents do not allow their children to travel on public transit. Therefore, although a mode of transportation is potentially available for a certain trip, its use may be prohibited, either by parental restriction or state law.

If use of a certain mode is not prohibited, the next potential obstacle is availability. For teenagers dependent on their parents, this depends on whether a parent is able and/or willing to transport them. As previously mentioned in the safety section, willingness and ability seem to vary from parent to parent, and may also vary in relation to the perceived importance of the activity, and 
the proximity of the activity's location. For teenagers permitted to use transit, availability depends on whether transit service is available to and from the place the teenager wishes to go, at the times they wish to go. Many teenage participants highlighted different limitations in transit's ability to fulfill their requirements, either through limited geographical coverage, or service span.

\section{Comments on Various Limitations in Bus Service Provision (Miami Focus Groups):}

"[I would like] buses that run more often. Buses that stop more places. I would like stops closer to my house and to be able to take the bus to and from school without having to transfer. And, I would like for it to run on weekends. The buses don't come often enough or close enough to my house. Sometimes the buses come two at a time and then you have to wait a really long time for another bus. I also think that they should have overnight service too - they only run a few at night and they're very general and they won't let you go close to your area. It's probably cheaper in the end to ride the bus versus driving a car, but [ for these reasons] I would rather ride in a car."

- Female, 18, Miami

"Most of the buses go to and from the Downtown areas. There aren't any buses you can take around here" - Male, 16, Tampa

"I can take the bus to the mall, but I can't get back. Buses stop running at 10pm. So either I can't go, or before I go I have to arrange for my Dad to pick me up."

- Male, 14, Miami

"Another problem, a big problem, is they don't have enough buses in this area. Not enough buses and not enough routes. Where I live, the bus only runs a few routes, and it doesn't come into my community. So you have to walk to a main road, takes twenty or thirty minutes. That's too long to walk to get a bus. The buses should come into the communities, but I guess they don't have enough buses to do that. Everybody has to walk and walk and walk just to get a bus."

- Female, Parent, Miami

Even if transit service was available, it was often regarded as too slow and indirect to be seen as a viable travel option. Most participants regarded the car as having a significant advantage on this issue.

"If I can get a ride, then I prefer to do that because the bus that I take stops at the causeway and it's not really near my house, and so I have to walk almost a mile after I get off the bus. I have friends who drive and they'll tell me to meet me here and then it takes a while because I have to ride the bus"

- Female, 18, Miami

All the teenage participants had experienced car travel, normally in the context of traveling with their parents. Driving experience was obviously limited to the older teenagers and several of the older teenagers from Tampa had their own car. All participants acknowledged the convenience associated with car travel. If a private car was available, it was viewed by most as the easiest way to move quickly from trip origin to trip destination. However, the car also had its access problems. One particular problem was finding a parking space. This was mentioned as a major problem in Miami, with parking in certain areas of the city either in limited supply or 
prohibitively expensive. Parking was not regarded as such a problem by the teenagers in Tampa, with complaints limited to certain locations such as college campuses and Ybor city.

"I'll use the bus more often when I am here [on campus]. My mom said they sell a lot more parking passes than they have parking spots for. I don't plan on being late for classes so I'll use the bus [Bull Runner].”

- Male, 16, Tampa

"I plan on going to UF and I know as a freshman you are not allowed a car on campus, so I will have to deal with that. Hopefully I will have older friends who can take me places, or use public transportation."

- Female, 17, Tampa

"My parents drive everywhere if there is a carnival if you have to pay a lot for parking then she will take the bus, otherwise they will drive. Downtown they charge $\$ 20$ or $\$ 40$ per day, if you work downtown and are a lawyer then that is what you have to pay.” - Female, 15, Miami

The following dialogue extracted from the focus group session with younger teenagers in Tampa illustrates the level of consensus on the travel time and convenience advantages of the car.

Dialogue: Tampa, Teenagers Aged 13-15:

"Car is better - you don't have to stop before you get to where you want to go. If you are the last person it would be $1 \frac{1}{2}$ hours before you get off your bus."

"Public Transportation takes a lot longer ... instead of going straight from point A to point B it takes longer on the bus. Takes more time."

"Same thing. You might have to hurry to some place, like to a meeting. Buses take a lot longer and they have to stop to let people off."

"If you need to get somewhere immediately or unexpectedly it is better to have your own car as you would need to figure out how to get there and buy a ticket ... you would have to figure out your routes."

"I don't think I would use the bus unless I had to. I think using your own car is better; you know where you need to go, on the bus you have to go on their route. Can't go direct."

\subsubsection{Reliability}

Reliability was a significant transportation issue for teenagers. Public transit, and buses in particular, were regarded by many participants as being unreliable. One major reason cited for unreliability in Miami was the fact that buses get delayed in traffic congestion:

"Sometimes the schedules are lying because the buses don't run on time. The sign says the bus with come at 4:45 but comes later - 5.15, 5.30, 6pm - and you can't depend on it. Traffic, they fall behind. The schedule doesn't help. I think that is why I don't use the schedule as the buses are always twenty minutes late.”

- Male, 14, Miami 
"I see that more up north [North Miami], the most the buses would be late is a couple of minutes but here it will come 15 or 20 minutes later."

- Female, 15, Miami

Another reliability problem mentioned in Miami was bus breakdowns and traffic collisions involving buses. According to the teenagers in the focus groups, these apparently occurred quite frequently and resulted in significant travel time increases (see dialogue on next page).

\section{Parents of 13-15 year old teenagers, Miami}

"That's the big drawback to buses ... the breakdowns. I won't use them."

“That's true. they breakdown often. And they're not that old. I don't know why they break down so much, but they do. They break down all the time. It's bad."

"And not only that, there have been accidents. A LOT of accidents."

"After an accident, the bus driver has to stop, call the police, file a report, and wait. You can sit and wait as well, or you can get off and wait for another bus."

"You never used to have all these bus accidents. Never. Now it's like, every second. What is going on?”

Further discussions suggested that the high incidence of accidents were at least partly due to inexperienced bus drivers who drove aggressively and were not as well trained as they should be.

"I've heard that due to political pressures they [bus drivers] aren't trained as well, they used to get six weeks training now it is cut back to four. I think some of the newer drivers play little games, you know, they may not pick up passengers at bus stops, or if they are running late they may go to a certain point on the route instead of the starting point. But its harder to play games now because they have GPS tracking systems."

- Male, Parent, Miami

Some examples were cited of how transit is much more reliable when separated from regular traffic, such as exclusive bus lanes. This also appears to be a major reason that rail services, and other grade separated public transit modes, are regarded as much more reliable. When bus lanes were provided, they were perceived as offering travel time savings over the car, as shown below:

".....taking the bus from Dadeland South to Cutler Ridge is so much shorter than when my mother drives me because of the traffic and depending on the time of the day. I travel in the evenings. It is a shorter trip than another time of the day so I would rather take the bus and get here quicker."

- Female (2), 15, Miami

"I don't think I'd use a bus, but I would maybe use a metro or subway. Buses seem dirtier and just more of a hassle" - Male, 14, Tampa

"If I was going to use a public transit system, I would want to use something that was on its own track, like a trolley or cable car, like at Channelside. Because nothing's holding it up - no car traffic. If you want to make it easier for someone to get from one place to the next, you have to take it off of the place where its very congested. I don't think that you could go underground, like 
a subway, because we're already at ground zero in Florida. They should build something that's still on the road, but on its own track, or above ground like a monorail.” - Female, 14, Tampa

"Subway is best, it's much faster that above ground because you don't hit traffic jams and stuff."

- Female, 14, Tampa

Similar views were expressed in the parent groups:

Miami Parents' Dialogue on the Benefits of Dedicated Transitways...

"The buses are part of the traffic. They drive just like we do. In Paris they have extra lanes for the buses, the cars are not allowed into the bus traffic. It makes it more reliable".

"She was saying about Paris ... further south, they do have those lanes, like the Falls area. For the first time my son took a small transit bus that takes that new street down there, going south [South Miami-Dade Busway]. He made it home in the same amount of time as if I had picked him up, which was fast. If he comes home on the regular school bus then he will be an hour later. If I pick him up on the metro rail, then he comes home an hour earlier, but he used transit that uses those special lanes."

"For that matter, you need to have a subway system like Paris, put it underground so you don't have the problems that you have with the buses. You take the subways..... it is more reliable."

"I never take the bus. The train is much better. It's stop-to-stop, no hassles. Buses get stuck in traffic, breakdowns, accidents, it's all problems." [Buses are] not reliable at all. I prefer the metro."

"The metro is faster, I agree."

Traffic congestion also affected the reliability of car travel, particularly in Miami. In Tampa, congestion problems were mentioned, but were generally limited to specific areas or times of day. In both places it appeared that traffic congestion was, for the most part, predictable, and you could therefore either plan your route to avoid congested areas, travel at times of the day when congestion was limited, or simply leave more time for your trip. Thus, reliability was one area where the car was far superior to public transit.

\subsubsection{Image}

Perceptions of public transportation were mixed. The majority of participants had a very negative image of bus transit, characterized as unreliable, unsafe, dirty and limited in service coverage, frequency and span. However, in Miami, some teenagers were regular bus users and appreciated the freedom of mobility that this service provided. Views on rail-based forms of public transit were much more positive, particularly the subway, which some teenage participants had experienced in other cities. It appears that rail-based public transit does not suffer from the "poor captive rider" stereotype often associated with bus users. The following dialogue between two older, car driving teens from Tampa illustrates the negative stereotype associated with buses, and how this is not reflected in perceptions of rail transit. 
Dialogue of 16-19 year old Tampa teenagers on the negative image of public bus transit:

"I'd take rail before I'd take the bus" - Male, 16, Tampa

"I agree. I don't know if it's fair or not, but rail has the right connotation compared to riding the bus. I am biased against riding the bus. Honestly."

- Female, 17, Tampa

"Most of the places buses go are bad areas."

- Male, 16, Tampa

"Its not that its 'uncool' to ride public transportation, but...I don't know....honestly, the bus is associated with...the ghetto. I feel bad but....."

- Female, 17, Tampa

"I feel the same way. Most of the places that do buses are heavily populated areas"

- Male, 16, Tampa

“Areas where people can't afford their own cars, areas they go through aren't nice areas."

- Female, 17, Tampa

"Buses are for people who can't afford to have a car and pay for insurance and gas and stuff and that is more the people the bus picks up. I don't fall into that class.” - Male, 16, Tampa

"Not that they are bad people, but ... I just feel awkward on a bus.” ～- Female, 17, Tampa

"You don't have a sophisticated public transport ridership, not like San Francisco or New York, a lot of people are taking the buses are poor, they take it out of necessity. When immigrants move here, they use public transport, they get a job become a little wealthier, first thing they do is buy a car."

- Male, Parent, Miami

One younger teen in Miami reported that her friends were impressed with her understanding of the bus system and this actually enhanced her image:

"My friends think its 'cool' that I take it because I know where I'm going - when they miss their school bus they call me on my cell phone and ask me how to get to school because there parents don't want to take them."

- Female (2), 15, Miami

However, it is apparent that, for the majority of teenagers, public transit is not perceived as a "cool" form of transportation, and definitely not a mode of choice. Teenagers are very image conscious and associate independent car travel with freedom and independence. It appears that the classic American "rite of passage" associated with getting your first car is very much alive. Bus transit is at a distinct disadvantage in this respect. 


\subsection{Summary I Discussion}

Low-density development patterns in Florida impose significant restrictions on teenage mobility. Long distances to activities mean that walking and cycling, modes that are more available to teenagers in other parts of the world, are often not realistic travel options. Teenage mobility is a very complex issue, which varies from individual to individual depending on age and personal circumstances. Teenagers with the highest level of mobility are those with their own car. However, many teenagers are not old enough to drive, not permitted to drive by their parents, or not in a financial position to afford to run their own car. These teenagers are either dependent on others for their transportation needs, or have to consider using transit. Use of transit is also subject to parental permission, and restricted to areas where transit service is available (in terms of both geographical coverage and service span) and direct enough to be a viable travel option.

Parental concerns over their child's safety appear to be the primary reason that permission to use either the private automobile or public transit is restricted. Some parents prefer that their children drive themselves, while others prefer that they use transit. In both cases, parental restrictions are often placed on when, where, and with whom these modes can be used. The core problem for transit was a perceived lack of safety in the general urban environment. There appeared to be a consensus, both among parents and teenagers, that using transit after dark was too dangerous, and not permitted under any circumstances. Female teenagers appear to be more likely to have their mobility restricted by parental safety concerns. Providing a transit security/police presence, as experienced in other cities, was seen as a way to address this problem.

Travel cost is also a significant issue in relation to teenage use of the private automobile. It is clear that most teenagers cannot afford the capital and operating costs of a car, which are commonly even greater than those imposed on older drivers due to higher insurance rates. Thus, although many car driving teenagers are responsible for their own operating costs (gas and sometimes insurance), they have to rely on assistance from their parents to obtain a vehicle in the first place. Thus, travel cost is an area where transit has a significant advantage over the car, and it appears that some teenagers with car access actually choose to use transit in order to save money for other things. The presence of discount fare programs increases this sense of the relative affordability of transit.

Availability and convenience of public transit versus the private automobile in relation to teenagers is a complex issue. If a private automobile is available for personal use, it offers the highest level of mobility. However, the above discussion has highlighted several reasons why many teenagers do not have access to their own vehicle. Even if a vehicle is available for personal use, access restrictions imposed by limited or expensive parking mean that driving is not a desirable option for trips to certain destinations. Other limitations include the fact that state law requires that 16 year old drivers must be off the roads by $11 \mathrm{pm}$, and 17 year old drivers must be home by $1 \mathrm{am}$. There is also the issue of driving under the influence (not mentioned in these focus groups) which restricts the young person's ability to drive after a night out. Transit use, in comparison, is restricted by the geographical coverage, span and frequency of service. Transit services in both Tampa and Miami were criticized on all these issues. Transit is also at a disadvantage due to being perceived as considerably slower than the private automobile. 
Reliability was also an area where the private automobile was regarded as having a significant advantage over transit. Buses were regarded as notoriously unreliable due to traffic congestion related delays, frequent breakdowns, and accidents. This lead to the feeling that buses could not be relied upon for time constrained trips. Reliability was also a major reason why rail based transit was generally preferred over bus transit - the grade separation associated with rail service carried the perception that these did not get delayed in traffic, and were more likely to run on time. This also lead many participants to highlight their positive experiences with Bus Rapid Transit style services, such as the South Miami-Dade Busway, where buses ran in their own dedicated busways, or on reserved bus lanes in the highway. These were seen to offer not only much more reliable service, but also travel times that were competitive with the automobile.

Finally, the perceived image associated with the different modes appears to play a significant role in teenage mode choice decisions. Although some regular teenage transit users in Miami did not appear to have any image concerns related to their transit use, many of the teenage participants believed that there was a negative social image attached to public transit use. Buses were associated with low-income, captive riders, providing mobility to people in "bad areas". Rail based transit did not suffer from this negative stereotype. With such a negative image, it seemed unthinkable for some teenagers to use bus transit, even if it was available. In contrast, the car was seen as providing the freedom and independence that is important to teenagers. It seems that public bus transit, at least in Florida, suffers from a serious image problem.

One stated aim of the focus group stage was to assess the extent to which teenage views towards transit varied across different socio-economic and demographic factors, such as age, gender, ethnicity, income level and residential location. As previously discussed, age and gender did appear to influence both underlying perceptions and actual transit use. Age has a major impact due both to the fact that teenagers under the age of 16 are not legally permitted to drive, and even once 16, certain curfew restrictions apply until the age of 18 . There was also a more indirect impact in that younger teenagers tended to rely more heavily on their parents for their transportation needs, and the level of parental control generally appeared to decrease with age. Thus, transit use tended to be greatest among the teenagers who were old enough to be allowed to travel independently, but that did not have car access. On the issue of gender, it appeared that male teenagers were given more freedom at a younger age than female teenagers, due to greater parental safety concerns for female offspring. Residential location also appeared to have a major influence on transit use, with the teenagers in Miami much more likely to use transit than those in Tampa, where transit service was often non-existent in their local areas. However, this exercise was limited to only two locations, and therefore it is not possible to make any firm conclusions on the influence of residential location. Any impacts related to the other independent variables were less obvious. Transit use by teenagers in Miami did not appear to vary by income level, although income level did appear to be a factor among the Tampa participants. Similarly, transit use did not appear to be directly correlated with ethnicity. However, it should be noted that these findings were obtained in the context of a qualitative study with a small sample size, and therefore cannot be used to make any inferences about bivariate relationships in Florida's population as a whole. 


\subsection{Resulting Opportunities for Promoting Transit}

Analysis of these eight focus group sessions has been extremely useful in understanding the strengths and weaknesses of transit in the minds of Florida teenagers. It has also offered insight into the ways in which parental views affect teenage travel behavior, both directly and indirectly. It seems logical to promote transit by highlighting its strengths, while also exposing the weaknesses of automobile travel. It also seems logical to target marketing campaign messages to both the teenagers and their parents in order to maximize success. Table 4.2 summarizes the different mobility issues that were observed, and how these may be used to develop marketing messages.

TABLE 4.2 - Identification of Potential Marketing Messages

\begin{tabular}{llll}
\hline \multicolumn{1}{c}{$\begin{array}{c}\text { Underlying } \\
\text { Issue }\end{array}$} & \multicolumn{1}{c}{ Teenager } & \multicolumn{1}{c}{ Parent } & \multicolumn{1}{c}{$\begin{array}{c}\text { Potential } \\
\text { Marketing Message }\end{array}$} \\
\hline $\begin{array}{l}\text { Independent } \\
\text { mobility }\end{array}$ & $\begin{array}{l}\text { Dependent on parents for } \\
\text { transportation }\end{array}$ & $\begin{array}{l}\text { Transporting children is } \\
\text { time-consuming }\end{array}$ & $\begin{array}{l}\text { Teenagers: Independence afforded by transit } \\
\text { Parents: }\end{array}$ \\
\hline Safety & $\begin{array}{l}\text { Concerned about the } \\
\text { Desponsibility of driving } \\
\text { child's transportation }\end{array}$ & $\begin{array}{l}\text { Concerned about child driving } \\
\text { unsupervised or traveling with } \\
\text { other teenage drivers }\end{array}$ & $\begin{array}{l}\text { Parent / } \\
\text { Teenager: }\end{array}$ \\
\hline Cost & Highlight the safety benefits of using transit \\
\hline
\end{tabular}

The first row in Table 4.2 makes reference to the fact that many teenagers were very aware of their dependency on their parents for transportation, and how this restricted the natural teenage desire for independence. Similarly, it was noted that many parents are not always willing and/or able to provide transportation for their children. Thus, a marketing campaign message connecting transit use with freedom from parental control, whilst also pointing out to parents how much more time they could have if their kids used transit, may be useful. Another opportunity exists due to parental concerns over the safety. Many parents are extremely concerned about their children driving a car, or being in a car with another teenage driver, and may respond favorably to a marketing message highlighting the relative safety afforded by having their children use transit. Another weakness associated with teenage car use is cost. A marketing message could therefore highlight how much money the parent could save by not having to provide a car for their teenage driver, or by highlighting to the teenager how much money could be saved to spend on other, more important things, such as clothes, music, or social events. With cost being such a crucial issue, it also seems logical to combine such a campaign with a teenage fare discount program, or limited free pass, to further encourage experimenting with transit use.

Obviously, a marketing campaign is only going to be effective in the long run if it is promoting a quality product. Safe transit service to and from locations that teenagers want to go - the mall, movie theaters, beaches, etc, must be available. Service span must also be considered due to the fact that many teenagers' social activities occur at night-time or on weekends. The negative image associated with buses is also a significant problem that is difficult to address. The results from this series of focus groups suggest that the provision of Bus Rapid Transit style services may be able to harness the positive image of rail-based modes while retaining cost efficiency. 


\section{Transit Agency Survey}

\subsection{Introduction}

A telephone survey of transit agencies across the country was conducted to gain an impression of industry practice on the topic of transit provision for teenagers and marketing efforts targeting this age group.

\subsection{Methodology}

The survey instrument was designed to ensure that different topics of interest were covered in the interview. However, the instrument was not designed in a rigid "question-answer" format, and was instead designed to permit a flexible interview that allowed other important issues that arose to be discussed. The primary issues of interest were (i) whether the agency has a marketing strategy targeted specifically at teenagers, (ii) types of marketing strategy or program, (iii) obstacles / lessons learned in marketing to teenagers, and (iv) whether the agency collects information on teenage ridership. The survey instrument is provided in the Appendix.

The sampling frame used for the survey was the American Public Transportation Association (APTA) membership directory, which provides the contact details of all member agencies across North America. Given that surveying all 344 agencies listed in the database was unrealistic, the database was stratified into small, medium and large agency categories. A random sample from each category was then contacted. A total of 124 agencies were contacted, from which a total of 36 survey responses were obtained, resulting in a response rate of 29.0 percent. Responding agencies had to either have some form of teen marketing program in place, or have had a program at some point in the past. The 29 percent response rate should not be used to infer that only 29 percent of transit agencies have teen marketing programs, as this was not a scientific random sample.

\subsection{Transit Agencies with Experience of Programs Targeted at Teenage Riders}

Table 5.1 on the next page presents the name and location of each of the 36 agencies that stated that they have, or had, a program targeting specifically at teenage riders. It can be seen that seven of the agencies were from Florida, including the agencies serving Miami and Tampa, the two focus group locations. The table shows that thirty-two agencies had at least one active program designed to increase youth mobility, while four agencies stated that they did not have current programs, but had had programs in the past. In each of these four cases, the teenage programs had been cancelled due to budget cuts. Explanatory responses were provided in three of these cases:

- "We had to cut back on all programs due to rising fuel costs." - MATA, Memphis, TN

- "We had a hard time marketing to our intended population. We also had a lot of downsizing and budget cuts that made things like this (marketing to teens) difficult to do." 
- "The (teen ridership) promotion went away because we weren't able to provide discounted fares for teens and youth. Our city already has a low income fare."

This feedback suggests that teenager marketing programs are susceptible to cancellation due to reallocation of program funding. This is consistent with marketing in general, which is vulnerable to funding cuts if resources are required elsewhere in the agency. The results also suggest that teenage marketing efforts are not uncommon in Florida.

TABLE 5.1-Agencies with Existing or Past Programs Targeting Teenagers

\begin{tabular}{|c|c|c|}
\hline Agency & Location & $\begin{array}{c}\text { Program } \\
\text { Status }\end{array}$ \\
\hline JTA (Jacksonville Transit Authority) & Jacksonville, FL & Current \\
\hline Lynx-CFRTA (Central Florida Regional Transportation Authority) & Orlando, FL & Current \\
\hline MDT (Miami Dade Transit) & Miami, FL & Current \\
\hline PalmTran (Palm Beach County Transportation Department) & W. Palm Beach, FL & Current \\
\hline SCAT (Space Coast Area Transit) & Brevard County, FL & Current \\
\hline HARTLINE (Hillsborough Area Regional Transit Authority) & Tampa, FL & Past \\
\hline TalTran (Tallahassee Transit) & Tallahassee, Fl & Current \\
\hline ABQ Ride (City of Albuquerque Transit) & Albuquerque, NM & Current \\
\hline Annapolis Transit & Annapolis, MD & Current \\
\hline Blacksburg Transit Agency & Blacksburg, TN & Current \\
\hline CATA (Central Arkansas Transit Authority) & Little Rock, AR & Current \\
\hline CATA (Center Area Transportation Authority) & State College, PA & Current \\
\hline DART (Dallas Area Rapid Transit) & Dallas, TX & Current \\
\hline DART First State (Delaware Area Regional Transit) & Wilmington, DE & Current \\
\hline DATA (Durham Area Transit Authority) & Durham, NC & Current \\
\hline Fairfax Connector & Fairfax, VA & Current \\
\hline Hampton Roads Transit & Hampton, VA & Current \\
\hline Harris County Transit & Houston, TX & Current \\
\hline Huntsville Transit & Huntsville, AL & Current \\
\hline Intercity Transit & Olympia, WA & Current \\
\hline KCATA (Kansas City Area Transportation Authority) & Kansas City, MO & Current \\
\hline King County Metro Transit & Seattle, WA & Current \\
\hline MARTA (Metropolitan Atlanta Rapid Transit Authority) & Atlanta, GA & Current \\
\hline MBTA (Massachusetts Bay Transportation Authority) & Boston, MA & Current \\
\hline MetroLink (Rock Island County Metropolitan Mass Transit District) & Rock Island, IL & Current \\
\hline RPTA (Regional Public Transportation Authority) & Mesa, AZ & Current \\
\hline Spokane Transit & Spokane, WA & Current \\
\hline Sun Metro & El Paso, TX & Current \\
\hline TriMet (Tri-County Metropolitan Transportation) & Portland, OR & Current \\
\hline Utah Transit Authority & SLC, UT & Current \\
\hline Valley Metro Transit & Phoenix, AZ & Current \\
\hline Yuba-Sutter Transit & Yuba City, CA & Current \\
\hline Wiregrass Transit Authority & Dothan, AL & Current \\
\hline MATA (Memphis Area Transit Authority) & Memphis, TN & Past \\
\hline MATS (Montgomery Area Transit System) & Montgomery, AL & Past \\
\hline SunTran & Tucson, AZ & Past \\
\hline
\end{tabular}




\subsection{Types of Program}

\subsubsection{Overview}

Responding agencies were then asked to describe the programs they provided. Table 5.2 summarizes the responses to this question.

\section{TABLE 5.2-Types of Program}

\begin{tabular}{lc}
\hline \multicolumn{1}{c}{ Response } & Frequency \\
\hline Transit passes & 9 \\
Reduced fares & 7 \\
Education & 2 \\
Bus passes and reduced fares combined & 7 \\
Bus passes and education combined & 2 \\
Reduced fares and education combined & 0 \\
Bus passes, reduced fares, and education combined & 3 \\
\hline TOTAL Agencies responding to this question: & 30 \\
\hline
\end{tabular}

Table 5.2 shows that three main types of program were in use; (i) transit passes, (ii) reduced fares, and (iii) education. Figure 5.1 below illustrates the overlap of these three program types in a Venn Diagram.

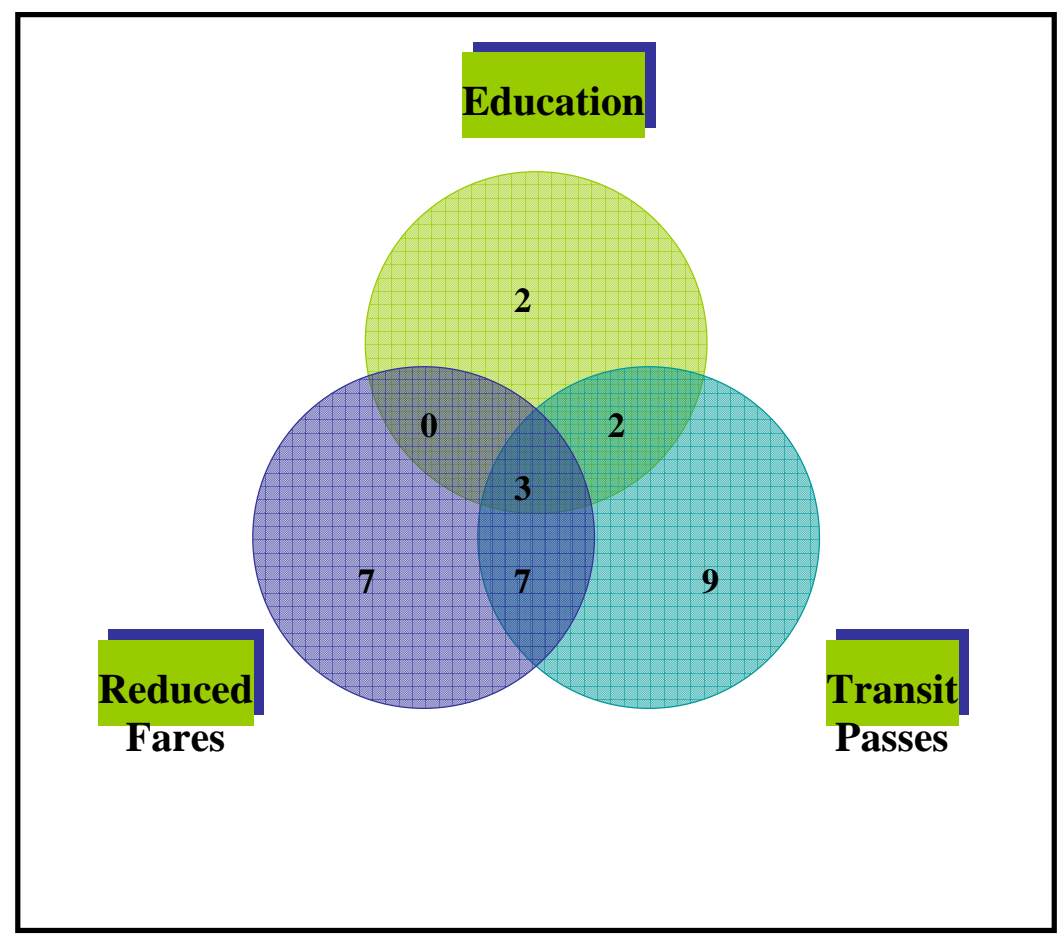

FIGURE 5.1-Venn Diagram - Program Overlap

Overall, the above diagrams show that the most common program types among responding agencies were passes and reduced fares, with a total of 21 agencies providing passes to teen riders and 17 agencies providing reduced fares. The third program type - based on teen 
education - was less common, employed by only seven agencies. In most cases this program type was combined with one or both of the other two program types.

\subsubsection{Transit passes}

A majority of agencies indicated that they use weekly and/or monthly bus passes to sustain existing ridership and encourage new ridership. These economic incentives were aimed at all teen groups, from middle school to the first years of college. Additional comments from agencies providing passes were as follows:

- "We have a $\$ 49$ pass for youth aged 12-17 for use June 1- August 31, 2005. That's one-third the usual cost. High school students must present a high school identification card to qualify for the pass. Middle school students without school identification must present a statement signed by a parent to verify age and middle school attendance. The goal of the pass is to

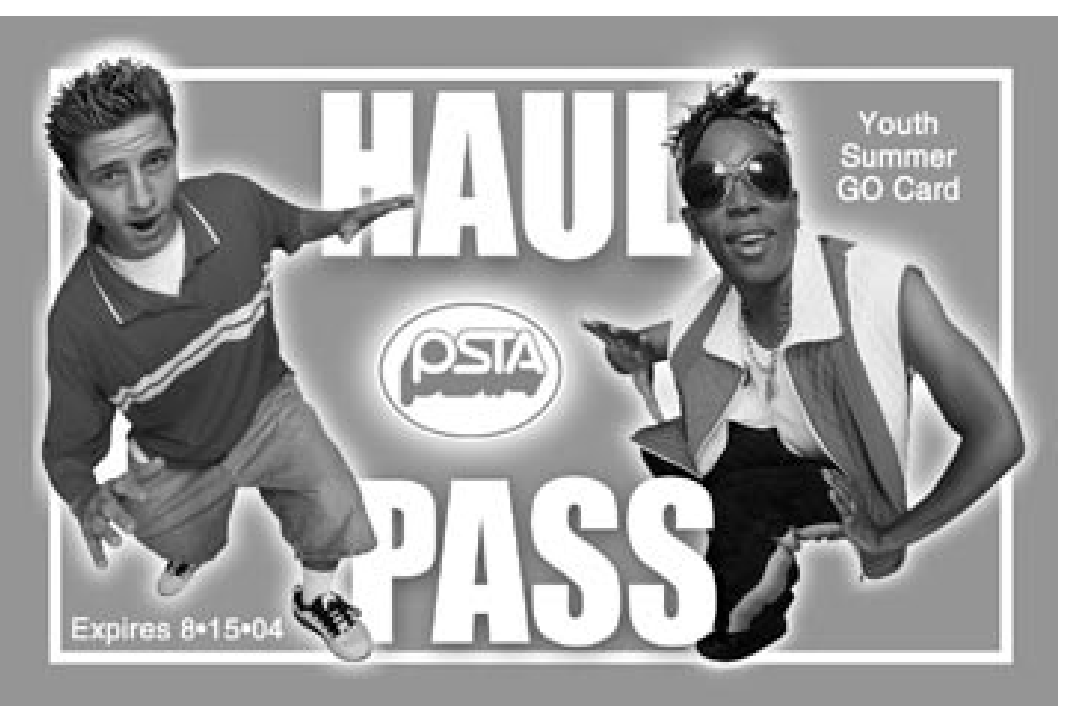
enhance opportunities for students by providing them with inexpensive travel to access employment, recreational facilities, area libraries, and retail facilities, while, at the same time, exposing the area's youth to transportation alternatives. We also sell semester passes to college students for \$195/semester for unlimited usage.” ～- CATA, State College, PA

- "We offer a reduced monthly pass for youth for \$20. We are very interested in getting more into marketing to this group. We are offering a summer youth pass called the Circuit City Pass. For \$30, youth all over the city can use the bus all summer. We also have a U-Pass system where people at local universities can use the bus for free just by showing their University ID."

- Intercity Transit, Olympia, WA

- "We offer low priced summer passes for \$25. We do programs for teens and we make up cups, bottles, key chains and put the mascot for the school on it from transit and we've even done radio ads on the pass. They can go on the bus all summer and we have a fun-for-kids' page on the website. It also links to other websites that have to do with transit. There are a lot of teens who use our bus service and Saturday nights it's packed with teenagers ${ }^{1}$. I don't need to promote that more, because they know about us and use us."

- Annapolis Transit, Annapolis, MD

\footnotetext{
${ }^{1}$ This statement contradicts the comments provided by focus group participants, who stated that transit was not safe to use after dark. It appears that, in this location at least, teenagers, and their parents, regard transit as safe to use at night
} 
- "We have a pass program for school children, which provides a \$10 a week pass that they can purchase through their school. We also have a U-Pass program that allows all local university students to purchase a semester pass for \$40 as well.” - MARTA, Atlanta, GA

These and other comments suggested that passes ranged in scope from weekly to monthly, plus seasonal and semester passes. In most cases the passes cost a fixed amount, but a small number of agencies provided the passes for free. Providing special passes for the summer months, when children are not at school, seems to be particularly popular. It can also be seen from the above comments that passes can be used either to encourage ridership where there is already a high level of awareness of local transit service, or to introduce teenagers to transit, allowing them to experience different transportation alternatives.

\subsubsection{Reduced fares}

Seven agencies offered per-trip reduced fares only, which were typically half-price. Reduced fares were viewed as the most basic program type, and several agencies were almost apologetic that this was all they did. Again, the major goal of providing reduced fares was to sustain existing teenage ridership and encourage new ridership by offering economic incentives. The reduced fares offered the advantage of providing cheap transit service to teenagers without requiring them to obtain the lump-sum required to buy passes.

\subsubsection{Education}

Two agencies offered only rider education programs. These school-based programs were aimed at advocating the benefits of public transit to youth in middle schools. Such programs presumably cost less to implement than offering reduced fares, although no empirical evidence was given to indicate how effective these programs were at encouraging ridership. Examples of different educational program types include:

- Visiting the schools to educate children on the availability of transit services and how to use it. "We have 'Teens in Motion' and 'Kids in Motion', hands-on transit education programs designed to teach teens and kids about transportation and its effects on our environment and our health. Prepared presentations are suitable for science, math, language arts, social studies, and health classes. In addition, 'Teens in Motion' and 'Kids in Motion' provides students the opportunity to win prizes in several contests.” - ABQ Ride, Albuquerque, NM

- Organizing group visits to transit facilities to learn about the different aspects of transit service provision and experience riding the bus

One transit agency, King County Metro Transit in Seattle, Washington, has been selected as an example of educational program best practice. The program is discussed in more detail below. 


\section{King County Metro Transit - Seattle, WA - The “Move It!” Campaign}

Partners for Smart Commuting, a coalition of local, regional, and state government agencies in Oregon, Washington, Idaho, Montana and Nevada - has been active in the effort to reduce single occupancy vehicle trips for several years. The Move It! Program is aimed at educating middle school youth to consider their personal mobility, with the long term goal of creating attitudinal and behavior change regarding transportation options in middle school youth prior to driving age. The campaign is the result of an Oil Rebate Grant and matching funds from public agencies associated with the coalition. The total budget for the program was $\$ 18,300$ (Lindsey, K. et al, 2003).

The program began with the establishment of the Youth Transportation Action Council (YTAC), consisting of enrolling 14 teenagers from three different middle schools and three different high schools in the cities of Issaquah and Sammamish, Washington. From January to May 2003, the YTAC group met with staff from Metro Transit, Issaquah Youth Center and the City of Issaquah Parks \& Recreation to discuss transportation in their communities and design a project to create awareness about transportation alternatives. Initial meetings focused on identifying the various transportation barriers facing teenagers. Table 5.3 below provides these results:

TABLE 5.3 - Barriers to Teenage Mobility Identified by the Youth Transportation Action Council in Washington State

\begin{tabular}{|c|c|c|c|c|c|c|c|}
\hline \multicolumn{8}{|c|}{ Barriers to Alternative Modes of Transportation } \\
\hline $\begin{array}{l}\text { Money Spent on } \\
\text { Transportation }\end{array}$ & $\begin{array}{l}\text { Alternative } \\
\text { Options } \\
\text { Unavailable }\end{array}$ & $\begin{array}{l}\text { Fear, Approval and } \\
\text { Public Safety }\end{array}$ & $\begin{array}{c}\text { Limited } \\
\text { Availibility of } \\
\text { Transportation }\end{array}$ & $\begin{array}{c}\text { Traffic } \\
\text { Wastes } \\
\text { Time }\end{array}$ & $\begin{array}{l}\text { Parking is } \\
\text { a Hassle }\end{array}$ & $\begin{array}{l}\text { Unwilling to } \\
\text { Travel } \\
\text { Physically }\end{array}$ & Distance \\
\hline high price on gas & no bike lanes & $\begin{array}{l}\text { safety of area you are } \\
\text { going to }\end{array}$ & $\begin{array}{c}\text { no adult available } \\
=\text { no driver }\end{array}$ & $\begin{array}{l}\text { rush hour } \\
\text { traffic }\end{array}$ & $\begin{array}{l}\text { access to } \\
\text { parking }\end{array}$ & $\begin{array}{l}\text { Too tired to } \\
\text { travel/move }\end{array}$ & $\begin{array}{l}\text { too much space } \\
\text { between you } \\
\text { and destination }\end{array}$ \\
\hline not enough gas & no bus service & $\begin{array}{c}\text { not a safe place } \\
\text { (destination) }\end{array}$ & \begin{tabular}{|c|} 
limited car \\
access \\
\end{tabular} & $\begin{array}{c}\begin{array}{c}\text { streets too } \\
\text { busy }\end{array} \\
\end{array}$ & no parking & $\begin{array}{l}\text { don't want to } \\
\text { walk/bike }\end{array}$ & too far away \\
\hline cost of gasoline & $\begin{array}{c}\text { no buses } \\
\text { available }\end{array}$ & paranoia (of parents) & & $\begin{array}{c}\text { takes too } \\
\text { much time to } \\
\text { get there }\end{array}$ & & & how far to travel \\
\hline \multirow[t]{4}{*}{$\begin{array}{c}\text { cost of travel (gas, } \\
\text { tickets) }\end{array}$} & $\begin{array}{c}\text { more carpool } \\
\text { lanes }\end{array}$ & parents permission & & $\begin{array}{c}\text { what time you } \\
\text { leave }\end{array}$ & & & $\begin{array}{c}\text { distance from } \\
\text { house to event }\end{array}$ \\
\hline & $\begin{array}{c}\text { no bus-only } \\
\text { lanes }\end{array}$ & $\begin{array}{l}\text { weather and time of } \\
\text { day }\end{array}$ & & \begin{tabular}{|c|} 
too much \\
traffic
\end{tabular} & & & \\
\hline & & & & $\begin{array}{c}\text { time } \\
\text { consuming }\end{array}$ & & & \\
\hline & & & & $\begin{array}{l}\text { time as in } \\
\text { traffic }\end{array}$ & & & \\
\hline & & & & & & & \\
\hline
\end{tabular}

*Source: Move It! Youth Pilot Project - Final Report. (2003).

Table 5.3 shows that the YTAC organized the different barriers into eight themes. It is interesting to note that the majority of barriers identified here were also identified in the Florida teenager focus groups conducted for this project, such as travel cost, transit service availability, parental permission, car / driver availability, traffic congestion, and travel distance. One issue not mentioned here is that of the negative image associated with transit. 
The stage of the process was to discuss the different solutions available for improving teenage mobility and developing different ways of disseminating this information to other teenagers. A booklet was designed that provided local travel information and explained the different options available. The booklet was supported by a website, posters, book covers, t-shirts, pencils, pens, clip magnets and carabineers, all featuring the Move It! branding (see Figure 5.2 below).

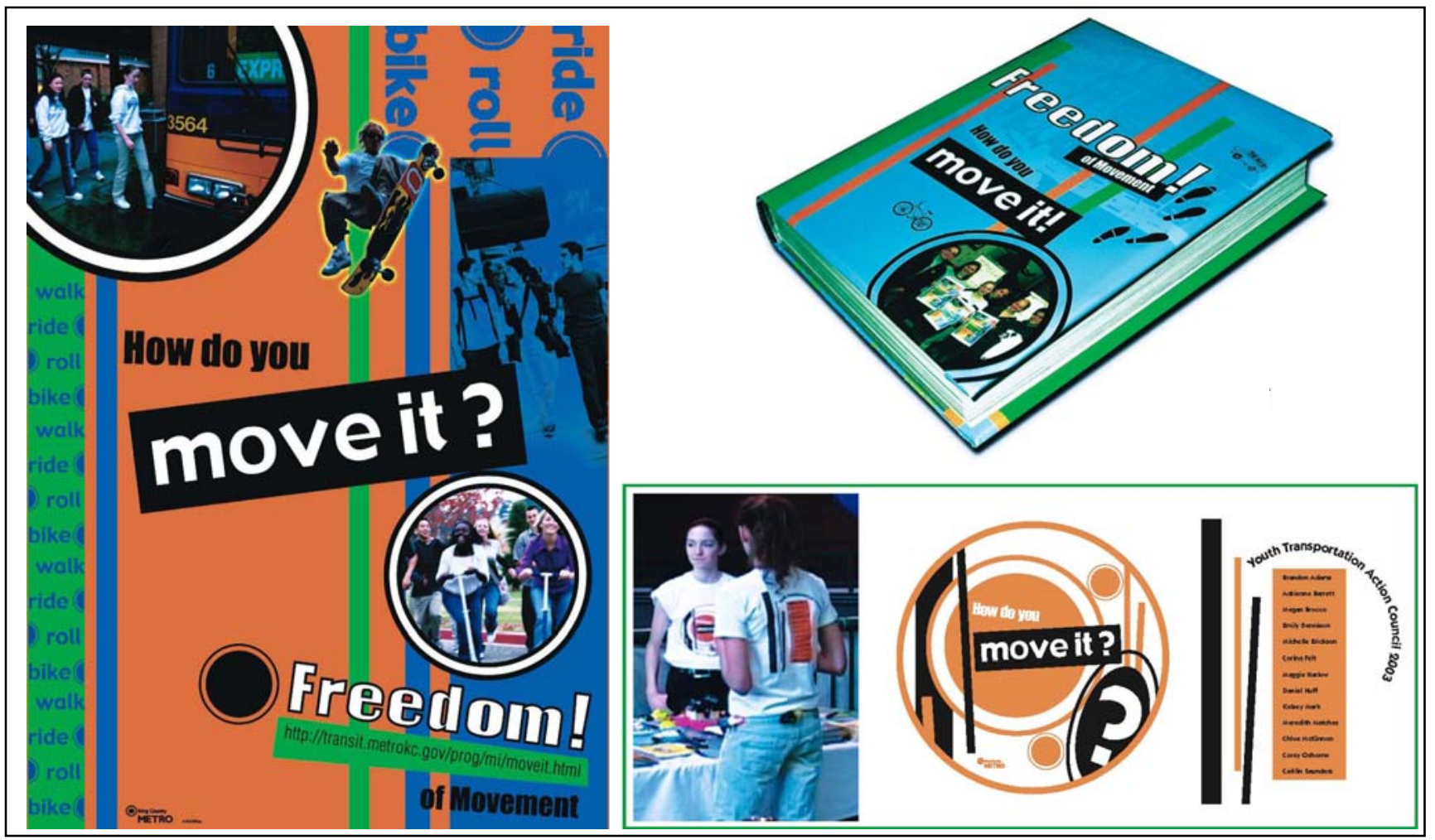

FIGURE 5.2 - Examples of Promotional Media Used in the Move It! Campaign

The initial idea was to conduct presentations at local school assemblies, but this was not possible as district school assembly agendas were determined a year in advance. Therefore, it was decided to host information tables at local events, interacting with table visitors and offering the incentives of free Move It! paraphernalia. A total of five information booth events were conducted, supported by press releases sent to community papers and notifications in other newsletters and local newspapers (Lindsey, K. et al, 2003).

The Move It! program was regarded as a great success; over 3,000 promotional items were distributed, 1,200 booklets were given out, and there were over 500 hits on the Move It! website. The program raised the local profile of the transit service, for both teenager and people of other age groups, and is considered to be a viable program format for other youth/community outreach efforts. (Lindsey, K. et al, 2003). 


\subsubsection{Program Type Combinations}

As shown in Figure 5.1, several agencies employed combinations of the three primary program types. This section discusses their experiences with this combination approach.

\section{Transit Passes and Reduced Fares}

Seven agencies offered a combination of bus passes and reduced fares. The goal is to combine both types of economic incentives in order to encourage ridership. One agency stated: "We have a Youth Reduced Farecard for students age 12 to 18 to get around town. The base fare with the Youth Reduced Farecard is only 50 cents on Metro buses and on The Bus in Kansas City, Kansas. We have a summer pass program where the kids can ride for $\$ 10$ per month!”

- CATA, Kansas City, MO

\section{Transit Passes and Education}

Two agencies offered education programs in conjunction with bus passes, combining economic incentives with advocacy. Comments on this combination included:

- "We have a transit education program for grades K-5 and we also have a secondary school pass and college pass for \$35 for the entire year and this gives teens and college students access to the whole DART system. We also have community outreach for teens and high schoolers. Southern Methodist University gets passes.” - DART, Dallas, TX

- "We have an amazing deal on our Transit Youth Pass. It's only \$13, half price, from the regular pass. This deal ends in June 2005, but then we have the summer youth pass that is good from June 1, 2005 until August 31, 2005 for only \$39.95. We also have the EWU Eagle Pass for all East Washington University students, staff, and faculty. Any EWU student is eligible to ride for free just by presenting their EWU ID. We try to promote these programs by talking (in schools) about the environment, congestion, quality of life, and economics."

- Spokane Transit, Spokane, WA

This combination approach seems to make sense. Offering a transit pass is only useful if the target audience is aware of available service and understands how to use it. The educational aspect of the program acts as a form of marketing for the transit pass.

\section{Transit Passes, Reduced Fares and Education}

Three agencies, PalmTran, DART First State, and TriMet, offered a combination of passes, reduced fares, and education to foster teen ridership. Comments on this approach were as follows:

- "We have an education program for youth K-12. They are allowed to come and ride scheduled buses or we can take the bus to them. We teach about transit and how to use transit and that every trip that they take doesn't have to be in a car. There is a reduced fare for the fixed route for youth, while children 46 inches in height or shorter get a free pass. Operation Lifesaver-we make presentations to groups that include introductory sessions, 
videotapes and Q\&A periods to promote rail safety at grade crossings. We haven't quite yet convinced the legislature that we need to have [free] busing for the older teens. We are also working on getting some programs in place that reminds parents to let teens know that they have other alternatives to driving."

- DART First State, Wilmington, DE

- "Current marketing campaign titled 'Go There, Do That', based around distributing folders to all middle and high schools in Palm Beach County. The folders were designed inhouse and feature a mailback response card that the teenagers can return to obtain a free day transit pass, worth \$2.00. Students aged 21 and under can obtain a discount on Palm Tran with a valid student card (regular fare is $\$ 1.25$, student fare is $\$ 0.60$ ). This campaign is now into its fourth year. The first three years were funded by a FDOT grant of $\$ 85,000$. This year we decided to continue to fund it through our own marketing budget. Previous teen marketing strategies included a radio campaign and a transit scavenger hunt."

- PalmTran, Palm Bch, FL

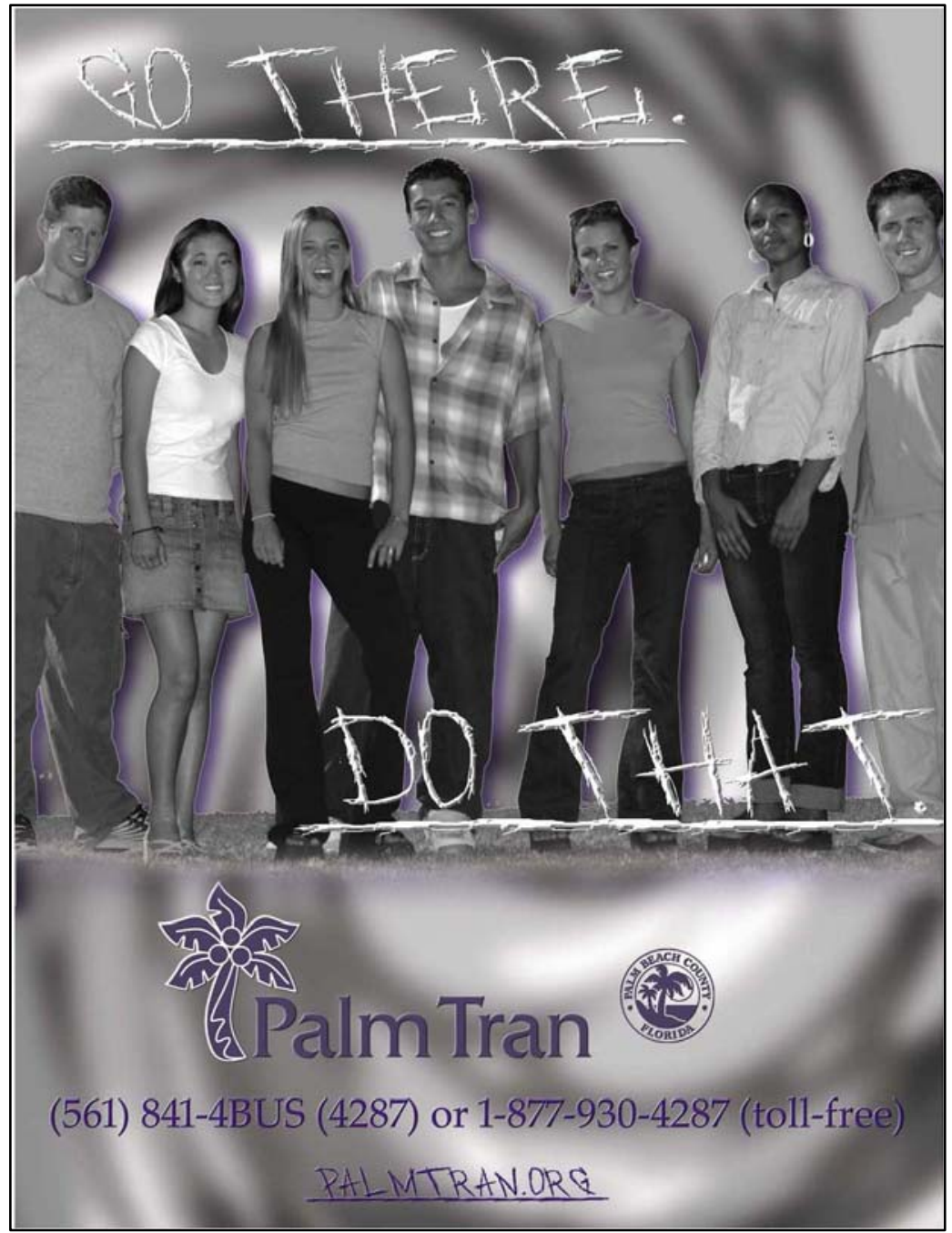

- "We have 'Tools for School', aimed at all youth, which can be accessed by their teachers in the school system in this area. This program aims for youth aged 7-17 and people who are seeking their GED. We sell a discounted monthly pass for $\$ 17$ at the local schools and supermarkets, as well as agency ticket counters. We also offer special field trips and programs which teach kids about using transit and these are offered at an inexpensive rate ... only $\$ 1$ per person for the round trip for all participants."

- TriMet, Portland, OR

Combining these three program types offers the potential for maximizing teenage ridership. Offering both types of economic incentive, passes and reduced fares, accommodates different types of teen rider - a regular rider will value the convenience and long-term savings offered by a transit pass, while an infrequent user or new user will appreciate the opportunity to pay for a 
smaller number of trips at a discounted price, perhaps then moving on to purchase a transit pass. One can also foresee the educational element benefiting the infrequent / new rider.

\subsection{Difficulties Associated with Marketing to Teenagers}

Responding agencies were then asked what obstacles they had experienced in marketing transit to teenagers. Responses were categorized into four key themes; image, schools, budget and parents. The frequency counts associated with each of these problems are shown in Table 5.4 below:

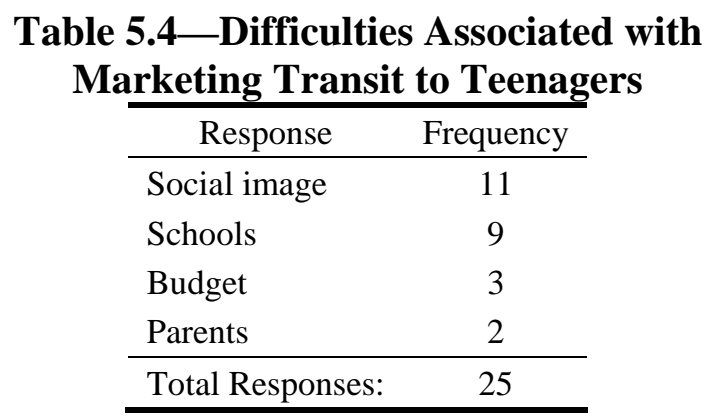

\subsubsection{Social image}

The most frequently cited marketing obstacle was social image, also described as the class implications of riding a bus. Further comments on this issue included:

- "People like to take their cars and view transit as a more low-class pursuit."

DART First State, Wilmington, DE

- "car ownership is a major issue for teens - the rite of passage to get a car when you turn 16" - Harris County Transit, Houston, TX

- "Public transit is not perceived as 'cool' among teenagers, so it's hard to market to that demographic [teens], its hard to make transit more appealing than cars."

- PalmTran, W. Palm Beach, FL

- "Everybody wants to drive their own car. Trying to appeal to teens and youth and let them know that they can get around on the bus [is a challenge.]” - ABQ Ride, Albuquerque, NM

These, and other comments, suggest that the image of the low-income, captive transit rider is as much of a negative stereotype among teenagers as it is among adults, and that there no easy solution to this pervasive issue. This finding correlates with views expressed by non-transit using teens in the focus group sessions (see Chapter 4). 


\subsubsection{Schools}

Difficulties in obtaining the cooperation of schools were also cited by nine agencies. Some examples quotes are provided below:

- "We have to go through the schools and sometimes they are helpful and sometimes they are not. They have a very aggressive school bus system and they really don't like the idea that we could be taking away business from them.” - DART First State, Wilmington, DE

- "The schools don't make it easy ... even though we're providing a big service for them. They [the schools] don't seem to see the benefits of this. The kids have to come in for photo IDs and we make attempts to go to summer school registration, but they don't make it easy, because I have to initiate and reinvent it all every year. But, through word of mouth, and the good thing about teens is that they talk a lot to each other, we have lots of people coming in to get the IDs at our agency.”

- Annapolis Transit, Annapolis, MD

- "It's a hard market to penetrate because you're supposed to reach them through the schools."

- Intercity Transit, Olympia, WA

It appears that schools are not very co-operative in some cases. This finding also correlates with the experience of the research team in attempting to recruit teenagers for the focus group sessions through the school system. It appears that many schools are simply too busy to devote time and resources to this non-curricular activity, although one agency mentioned an additional problem issue caused by the fact that public transit was perceived as being in competition with the school bus system for teenage passengers.

\subsubsection{Budget}

Budget restrictions were also a major issue. Feedback was limited, with most transit managers simply noting "budget and infrastructure issues" as obstacles, without elaboration. More detailed comments included:

- "When you offer a cheap (subsidized) program, you don't want to spend more money to promote a (teen) program. The county doesn't have a (school?) bus system and we are always stepping up to the plate ... by sending extra buses to the schools."

- Annapolis Transit, Annapolis, MD

- “In this county ... they don't value growing younger teen ridership. They want immediate regular riders. They are more interested in funding people who can switch modes and be regular riders. We had a woman who would go out for education at the schools and they totally cut her program."

- King County Metro Transit, Seattle, WA

These comments suggest that programs targeting teenage riders are vulnerable to discontinuation due to budget constraints, and this was also mentioned in Section 3.2 as the primary reason that 
programs are discontinued. It also appears that teenage riders are not as valued as adult riders. One way to address this problem is for Federal or state government to provide "start-up" funding to agencies considering teenage programs. PalmTran was able to build a successful teen marketing program through an \$85,000 grant from the Florida Department of Transportation.

\subsubsection{Parents}

Securing the cooperation of parents was also cited by two agencies. Details were mainly limited to "getting parents to cooperate" without elaboration. The two agencies listed specific challenges such as getting parents to purchase a transit pass, or producing the proper identification required to complete the purchase.

\subsection{Tracking Teenage Ridership}

Ten agencies indicated that they track teen ridership, meaning that the majority of surveyed agencies did not. Options for tracking ridership were either on-board surveys or farebox data (assessing transit pass or discounted fare use). On-board surveys obviously offer the potential to use the survey samples to infer the age stratification of total ridership, but also suffer from the problems of having to address the legal issues associated with surveying minors. For this reason, some agencies only surveyed people aged 18 and over. There were also problems associated with inferring teenage ridership through transit pass use. In several cases, agencies stated that the passes and discounts also applied to other riders, such as seniors, and that it was impossible to determine the proportion of total passes or discounted fares that could be attributed to teenagers. Some agencies only knew the proportion of their riders that were under 18, of which teenage riders are only a subset. Of those agencies that did track teenage ridership, ridership ranged from 10 to 20 percent of total ridership.

The issues discussed above, combined with the additional effort and resources required to track teenage ridership, appear to contribute to the low incidence of teenage ridership data collection. It is also interesting to note that the agencies that employed combinations of program types were also the agencies that tracked teenage ridership. This suggests that the existence of teenage transit programs and teenage ridership tracking are correlated. It is possible that the reason for this correlation is that such programs are more likely to be retained if there is evidence that teenage ridership has increased as a result. One example of this is PalmTran, which was given a three-year grant by FDOT to implement a teenage marketing program. After three years, analysis of pass usage showed that several thousand teenagers had responded to the "Go There - Do That" Campaign, and thus the agency decided to continue to fund the program out of its own operating budget. 


\subsection{Summary I Discussion}

Based on the responses to this survey, it appears that there are multiple approaches to promoting transit to teenagers. These approaches include discounted passes and reduced fares (economic incentives), as well as education. Most agencies use only one or two approaches, while three agencies, PalmTran, TriMet, and DART First State, employ the full range of approaches. TriMet and DART First State also actively track teenage ridership numbers, while PalmTran tracks the success of its program by counting youth pass use. These activities provide valuable benchmarking data, and evidence of program success. Most agencies in this survey do not track ridership, which poses a major problem; without tracking, the success of teen rider programs cannot be objectively assessed or evaluated for ongoing improvement, adding to the likelihood of the program being discontinued if funding becomes limited.

Despite a clear need for solutions to teen transit, there are obstacles to marketing these programs. The major issue is perception: what will my friends think? Many teens (like their parents) see buses as "dirty, bumpy and slow," as well as unsafe. In addition, many teens see driving or owning a car as a right of passage, the ultimate symbol of independence and prestige. This is a pervasive issue, with no easy or simple resolution. The reality is that socio-economic perceptions of this magnitude cannot be changed easily, if at all.

Another challenge is the bureaucratic inertia of the school system. Most agencies noted that schools are resistant to marketing efforts targeted on teens, even if that marketing is for a worthwhile public service. Another reason for reticence in the school system is that the school bus system also provides transportation service to teenagers, and public transit may be seen as competition (see Section 2.5 for more information). In addition, agencies cited budget cuts and lack of parental cooperation as major problems.

In sum, transit managers recognize that teens are an important market and constituency for transit. By offering reduced fares or transit passes, transit agencies increase the appeal of buses to teens who are looking for ways to save money; at the same time, education informs teens of the advantages of not having to rely on their parents to provide their transportation. Thus, economic incentives address the fact that teens have limited disposable income, while education informs teens that public transit maximizes their independence. By combining these elements with ridership tracking, agencies may maximize their ability to attract and retain teenage transit ridership. 


\section{Conclusions / Recommendations}

\subsection{Report Summary}

In the context of increasing auto dominance in Florida (and across much of the United States), the need to provide transit service that is appealing to teenagers is important for a variety of reasons. First, inherent mobility restrictions make teenagers a prime market segment for transit to target, as a means to boosting current ridership. Secondly, it is recognized that the values and habits formed during teenage years are often retained through to adult life. Exposing teenagers to transit during their teenage years makes it more likely that they will continue using transit as an adult. Thirdly, the teenagers of today are the voters of tomorrow, and transit use as a youth may increase the likelihood of support when asked to vote on a transit related issue, either as member of a constituency or as an elected official. Finally, the success of the transit industry depends on attracting talented young people who understand the importance of transit, and are subsequently willing to commit to a career in this field.

There are over 28 million teenagers in the United States, of which over 1.4 million reside in Florida. In terms of aggregate person trips, this age group relies heavily on the automobile, with transit accounting for only around 1 to 3 percent of total trips. Data limitations make it difficult to isolate teenage transit ridership, but it can be observed that passengers aged 18 and under make up 9 to 21 percent of total U.S. transit ridership (depending on urban area size), and it is hypothesized that a large proportion of these are teenage riders. Considering that people under 18 years old make up over one quarter of the total U.S. population, it can be concluded that youth riders are an underrepresented transit user group. On-board survey data suggests that transit ridership in Florida is comparable to the national average, with some locations experiencing higher than average youth ridership due to local circumstances (i.e. college town). A major problem in assessing teenage ridership is the fact that the teenage age group tends not to be isolated from other age groups in data collection efforts. This makes it difficult to track teenage ridership and obtain a quantitative understanding of teenage mobility issues.

This study featured a qualitative research element, designed to gain a deeper understanding of teenage mobility issues and the extent to which parental influence affects teenage travel behavior. Overall, it was found that there are a number of significant restrictions on teenage mobility. While some teenagers have access to their own vehicle, driving age regulations, cost implications and parental safety concerns all limit teenage vehicle access. Low-density urban development patterns often mean that walking and cycling, modes commonly used by teenagers in other parts of the world, are not feasible. Thus, teenagers without their own car are often either dependent on others for their mobility needs, or may consider using transit, if available. A series of mobility themes were identified that played a major role in determining teenagers' mode choice decisions - safety, cost, access/availability, reliability, and image. On many of these issues, the private vehicle was viewed as having a distinct advantage over transit, which was viewed by a number of study participants as inconvenient, unreliable and used primarily by captive riders. However, some areas were identified where transit had some strategic advantages over the automobile, either from a teenage or parental viewpoint. These were used to develop possible marketing messages (see Section 6.2 below). 
A survey of transit agencies across the country was conducted to assess industry experience with teenage transit users. Thirty-six agencies either had existing teenage ridership programs in place, or had programs in the past. These interviews suggested that there were three main program types used to promote transit to teenagers; educational, reduced fares and transit passes. Transit passes were the most common of these, followed by reduced fares. Some agencies employed a combination of these three program types. The transit agencies tended to view these programs as a success, but it was more difficult to assess whether they had any impact on ridership, due to the fact that the majority of interviewed agencies did not track teenage ridership. Major obstacles identified in marketing to teenagers included addressing transit's negative social image, gaining the co-operation of the school system, gaining the co-operation of the parents, and retaining the program budget. Transit agency's reported that the school system was often reluctant to get involved with promoting transit, either because they were too busy, or because they did not differentiate between social programs such as transit and private sector marketing consultants. Another issue was the sense of competition between the transit agency and school bus service providers, due to the fact that school bus providers are funded based on how many children they transport. With budget being such a major issue, it was no surprise that two of Florida's most successful programs, PalmTran's “Go There, Do That” and St Lucie County's “Teenage Transportation Planners” were both supported by state or Federal grants.

\subsection{Recommendations / Examples of Best Practice}

Given the above discussion, it is clear that teenagers have considerable potential as transit riders, and that some transit agencies have a good understanding of how this age group can be attracted to using transit. A series of recommendations, based on the findings of this study, have been developed to aid transit agencies interested in implementing programs that target teenage riders, or agencies seeking to improve existing programs.

\subsubsection{Track Teenage Ridership}

This study has found that most agencies do not isolate teenage riders from other minors in their data collection efforts, despite the fact that a 16 year old may have completely different mobility needs, and transit use opportunities, compared to a 7 year old. Indeed, some agencies do not even survey their riders aged under 18 years. If a transit agency is serious about targeting teenage riders, it must establish a data collection plan that provides accurate data on teenage ridership at regular time intervals. This report recommends that the youth age category used in on-board surveys (typically defined as "under 18" or "under 17") be divided into two or even three subcategories, for example:

- Under 12; 13 to 18/19, or

- Under 12; 13 to 15 (pre driving age); 16-18/19 (post driving age)

Another option for tracking teenage ridership is through farebox data, such as youth pass usage or discounted youth fares. The ability to isolate the youth fares from other discounted fares such as those provided for seniors or disabled travelers is the crucial issue here. Tracking ridership allows the performance of promotional programs to be assessed, and subsequently improved over time. Given the vulnerability of marketing programs to budget cuts, tracking ridership also provides evidence of program impact, which can be used to justify the retention of program funding if this is ever threatened. 


\subsubsection{Explore External Funding Options}

This study found that retaining a budget for teenage programs was often problematic. It was also found that several of the most successful programs were supported by state and Federal grants ${ }^{2}$. It appears that grant assistance is a major factor in long-term program success. Although the availability of such financial assistance has not been fully assessed in this study, it does appear that different external funding sources are available.

\subsubsection{Form Partnerships with the School System and Other Local Organizations}

Another element in the success of teenage ridership programs appears to be the ability of the transit agency to collaborate with other organizations. Accessing the population of teenagers in any local area commonly requires the co-operation of the school system. However, transit industry experience (and experience gained in conducting this study) shows that engaging teenagers through the school system is often difficult and time consuming. To address this, St Lucie County MPO collaborated with the St Lucie Board of County Commissioners and the local school board to ensure the participation of the local high school. This collaboration was formalized through a written contract between the school board and the St Lucie MPO. PalmTran appeared to be successful in gaining the support of the local school system without requiring a formal contract.

\subsubsection{Use a Strategic Approach to Developing Marketing Messages}

This study has found that transit is often at a disadvantage in comparison to the automobile from the point of view of teenagers and their parents. However, there are some areas (independent mobility, safety, and cost) where transit may hold a strategic advantage. Table 6.1 (reproduction of Table 4.2) below summarizes the different issues that were identified and suggests how these may be used to develop effective marketing messages.

\section{TABLE 6.1 - Identification of Potential Marketing Messages}

\begin{tabular}{llll}
\hline \multicolumn{1}{c}{$\begin{array}{c}\text { Underlying } \\
\text { Issue }\end{array}$} & \multicolumn{1}{c}{ Teenager } & \multicolumn{1}{c}{ Parent } & \multicolumn{1}{c}{$\begin{array}{c}\text { Potential } \\
\text { Marketing Message }\end{array}$} \\
\hline $\begin{array}{l}\text { Independent } \\
\text { mobility }\end{array}$ & $\begin{array}{l}\text { Dependent on parents for } \\
\text { transportation }\end{array}$ & $\begin{array}{l}\text { Transporting children is } \\
\text { time-consuming }\end{array}$ & $\begin{array}{l}\text { Teenagers: Independence afforded by transit } \\
\text { Parents: } \\
\text { Don't have to spend time providing } \\
\text { child's transportation }\end{array}$ \\
\hline Safety & $\begin{array}{l}\text { Concerned about the } \\
\text { responsibility of driving }\end{array}$ & $\begin{array}{l}\text { Concerned about child driving } \\
\text { unsupervised or traveling with } \\
\text { other teenage drivers }\end{array}$ & $\begin{array}{l}\text { Parent / } \\
\text { Teenager: }\end{array}$ \\
\hline Cost & Hightight the safety benefits of using transit \\
\hline
\end{tabular}

This study has found examples of agencies that have developed the sort of marketing messages proposed above. These examples are shown below.

\footnotetext{
${ }^{2}$ King County, Seattle, WA. “Move It!”. Oil Rebate Grant of $\$ 18,300$

PalmTran, West Palm Beach, FL. “Go There, Do That”. FDOT Grant of \$85,000.

St Lucie MPO, St Lucie County, FL. “Transportation Planning by Teenagers”. FHWA-TCSP Grant of \$117,000.
} 


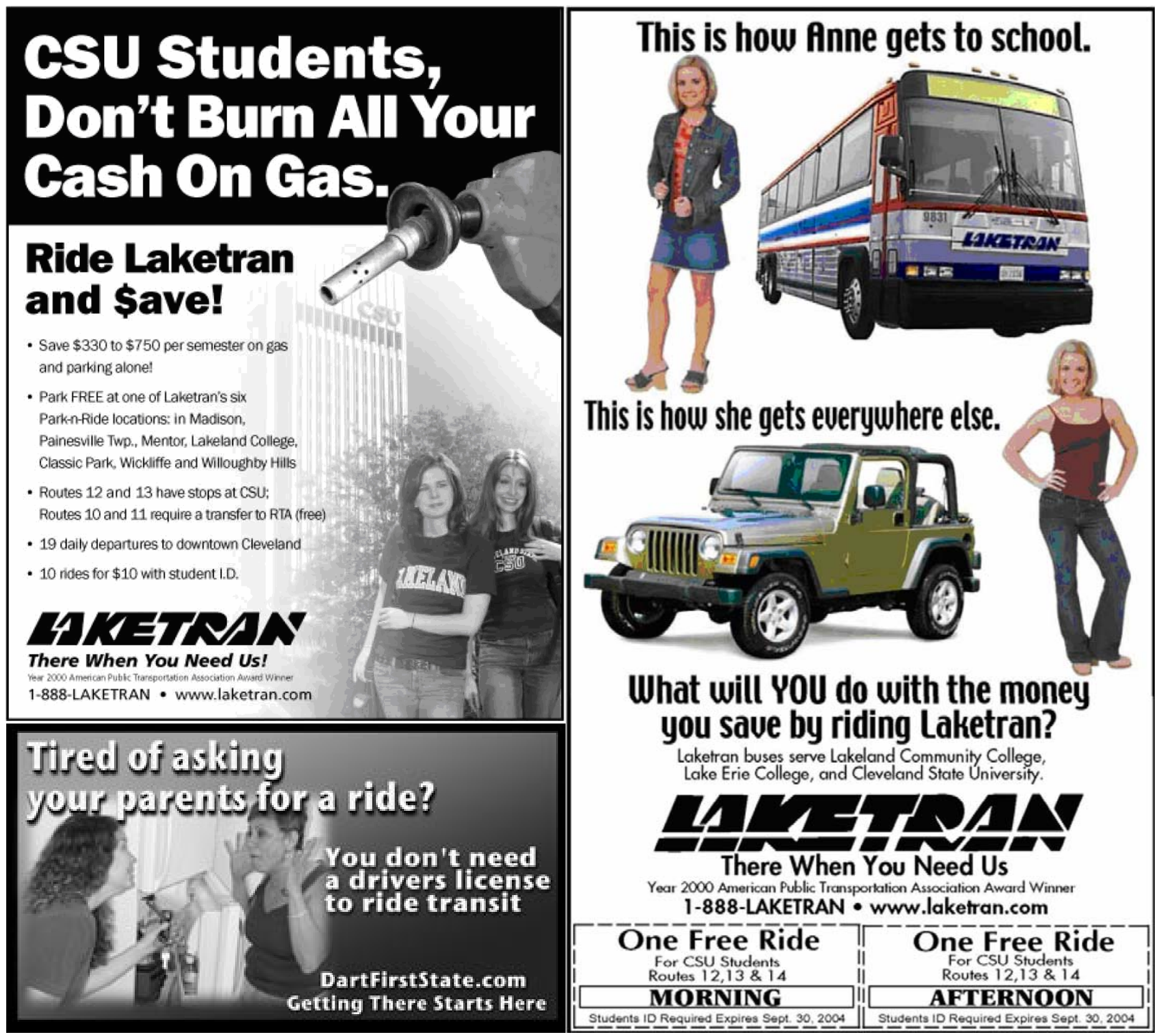

FIGURE 6.1 - Examples of Marketing Messages that Focus on Transit Strengths / Auto Weaknesses

The two advertisements provided by Laketran (Lake County, Ohio) show how the issue of the high cost of automobile use has been used to target choice riders by highlighting the relative affordability of transit. One advertisement points out how much could be saved per semester by riding the bus, while the other points out that transit may be an affordable option for getting to and from school. It is important to note that both advertisements also highlight the special youth fare programs that are on offer (10 rides for \$10 with student I.D / two free rides on Laketran). Other research has shown that marketing efforts are much more likely to succeed when combined with incentives such as transit passes or discounted fares. It is therefore recommended that, if financially feasible, marketing programs targeting teenagers should incorporate some form of incentive. 
The advertisement from DartFirstState, Wilmington, Delaware, focuses on the issue of independent mobility, pointing out that transit can provide independent mobility if a car is not available, and also noted the problem of parental reticence to providing their teenagers transportation needs. No examples could be found of advertisements that highlight the safety benefits of teenagers traveling by transit instead of by car. Perhaps there is some potential for a campaign targeted at parents, featuring a caption like "where would you prefer your child to be, sitting on a bus or behind the wheel of your car.....?"

It is also recommended that transit agencies conduct their own market research before embarking on a teenage ridership program. Even a small exercise, such as a couple of focus groups, can be useful in identifying local teenage mobility issues, which could inform both the design of the marketing campaign, and teenagers' desired transit service improvements. Several examples were discussed in this study where agencies went one step further than market research, and actually placed teenager participation at the center of the project (i.e. King County's Move It! program and St Lucie County's Teenager Transportation Planners). This appears to be a good way of accessing the world that teenagers' inhabit, and is also a recommended strategy.

\subsubsection{Consider Teenage Mobility Needs in Transit Service Provision}

This study's focus group exercise found that transit services often did not cater to teenage mobility needs, particularly the recreational activities often conducted at night or on weekends. Service span was frequently criticized for not running late enough to accommodate the return trip home. Although it is unrealistic to expect transit service provision to be tailored to one market segment, an audit of local teenage mobility needs may allow a local transit service to determine where and when teenagers want to travel. Subsequent minor alterations to transit service may go a long way to increasing ridership.

Concerns over safety while using transit was a major issue, regardless of age. Although the wider problem appears to be lack of perceived safety in the urban environment as a whole, there was a feeling among focus group participants that more could be done to address this issue. Participants' favored solution was to employ security guards or transit police. Although it is impossible to station a security guard at every bus stop, perhaps security personnel could be provided at key locations like transit transfer centers, possibly doubling as providers of information. On-board security, riding random routes over the course of the day, could also address this negative perception. 


\subsubsection{The Virtuous Circle}

Although all the above recommendations have been discussed individually, it is important to note that they are all inter-related:

- The availability of teenage ridership data provides evidence that is useful when applying for external program funding, and also provides evidence of campaign impact as it progresses, making project funding more likely to be retained (transit pass returns in West Palm Beach were used as evidence of the campaign's success, leading the agency to continue to fund the program after the external funding period ended).

- The availability of teenage ridership data allows the transit agency to understand teenage mobility needs and to cater service provision to these needs

- Project funding makes it more likely that the project will be taken seriously by external organizations such as the school system. St Lucie MPO noted that securing external funding gained the project legitimacy when soliciting the support of other local organizations.

- External project funding makes it unlikely that the project will be terminated, at least while this funding is available, because it cannot be rerouted to other agency departments.

This suggests that program success would be maximized by implementing a combination of the above recommendations. Added justification for this recommendation is provided by considering the fact that the transit agencies that have had the most success in promoting transit to teenagers have been those employing such a combination approach. 


\section{References}

Bonet, J. (2005). Teenager Transportation Planners - A New Form of Public Involvement. Presented at the 2005 Transplex Conference, Orlando, FL. June 2005. Supplemented by personal communication, July 2005.

Baltes, M. (1994). Assessment of Methodologies for Funding of Florida's Student Transportation. Final Report. Center for Urban Transportation Research, University of South Florida, Tampa, Florida.

Chain Reaction (2004). Project for Public Spaces. Retrieved September 3, 2004 from http://www.pps.org/tcb/chain_reaction.htm.

Clifton, K.J. (2003). Independent Mobility among Teenagers: An Exploration of Travel to AfterSchool Activities. Presented at the Transportation Research Board, $82^{\text {nd }}$ Annual Meeting, Washington, D.C.

Cvijanovich, N. Z., Cook, L. J., Mann, M. N., \& Dean, J. M. (2001). A population-based study of crashes involving 16- and 17-year-old drivers: the potential benefit of graduated driver licensing restrictions. Pediatrics, 107, 632 - 637.

Davis, L., Carter, A., Hong, J. and Kimber, E. (2002) 10 most improved transit agencies. Metro Magazine, 98(4), 28-26.

Goodwin, P., Bailey, J.M., Brisbourne, R.H., Clarke, M.I., Donnison, J.R., Render, T.E., Whiteley, G.K. (1983). Subsidized Public Transport and Demand for Travel. Gower, Aldershot.

Gurin, D.B. (1974). Travel Patterns of Suburban High School Males and Programs to Increase Their Mobility. In Transportation Research Record 508, TRB, National Research Council, Washington, D.C., pp1-12.

Hartos, J.L., Eitel, P., Haynie, D.L. \& Simons-Morton, B.G. (2000). Can I take the car? Relations among parenting practices and adolescent problem-driving practices. Journal of Adolescent Research, 15(3), 352-367.

Hillman, M., J. Adams., and J. Whitelegg. (1990). One False Move: A Study of Children's Independent Mobility. Policy Studies Institute, London

Lindsey, K., Ratner, D. \& Freeman, G. (2003). Move It! Youth Pilot Project - Final Report. King County Department of Transportation, Metro Transit Division, Sales and Marketing. 
McCaskey, D. (2002). DART First State Launches New Safe Teen Driving Campaign about Offering Teens and their Parents a Safer Choice by also Learning How to Ride Transit. Delaware's Bus, Train, \& Intermodal Transportation Provider. Retrieved on September 3, 2004 from http://www.dartfirststate.com/articles/teendriving.

O’Brien, C., and R. Gilbert. (2003). Kids on the Move in Halton and Peel. The Centre for Sustainable Transportation. Funded by the Ontario Trillium Foundation, Ontario Ministry of Culture.

Preusser, D. F., Williams, A. F., \& Lund, A. K. (1985). Parental role in teenage driving. Journal of Youth and Adolescence, 14(2), 73 - 84.

Project Action of Easter (1997). On our own: A project to introduce high school students with physical disabilities to public transportation \& ridership in New York City. Project Action Publication, 95-0006.

Stafford, J., Pettersson, G., Young, H., Mather, A. (1999). Young people and crime on public transport report. Department of the environment, transport and the regions.

St Lucie County MPO \& St Lucie County School District. (2002). Preserving our Community Surveying Solutions to Gridlock. Funded by a grant from the Federal Highways Administration and U.S. Department of Transportation

Tranter, P., and E. Pawson. (2001). Children's Access to Local Environments: A Case Study of Christchurch, New Zealand. Local Environment, Vol 6, No. 1, pp27-48.

Van Vliet, W. (1983). Children’s Travel Behavior. Ekistics, Vol 50, No 298, pp 61-65 Waller, P.F., Olk, M.L. \& Shope, J.T. (2000). Parental views of and experience with Michigan’s graduated licensing program. Journal of Safety Research, 31(1), 9-15.

Volinski, J. (2003). Lessons Learned in Transit Efficiencies, Revenue Generation, and Cost Reductions - Second Edition. Center for Urban Transportation Research, University of South Florida, Tampa, Florida.

Waller P.F., Olk M.L, Shope J.T. (2000). "Parental views of and experience with Michigan's graduated licensing program." Journal of Safety Research, Vol. 31, No. 1, 9-15.

Yearsley, I. (1997). Safer Than it Seems - Personal Safety on Public Transport. Journal of Global Transport.

Zeilinger, C. (2004) Mobility: Today’s Young Riders, Tomorrow’s Future. In Community Transportation. Summer 2004 Issue (Young Riders: the Next Generation). Community Transportation Association of America, Washington, D.C. 


\section{Appendix - Research Instruments}

\section{TEENAGE ATTITUDES AND PERCEPTIONS REGARDING TRANSIT USE - TOPIC GUIDE FOR TEENAGER FOCUS GROUPS}

This topic guide provides a general overview of the discussion topics to be covered in the focus group sessions. The topic guide will be used by the focus group moderators to ensure that the structure of the session is maintained, and that the time is used effectively. It should be noted that free discussion is encouraged in the sessions and that the moderator will permit digression onto related topics if they feel they are of importance to the main topic area.

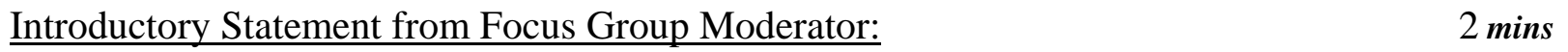

"Hello everyone and thanks for coming along today / tonight. My name is ' $x x x x x x x x$ ' and I am helping conduct a research project for the University of South Florida on public views on local transportation. Today we will be talking about your views on the different options you have for getting around. This is intended to be an informal discussion group, so please feel free to give your views on what we are discussing as we go along. Remember, there are no right or wrong answers, and the main thing is to be honest about your view on each topic of discussion. As you can see, I will be taping the discussion."

[points to tape recorder / microphone]

"This is so that I will have an accurate record of what was said. Please try to ignore the tape recorder, everything discussed today / tonight is completely confidential. Please try to speak one at a time and try not to interrupt anyone else while they are talking. The discussion will last for approximately one hour. If anyone needs to make any calls or go to the bathroom, could they do so now before we get started. Are there any questions before we get started?"

[answer any questions / switch on tape recorder]

$\underline{\text { Introductions / Current Travel Behavior }}$

10 mins

$\Rightarrow$ Moderator asks each group member to state their first name, age, the area where they live, and to provide some details on their travel behavior, including the following aspects:

- Modes of transport used for travel (car driver, car passenger, school bus, service bus, train, walk, cycle, etc)

- Different trip purposes

- Main destinations

- Time of day of travel

$\Rightarrow$ Moderator ascertains whether young people are "choice” or “captive” transit riders.

$\Rightarrow$ Moderator to check for evidence of peer pressure as topic is discussed 
$\Rightarrow$ Moderator probes on whether travel behavior will change as the young people get older. How do they expect their travel behavior to change?

- Will they get their own car?

- Will they continue to use public transit?

- If they move away (college / etc) how will their travel behavior change?

Attitudes towards Travel in Local Area

10 mins

$\Rightarrow$ Views on different aspects of travel:

- Is travel relatively easy or difficult?

- How have things changed over the years - better or worse?

- Comparing car travel with public transport

$\Rightarrow$ Any specific problems associated with car travel?

- Congestion? If so, where, when, and how severe? PROBE

- Parking

- Fuel prices

- Other?

$\Rightarrow$ Perceptions of public transport:

- Perceptions of different modes - bus, rail, etc

- (To choice riders) Is it possible to use public transport instead of a car for certain trips? If yes, why is it not used? If no, why not?

- (To captive riders): What is it like to use public transport - easy / hard, cheap / expensive?

Influence of Parental Views on Teenager Travel

10 mins

$\Rightarrow$ Moderator to probe each group member on the extent to which their travel behavior is influenced by their parents:

- How do their parents travel / do their parents use public transit?

- How do their parents feel about them (their children) traveling in cars (driving their car / being in cars driven by other young people)

- How do their parents feel about them (their children) using public transit

- How do their parents views affect each young person's travel behavior?

- How will parental influence (if any) change as the young person gets older?

$\Rightarrow$ Moderator to check for group interaction as this topic is discussed - any evidence of peer pressure? 
$\Rightarrow$ Is car travel adequate in the city?

$\Rightarrow$ Is public transit adequate in the city?

$\Rightarrow$ What should be done to improve transport in and around the city?

$\Rightarrow$ If these improvements were made, would your travel behavior change? If so, how?

Closing Statement from Moderator

"Well, we are just coming to the end of our time here. Thanks everyone for sharing your views with us. Your input has been very useful and will be taken into account when we report the research findings. Before we finish, are there any other comments or issues that anyone would like to raise?

[answer any questions / switch off tape recorder]

\section{THANK AND CLOSE}




\section{TEENAGE ATTITUDES AND PERCEPTIONS REGARDING TRANSIT USE - TOPIC GUIDE FOR PARENT / GUARDIAN FOCUS GROUPS}

This topic guide provides a general overview of the discussion topics to be covered in the focus group sessions. The topic guide will be used by the focus group moderators to ensure that the structure of the session is maintained, and that the time is used effectively. It should be noted that free discussion is encouraged in the sessions and that the moderator will permit digression onto related topics if they feel they are of importance to the main topic area.

Introductory Statement from Focus Group Moderator:

2 mins

"Hello everyone and thanks for coming along today / tonight. My name is ' $x x x x x x x x$ ' and I am helping conduct a research project for the University of South Florida on public views on local transportation. Today we will be talking about your views on the different options you have for getting around. This is intended to be an informal discussion group, so please feel free to give your views on what we are discussing as we go along. Remember, there are no right or wrong answers, and the main thing is to be honest about your view on each topic of discussion. As you can see, I will be taping the discussion.”

[points to tape recorder / microphone]

"This is so that I will have an accurate record of what was said. Please try to ignore the tape recorder, everything discussed today / tonight is completely confidential. Please try to speak one at a time and try not to interrupt anyone else while they are talking. The discussion will last for approximately one hour. If anyone needs to make any calls or go to the bathroom, could they do so now before we get started. Are there any questions before we get started?"

[answer any questions / switch on tape recorder]

$\underline{\text { Introductions / Current Travel Behavior }}$

10 mins

$\Rightarrow$ Moderator asks each group member to state their first name, age, the area where they live, and the first name and age of their participating child. They are then asked to provide some details on their travel behavior, including the following aspects:

- Modes of transport used for travel (car driver, car passenger, school bus, service bus, train, walk, cycle, etc)

- Different trip purposes

- Main destinations

- Time of day of travel

$\Rightarrow$ Moderator to ascertain whether parents are “choice” transit riders or "captive” transit riders. 
$\Rightarrow$ Views on different aspects of travel:

- Is travel relatively easy or difficult?

- How have things changed over the years - better or worse?

- Comparing car travel with public transport

$\Rightarrow$ Any specific problems associated with car travel?

- Congestion? If so, where, when, and how severe? PROBE

- Parking

- Fuel prices

- Other?

$\Rightarrow$ Perceptions of public transport:

- Perceptions of different modes - bus, rail, etc

- (To choice riders) Is it possible to use public transport instead of a car for certain trips? If yes, why is it not used? If no, why not?

- (To captive riders): What is it like to use public transport?

Influence of Parental Views on Teenager Travel

25 mins

$\Rightarrow$ Moderator to probe each parent in detail on the different ways in which they think they influence their child's travel:

- How do they feel about their children traveling in cars (driving their car / being in cars driven by other young people)

- How do they feel about their children using public transit (safety / cost / etc)

- What level of influence./ control do they exert on their child's travel behavior?

- Will their parental influence change as their child gets older?

$\Rightarrow \quad$ Moderator also to assess parent interaction as this issue is discussed - is there any agreement / disagreement on how they view their child's use of transit

$\Rightarrow \quad$ Are there any improvements to transit that should be made / that would improve their children's use of public transit?

$\Rightarrow \quad$ If these improvements were made, would they change anything about the way their view their children's use of transit?

Closing Statement from Moderator

2 mins

"Well, we are just coming to the end of our time here. Thanks everyone for sharing your views with us. Your input has been very useful and will be taken into account when we report the research findings. Before we finish, are there any other comments or issues that anyone would like to raise?

[answer any questions / switch off tape recorder]

\section{THANK AND CLOSE}




\section{TRANSIT AGENCY SURVEY - QUESTIONNAIRE}

\section{Name:}

Transit system:

City, State:

1. Do you currently have any specific marketing strategies or programs which are aimed at recruiting and maintaining teen ridership?

$$
\text { Yes } \quad \text { No }
$$

If yes, what types of programs and marketing strategies are you using to recruit and/or maintain teen ridership?

2. If you do have a teen ridership program in place, please describe the types of obstacles you face in marketing strategies targeted to teens:

3. What types of obstacles do you face in your promotional efforts which are targeted towards teens:

4. Do you have any information on teen ridership numbers for your transit system?

Yes $\quad$ No

If yes, please provide information on teen ridership:

5. Do you have any data, which has been derived from on-board surveys, that was collected from teens?

Yes

No

If yes, please provide this information: 